\title{
Assessing the potential of maximum tree-ring density in developing divergence-free white spruce chronologies, Northwest Territories, Canada
}

By

Sarah L. Quann

A thesis submitted to the Faculty of Graduate and Postdoctoral Affairs in partial fulfillment of the requirements for the degree of

Master of Science

in

Geography

Carleton University

Ottawa, Ontario

C 2014 Sarah L. Quann 


\begin{abstract}
Tree cores were collected from white spruce at two study locations near Inuvik, Northwest Territories to evaluate the climate sensitivity of ring-width and maximum density indices. Over 200 trees were sampled to develop four ring-width chronologies dating back as far as $1025 \mathrm{CE}$ and two density chronologies spanning 1321 to $2012 \mathrm{CE}$ and 1383 to $2012 \mathrm{CE}$, respectively. The chronologies originating from the Campbell Dolomite Uplands are responsive to local precipitation and temperature. The chronologies from Husky Lakes are sensitive to growing season temperatures. The ringwidth chronologies at both study locations are weakly and inconsistently correlated with growing season conditions between 1910 and 2009. The density chronologies are consistently correlated to temperature variables at Husky Lakes, and show no evidence of the divergence issue noted in previous ring width studies from this region. These results support the use of maximum density as a temperature proxy throughout the $21^{\text {st }}$ century.
\end{abstract}




\section{Acknowledgements}

This thesis would not have been possible without the encouragement, support, and guidance of family, friends, and colleagues. These past two years have been challenging in many ways and each of you has supported me in your own way.

I want to thank my supervisor, Dr. Michael Pisaric for his guidance, support, and very productive Skype chats. You opened the door to so many opportunities in field work and travel and I thank you. I also want to thank Dr. Elyn Humphreys, Dr. Dan Smith, and Dr. Chris Burn for their encouragement and positive presence. Thank you to Dr. Murray Richardson and Dr. Timothy Patterson for their insightful comments on this research. Thanks go as well to Dr. Trevor Porter for his expertise in the field and for his patience in addressing my questions over the past two years. I'd also like to thank Robert Wu at the CUPL for his help with sample processing.

To my family and friends: thank you for being there for me! Thanks to Ma and Doc for the calls, care packages, and much appreciated visits. To Elyse for the Skype chats and adventures. To Sylvia and Gary for the food, company, and of course: laundry. I am more grateful to Brennan McConnell than words can express: your love and constant support makes every day wonderful. You have all helped keep me comfortable and given me the space and time to relax. To the friends and DGES colleagues who were there for a quick (or long!) chat about anything and everything and helped me through this process, thank you. Emma, Graham, Brendan, Jill, Bethany, and Bryan: I am so grateful for your feedback and friendship. 
Funding support for this research was provided by an NSERC CGS M scholarship, a W. Garfield Weston Award for Northern Research (Masters), and a funding grant from NSTP. 


\section{In wildness is the preservation of the world.}

Nature confronts us with its beauty in a flower or a furry animal. The awesome nature of nature is displayed in a lightning bolt or a majestic mountain. Every variety of tree has its own uniquely textured bark. Each annual ring in a tree trunk is a natural record of the growing conditions in each year it grew. These things remind us we are not in charge, and we are moved by the experience.

This wildness is everywhere around us, and we are renewed by it when we interact with it. At night in the city we look up and see the ancient moon. When we live with a pet, it reminds us we are creatures too. We are part of this larger whole. We don't just appreciate nature-we are nature. When we open our eyes and learn to be a part of it, it renews and lifts our spirits.

Henry David Thoreau, 1862 


\section{Table of Contents}

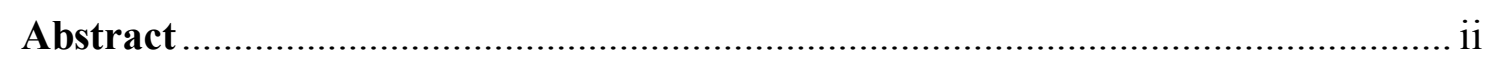

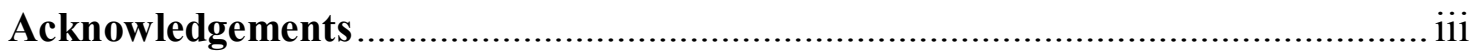

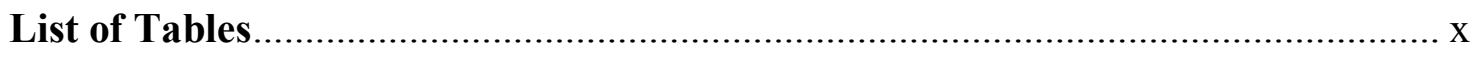

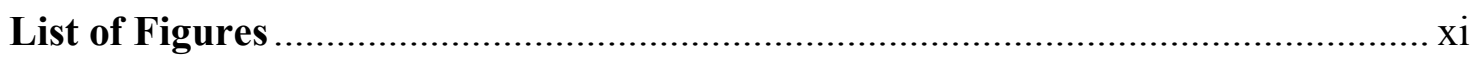

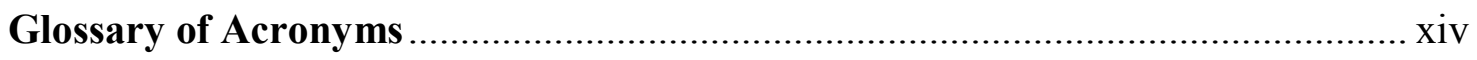

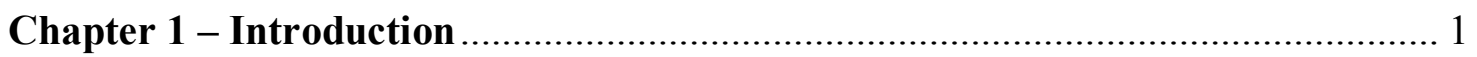

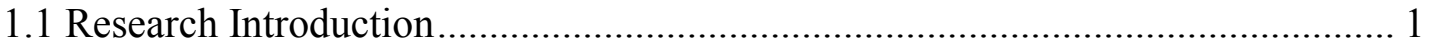

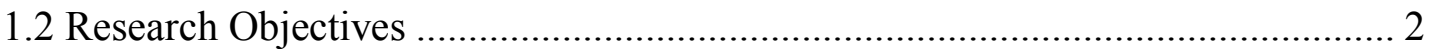

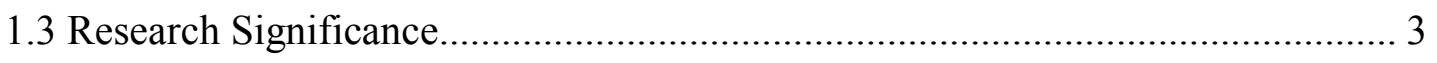

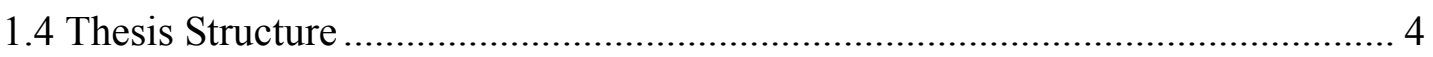

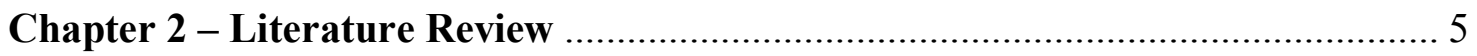

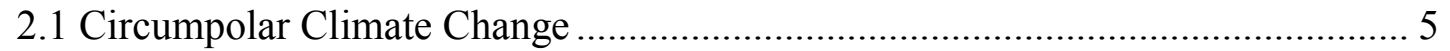

2.1.1 Northern Climate Trends ......................................................................... 5

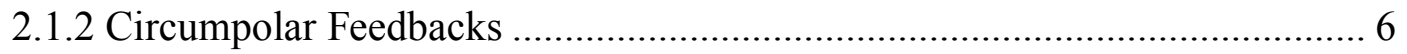

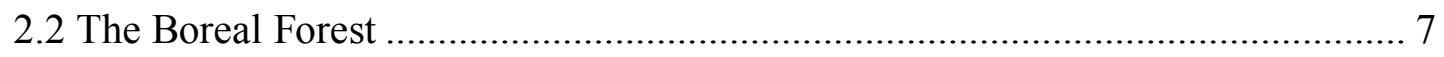

2.2.1 Global Distribution and Composition ..................................................... 7

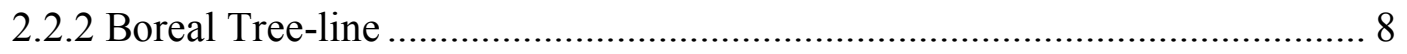

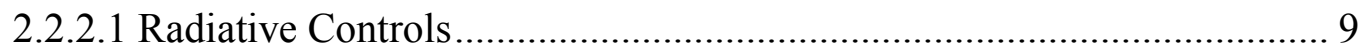

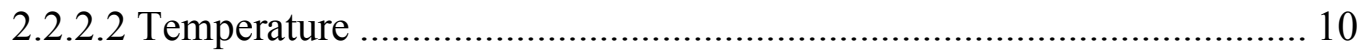

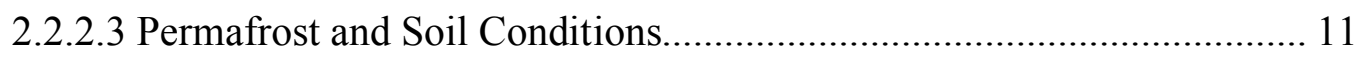

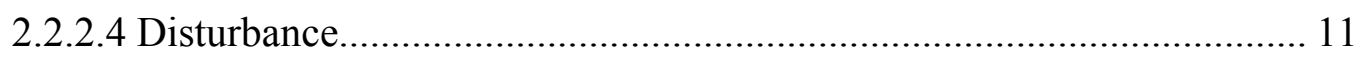

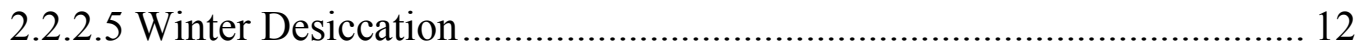

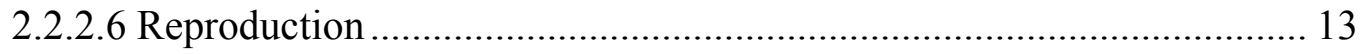

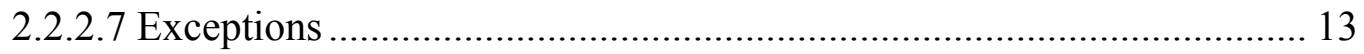

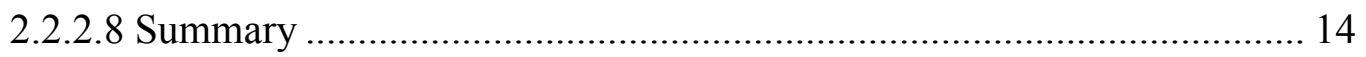

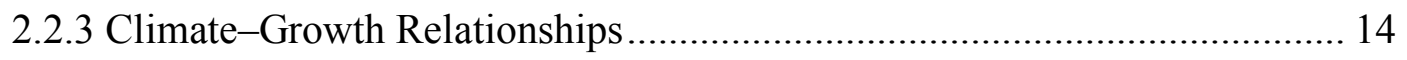

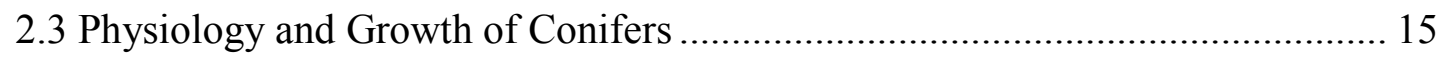

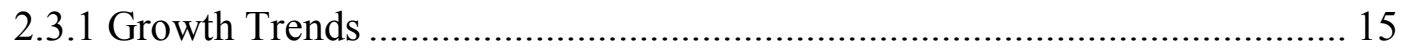

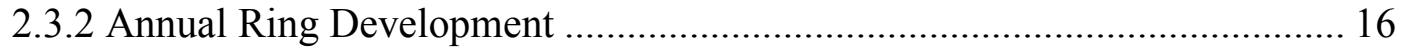

2.4 Methods of Dendrochronological Analysis ................................................ 18 
2.4.1 Paleoclimatology, Dendrochronology, and Dendroclimatology ................. 18

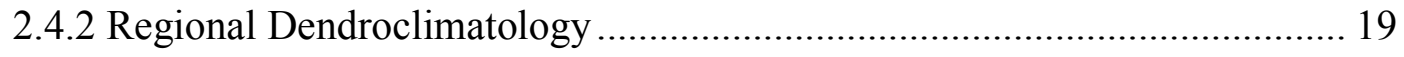

2.5 The Divergence Problem .............................................................................. 20

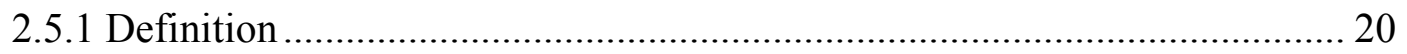

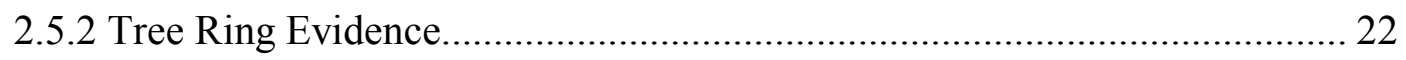

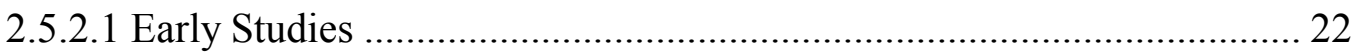

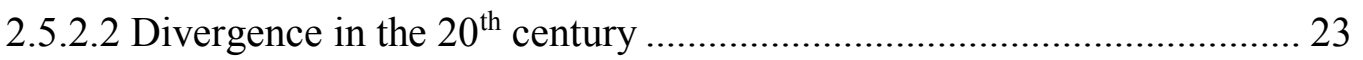

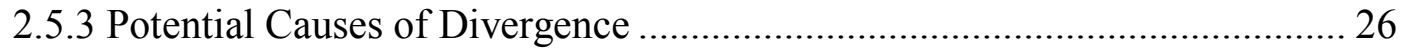

2.5.3.1 Temperature-induced drought stress ................................................. 27

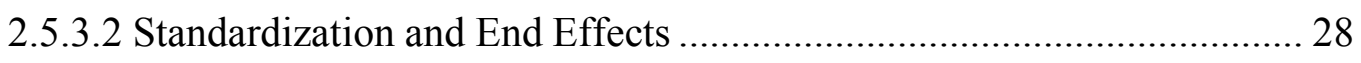

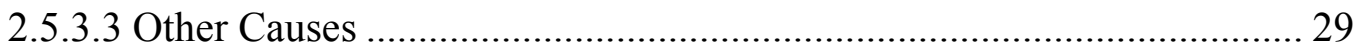

2.5.4 Developing Divergence-free Reconstructions ...................................... 30

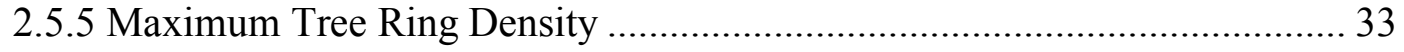

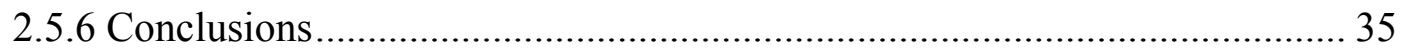

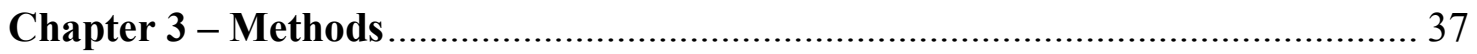

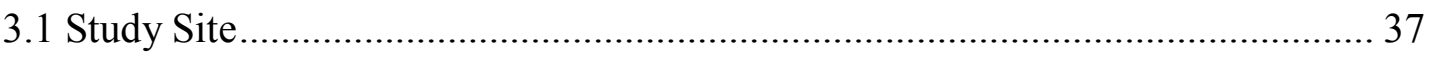

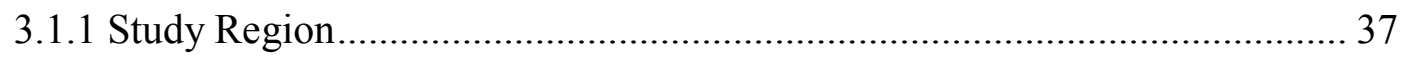

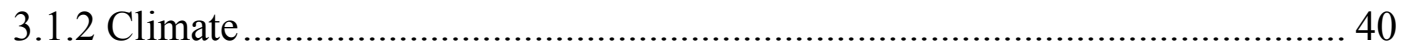

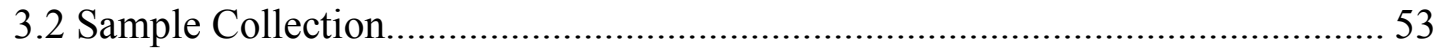

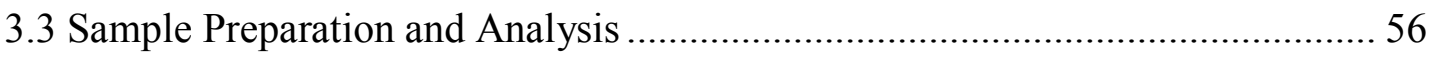

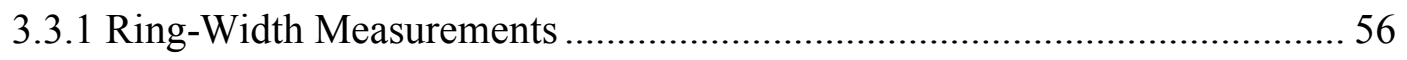

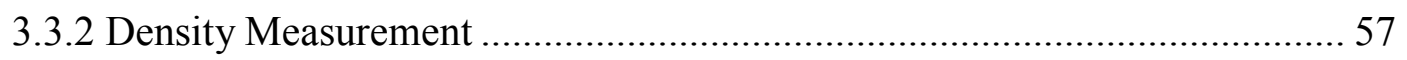

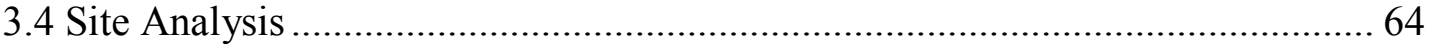

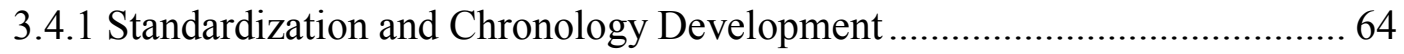

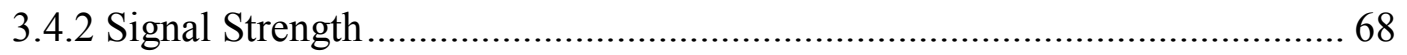

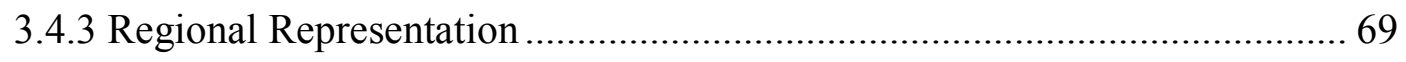

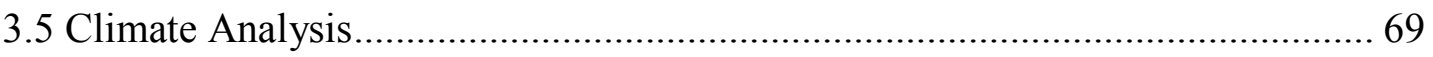

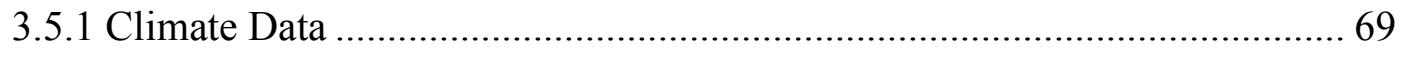

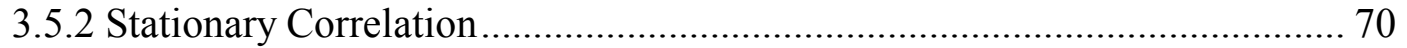

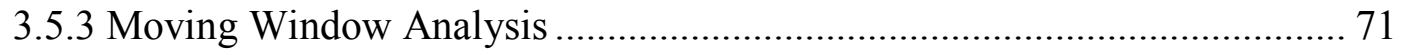

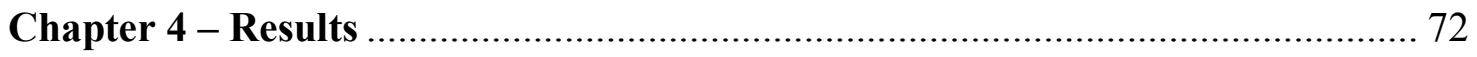

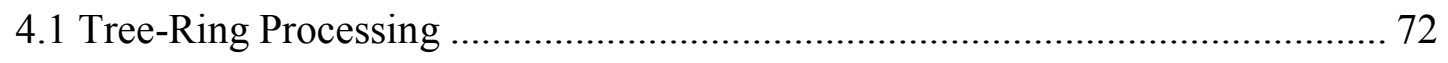




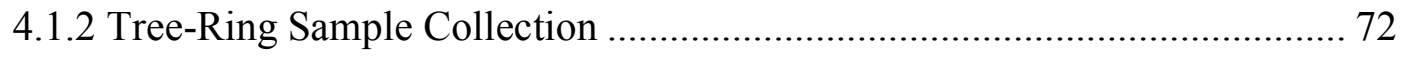

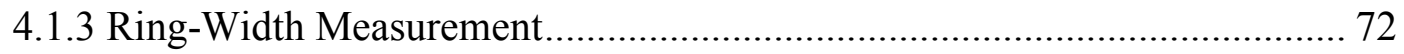

4.1.4 Maximum Density Measurement........................................................... 75

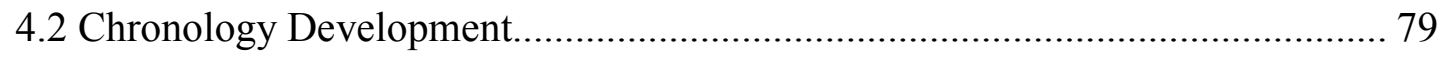

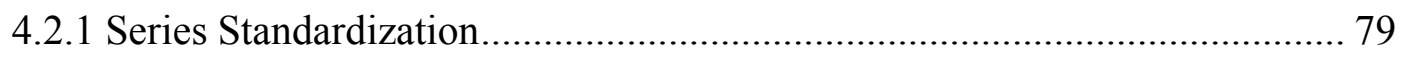

4.2.1.1 Ring-Width Series Detrending .......................................................... 79

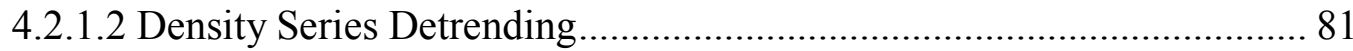

4.2.2 Chronology Summary Statistics ................................................................ 81

4.2.2.1 Ring-Width Chronologies ................................................................... 81

4.2.2.2 Maximum Density Chronologies ........................................................ 85

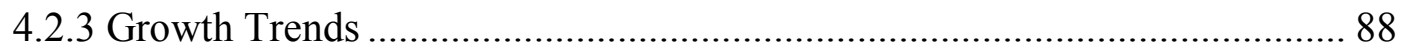

4.3 Regional Representation of Chronologies ....................................................... 94

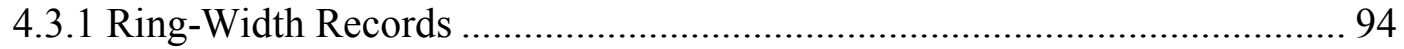

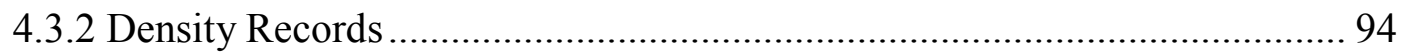

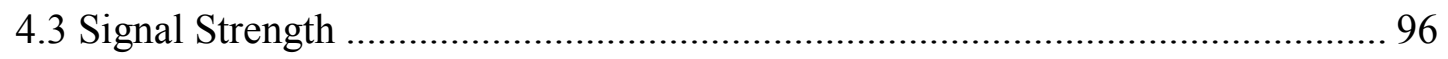

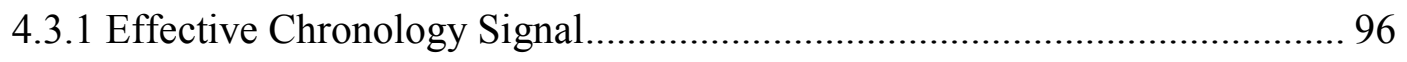

4.3.2 Expressed Population Signal...................................................................... 96

4.3.2.1 Ring-Width Population Signal ............................................................. 97

4.3.2.2 Density Population Signal ................................................................. 99

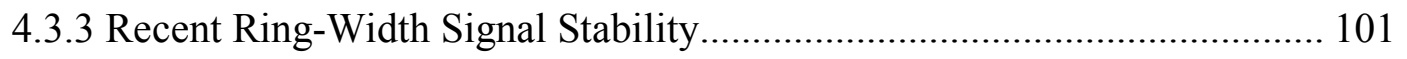

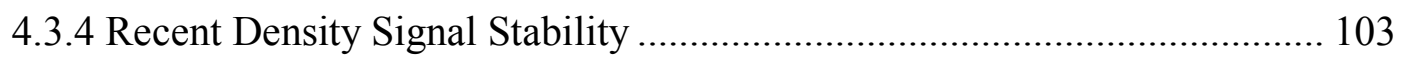

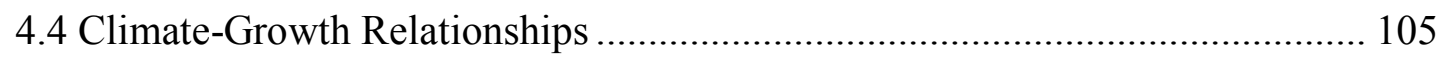

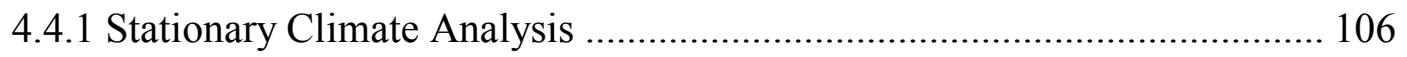

4.4.1.1 Stationary Climate Record and Ring-Width ...................................... 106

4.4.1.2 Stationary Climate Record and Maximum Density ............................. 106

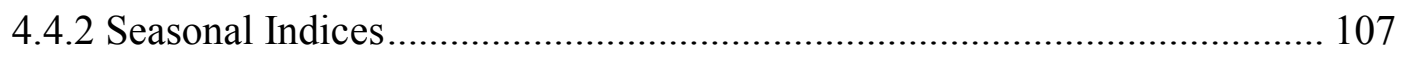

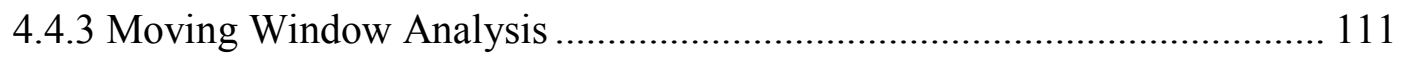

4.4.3.1 Ring-Width and Local Temperatures ................................................... 111

4.4.3.2 Maximum Density and Local Temperatures......................................... 113

4.4.3.3 Ring-Width and Regional Temperatures.............................................. 115

4.4.3.4 Maximum Density and Regional Temperatures................................... 118

4.4.3.5 Relationship with Composite Seasonal Indices ................................... 120 


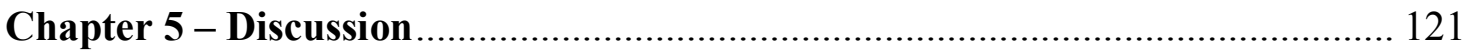

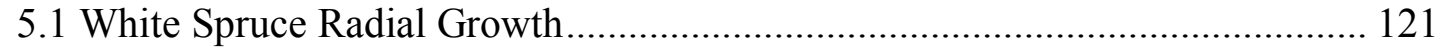

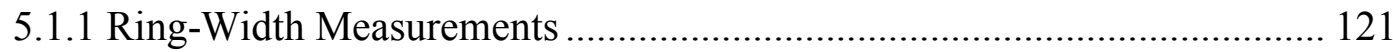

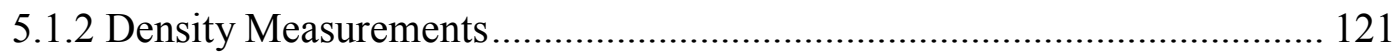

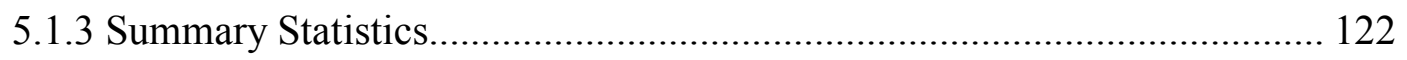

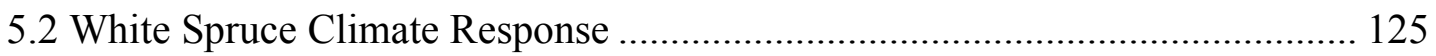

5.2.1 Climate and Tree-Ring Proxies........................................................... 125

5.2.2 Climate Extremes and Tree Growth ....................................................... 126

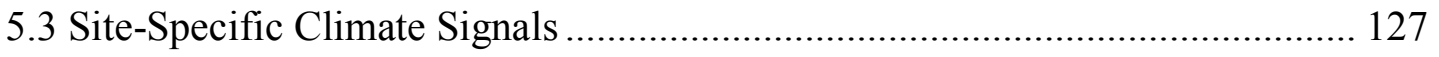

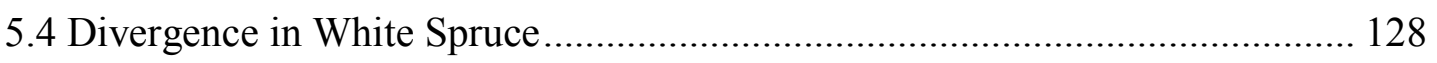

5.5 Reconstruction Potential of Maximum Density ............................................. 129

5.6 Impact of Arctic warming on white spruce growth ...................................... 129

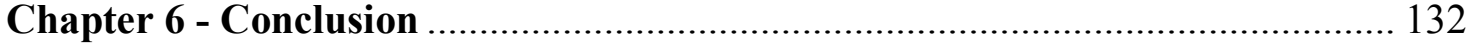

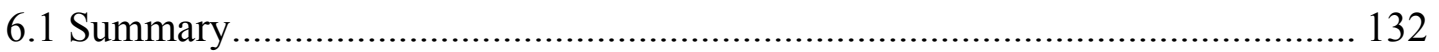

6.2 Recommendations for Future Research...................................................... 135

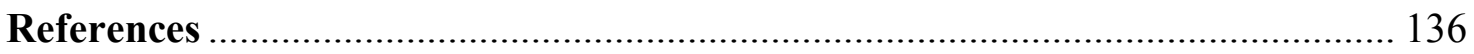




\section{List of Tables}

Table 3.1 - The coordinates and elevation (m) of the 5 white spruce sample sites, Northwest Territories, Canada and the number of each sample type collected at each site.

Table 4.1 - The number of $5.2 \mathrm{~mm}$ cores and subfossil samples retained in relation to the number collected at each of the 5 sample sites. The fraction of the number of trees $(\mathrm{N}$ Trees) and the number of cores ( $\mathrm{N}$ Cores) retained versus collected is presented 73

Table 4.2 - Correlation coefficients from the statistical comparison of the three detrending methods (SF, SF RCS, and NEXP) tested at each ring-width site (CDU1, CDU2, HL1, and HL3). Correlations are significant at the 95\% confidence interval.... 79

Table 4.3 - Summary site statistics for the ring-width chronologies describing the number of series in each chronology, the chronology length, the temporal span of the chronology, the series intercorrelation value (SI), the mean sensitivity (MS) and the mean length of series (MLS).

Table 4.4 - Summary site statistics for the ring density chronologies describing the number of series in each chronology, the chronology length, the temporal span of the chronology, the series intercorrelation value (SI), the mean sensitivity (MS) and the mean length of series (MLS).

Table 4.5 - Correlation matrix between the ring-width SF chronologies with correlation coefficients displayed. All correlations are significant at the $95 \%$ confidence interval...88 Table 4.6 - Correlation coefficients between CDUMXD, HLMXD, CANA172, and CANA173. All correlations are significant at 95\% confidence interval

Table 4.7 - Correlation coefficients for tree growth and the seasonal indices based on the monthly correlation values from the composite record. Correlations shown are significant at the $95 \%$ confidence interval. 108

Table 4.8 - Correlation coefficients for tree growth and the seasonal indices based on the monthly correlation values with local station records in Inuvik and Tuktoyaktuk. Correlations shown are significant at the $95 \%$ confidence interval

Table 5.1 - A comparison of TRW chronology summary statistics (series intercorrelation and mean sensitivity) from CDU and HL to other northern white spruce chronologies ....

Table 5.2 - A comparison of MXD chronology summary statistics (series intercorrelation and mean sensitivity) from CDU and HL to other northern white spruce chronologies.... 


\section{List of Figures}

Figure 3.1 - Ecoregions of the Northwest Territories as of 2007 (reproduced from Ecosystem Classification Group, 2009).

Figure 3.2 - Average Inuvik instrumental temperature and precipitation from 1957 to 2012 (AHCCD, 2014). The shaded bars represent average monthly precipitation totals, the solid line represents average mean monthly temperature, the long dashed line is the average maximum monthly temperature, and the short dashed line is the average minimum monthly temperature. All monthly values were averaged over the length of the instrumental record 43

Figure 3.3 - Average Tuktoyaktuk instrumental temperature and precipitation from 1957 to 2012 (AHCCD, 2014). The bars represent average monthly precipitation totals, the solid line represents average mean monthly temperature, the long dashed line is the average maximum monthly temperature, and the short dashed line is the average minimum monthly temperature. All monthly values were averaged over the length of the instrumental record

Figure 3.4 - Inuvik seasonal mean temperature (black lines) and 5-year moving average (dashed grey lines) during a) winter, b) spring, c) summer, and d) autumn from 1957 to 2012 (AHCCD, 2014)

Figure 3.5 - Inuvik total seasonal precipitation (black lines) and 5-year moving average (dashed grey lines) during a) winter, b) spring, c) summer, and d) autumn from 1957 to 2012 (AHCCD, 2014) 46

Figure 3.6 - Tuktoyaktuk seasonal temperature (black lines) and 5-year moving average (dashed grey lines) during a) winter, b) spring, c) summer, and d) autumn from 1957 to 2012 (AHCCD, 2014)

Figure 3.7 - Tuktoyaktuk total seasonal precipitation (black lines) and 5-year moving average (dashed grey lines) during a) winter, b) spring, c) summer, and d) autumn from 1957 to 2007 (AHCCD, 2014).

Figure 3.8 - Study site at the Campbell Dolomite Uplands at CDU1 illustrating the rocky bedrock substrate and open canopy white spruce trees. These site characteristics are shared by CDU2 50

Figure 3.9 - Study site at Husky Lakes at HL3 illustrating the hummocky, moist growing conditions. These site characteristics are representative of HL1 and HL2 as well. 51

Figure 3.10 - White spruce sampling locations, Northwest Territories, Canada (NRCAN, 2014). The dashed line indicates the approximate position of tree-line based on Brown et al. (2001). The inset on the bottom right illustrates the location of the study region in the northwestern Northwest Territories, Canada

Figure 3.11 - Graphic illustrating the further processing of subfossil samples to extract a $12 \mathrm{~mm}$ wide central strip for density analysis. The area removed for density analysis encompassed a strip from bark to pith to bark across the diameter of each sample 57 
Figure 3.12 - The Waltech high precision twin-bladed saw illustrating the lathe cut from a $12 \mathrm{~mm}$ subfossil sample. The same process was used with the $12 \mathrm{~mm}$ living tree core samples.

Figure 3.13 - The Soxhlet extraction apparatus set up. The samples were placed into a glass Fredrichs condenser and boiling acetone, seen below the condenser, cycled through the apparatus, filling the flask through condensation and soaking the samples 60 Figure 3.14 - Ten $2 \mathrm{~mm}$ by $12 \mathrm{~mm}$ sample lathes mounted in the x-ray densitometer apparatus at the University of Victoria Tree Ring Laboratory

Figure 4.1 - Illustrations of the range of density images produced through X-ray densitometry. In a) a good image is shown, with distinct ring boundaries (C1D05A); b) the appearance of decay in a sample increasing toward the bark (H1L08A); c) narrow sections of samples cannot be resolved by the x-ray beam (H1L11A); d) the ring angle of the sample becomes more twisted toward the bark of the sample, such that the $\mathrm{x}$-ray beam is penetrating multiple rings at once (H1D14A)

Figure 4.2 - Ring-width index (RWI) (in black) and sample depth (in grey) of a) the CDU1TRW chronology (1158 to 2012); b) the CDU2TRW chronology (1025 to 2012); c) the HL1TRW chronology (1321 to 2012); and d) the HL3TRW chronology (1383 to 2012)

Figure 4.3 - Detrended maximum density chronology (in black) and sample depth (in grey) of a) the CDU density chronology (1308 to 2012) and b) the HL density chronology (1321 to 2012).

Figure 4.4 - Time series plots of the ring-width (RWI) and maximum density (MXD) chronologies at CDU smoothed using a 10 -year moving average. The solid black line is CDU1TRW RWI, the solid grey line is CDU2TRW RWI, and the dashed black line is CDUMXD.

Figure 4.5 - Time series plots of the ring-width (RWI) and maximum density (MXD) chronologies at HL smoothed using a 10-year moving average. The solid black line is HL1TRW RWI, the solid grey line is HL3TRW RWI, and the dashed black line is HLMXD.....

Figure 4.6 - The standardized density chronologies plotted against each other. The MXD index for CDUMXD is the narrow black line and for HLMXD is the narrow grey line. Sample depth is displayed for CDUMXD as the dotted black line and for HLMXD as the dotted grey line

Figure 4.7 - The EPS of the ring-width chronologies and the number of trees used to calculate the EPS over a 50-year window, lagged by 25 years for a) CDU1TRW; b) CDU2TRW; c) HL1TRW; and d) HL3TRW. The black lines are the EPS values and the grey lines are the average number of trees used to calculate a specific EPS value. The dashed line illustrates EPS $=0.85$

Figure 4.8 - The EPS of a) the CDUMXD chronology and b) the HLMXD chronology and the number of trees used to calculate the EPS over a 50 -year window, lagged by 25 
years. The black lines are the EPS values and the grey lines are the average number of trees used to calculate a specific EPS value. The dashed line illustrates EPS $=0.85 \ldots . .99$ Figure 4.9 - The EPS values for the ring-width chronologies are plotted for the past 110 years along with the average number of trees used to calculate the statistic for a) CDU1TRW; b) CDU2TRW; c) HL1TRW; and d) HL3TRW. The black lines are the EPS values and the grey lines are the number of trees used to calculate a specific EPS value. The dashed line illustrates EPS $=0.85$. 101

Figure 4.10 - The EPS values for the density series are plotted for the past 110 years along with the average number of trees used to calculate the statistic for a) CDUMXD and b) HLMXD. The black lines are the EPS values and the grey lines are the average number of trees used to calculate a specific EPS value. The dashed line illustrates EPS = 0.85 . 103

Figure 4.11 - Moving 20-year interval analysis of a) CDU1TRW and minimum JAS temperature; b) CDU2TRW and maximum previous July temperature; c) HL1TRW and minimum June temperature; and d) HL3TRW and maximum previous July temperature. The black lines illustrate the correlation over time and the dashed lines illustrate the bounds of significant values ( $\mathrm{r}=0.444$ to -0.444$)$ 111

Figure 4.12 - Moving 20-year interval analysis between a) CDUMXD and minimum JAS temperature and b) HLMXD and maximum July temperature. The black lines illustrate the correlation over time and the dashed lines illustrate the bounds of significant values $(r=0.444$ to -0.444$)$. 114

Figure 4.13 - Evolutionary moving window analysis using the composite temperature record between a) CDU1TRW and minimum monthly temperature; b) CDU2TRW and maximum monthly temperature; c) HL1TRW and minimum monthly temperature; and d) HL3TRW and minimum monthly temperature. The colour scale illustrates the range of depicted correlation coefficients, significant at the $95 \%$ confidence interval 117

Figure 4.14 - Evolutionary moving window analysis using the composite temperature record between a) CDUMXD and minimum monthly composite temperature and b) HLMXD and minimum monthly temperature. The colour scale illustrates the range of depicted correlation coefficients, significant at the $95 \%$ confidence interval 119 


\section{Glossary of Acronyms}

CDU

CDU1, CDU2

CDU1TRW

CDU2TRW

CDUMXD

CE

EPS

$\mathrm{HL}$

HL1, HL2, HL3

HL1TRW

HL3TRW

HLMXD

MS

MXD

NEXP

RCS

$r_{\text {eff }}$

RWI

SF

SF RCS

SI

TRW
Campbell Dolomite Uplands, one of the study sites south of Inuvik Respective tree ring sampling sites on the Campbell Dolomite Uplands

the ring-width chronology from Campbell Dolomite Uplands site 1 the ring-width chronology from Campbell Dolomite Uplands site 2 the maximum density chronology from samples collected at Campbell Dolomite Uplands

Common Era

Expressed Population Signal

Husky Lakes, one of the study areas southeast of Tuktoyaktuk

Respective tree ring sampling sites near the Husky Lakes

the ring-width chronology from Husky Lakes sites 1 and 2

the ring-width chronology from Husky Lakes site 3

the maximum density chronology from samples collected at Husky

Lakes

Mean Sensitivity

Maximum Latewood Density (also: Maximum Density)

Negative Exponential Curve, a detrending method

Regional Curve Standardization, a detrending method

Effective Chronology Signal

Ring-Width Index, a dimensionless ring-width chronology

resulting from the detrending process

Signal-Free, a detrending method

Signal-Free Regional Curve Standardization, a detrending method Series Intercorrelation

Total Ring-Width 


\section{Chapter 1}

\section{INTRODUCTION}

\subsection{Research Introduction}

Over the course of the $20^{\text {th }}$ century, northern latitudes have experienced dramatic shifts in temperature, with recent surface temperatures exceeding instrumental and proxy records for at least the past 400 years (Overpeck et al., 1997; Serreze et al., 2000; ACIA, 2005; IPCC, 2007; Kaufman et al., 2009; Tingley et al., 2013). Reliable historical climate data has become increasingly important to understanding current environmental conditions and for projecting future trends. However, instrumental records in high latitude regions are geographically sparse and temporally limited with many records spanning only the past 50 years (Overpeck et al., 1997; Bradley, 2011). In these remote locations, paleoclimate proxies provide valuable information about long-term climatic trends (Jacoby and D’Arrigo, 1989) that are lacking from the short instrumental records.

Trees have long been used as climate proxies as they are highly sensitive to temperature and precipitation (Fritts, 1976). In northern environments, particularly at the forest-tundra transition zone, growing season temperatures are the most important limiting variables to tree growth, making them ideal for temperature reconstructions (D’Arrigo et al., 1992; Jacoby and D'Arrigo, 1995; Esper and Schweingruber, 2004). Due to this temperature sensitivity, it has been predicted that trees will respond to warming temperatures with increased radial ring-width (Schweingruber et al. 1993; McKenzie et al., 2001; Lloyd and Bunn, 2007; Way and Oren, 2010). This assumption has been challenged by contemporary studies (e.g. D'Arrigo et al., 2004) that have found that some trees respond to rising temperatures with increases in annual ring width up to 
an optimal threshold after which ring width declines with further increases in temperature (D’Arrigo et al., 2004; Wilmking et al., 2004; Rossi et al., 2008).

Recent studies of tree growth in high northern latitude regions have found evidence of this threshold, namely, a decoupling of the relationship between tree growth and temperature since about the mid-20 ${ }^{\text {th }}$ century (Jacoby and D'Arrigo, 1995; Briffa et al., 1998a; Barber et al., 2000; Briffa et al., 2004; Wilmking et al., 2004, 2005; Pisaric et al., 2007; Wilson et al., 2007; Grudd, 2008; Porter and Pisaric, 2011). This decoupling is known as the 'divergence problem' and its effects are widespread across the circumpolar north (Briffa et al., 1998a; Barber et al., 2000; Lloyd and Fastie, 2002; Wilmking et al., 2004; D’Arrigo et al., 2008; King, 2009; Porter and Pisaric, 2011). This is significant as tree-ring based climate reconstructions derived from northern forests provide data used in global climate and carbon cycling models (Briffa et al., 1998a; Chapin et al., 2000). The divergence problem may lead to the underestimation of past temperatures in climate reconstructions and an overestimation of the carbon accumulation potential of northern boreal ecosystems (Briffa et al., 1998a; Barber et al., 2000). This research proposes to investigate the impact of the divergence problem on tree-ring based temperature indices using white spruce (Picea glauca (Moench) Voss) from tree-line in the Northwest Territories near Inuvik and Tuktoyaktuk.

\subsection{Research Objectives}

The development of divergence-free temperature reconstructions is important for understanding past climate conditions and placing current temperatures in a long-term context. While the divergence problem has been widely identified in studies measuring total annual ring-width (TRW) (e.g. Barber et al., 2000; Lloyd and Fastie, 2002; 
Wilmking et al., 2004; Pisaric et al., 2007; Porter et al., 2013b), it is unclear if other treering indices such as the maximum density (MXD) of annual rings are similarly impacted. Divergence in annual ring-width of white spruce near treeline of the Northwest Territories has been documented extensively through the work of Porter (2012) and Muise (2013); therefore this research hypothesizes the existence of divergence in TRW at the study sites. This research will attempt to increase the understanding of the relationship between MXD and climate in order to establish the utility of MXD as a temperature proxy. To quantify the relationship between TRW and MXD and climate conditions, this research asks:

1. Do TRW and MXD respond similarly to climate conditions over time?

2. Can divergence-free temperature reconstructions be developed using MXD chronologies?

In order to answer these questions, the following objectives have been identified:

1. Develop white spruce TRW and MXD chronologies near the Northwest Territories tree-line.

2. Evaluate the sensitivity of TRW and MXD chronologies to climate variables.

3. Assess the temporal stability of white spruce climate-growth relations.

\subsection{Research Significance}

Arctic and boreal ecosystems are sensitive to even slight fluctuations in climate conditions (Overpeck et al., 1997; Chapin et al., 2000). Changes in circumpolar ecosystems can have impacts at lower latitudes as well, influencing thermohaline circulation and fluxes of methane and carbon (Houghton et al., 1990; Weller et al., 1995; Serreze et al., 2000). Tree-ring based climate reconstructions are important in developing 
and validating climate models for understanding past climate conditions, and for placing current temperatures in a longer-term context (Briffa et al., 1998a; Wilmking et al., 2005).

Due to the impact of the divergence problem on the growth of some northern circumpolar trees, the development of temperature reconstructions for the $20^{\text {th }}$ century from northern regions can be tenuous. This research will attempt to improve the accuracy of modern temperature reconstructions through the use of MXD as it has been shown to produce divergence-free chronologies (Anchukaitis et al., 2013). In addition to an evaluation of tree-ring based proxy indices, this research will both update and increase the number of TRW and MXD chronologies in northern regions where tree-ring records, especially of MXD, are sparse (D’Arrigo et al., 2008).

\subsection{Thesis Structure}

This thesis consists of 6 chapters. Chapter 1 presents a brief introduction to the background and objectives of this research. Chapter 2 provides a theoretical background of the components of the circumpolar boreal forest and its relationship with climate systems, along with a description of the divergence problem. Chapter 3 outlines the methodology and methods used to conduct this research as well as a description of the study location. Chapter 4 presents the results of the chronology development process and climate-growth analyses. Chapter 5 discusses the relationship between tree growth and climate based on the comparative analyses of ring-width and density records. Chapter 6 summarizes and concludes this thesis. 


\section{Chapter 2 - Literature Review}

\subsection{Circumpolar Climate Change}

\subsubsection{Northern Climate Trends}

Observational and proxy evidence indicate a distinct warming trend in northern high latitude regions during the $20^{\text {th }}$ century and into the $21^{\text {st }}$ century that do not conform to natural centennial-scale periodicity (Overpeck et al., 1997; Serreze et al., 2000; Kaufman et al., 2009). High latitude regions have warmed disproportionately compared to midlatitude regions (Serreze et al., 2009; Hansen and Karl, 2013; Overland et al., 2013), where the greatest degree of warming has occurred between $40-70^{\circ} \mathrm{N}$ (Overpeck et al., 1997; Serreze et al., 2000; Serreze and Francis, 2006). Recent climate trends point toward increases in both temperature and precipitation in high latitude regions during the $20^{\text {th }}$ century that are most pronounced in the late autumn and winter and are linked to delays in ice formation and snow cover (Serreze et al., 2000; Overland et al., 2013).

Mean annual Arctic temperatures have increased by an average of $1.5^{\circ} \mathrm{C}$ as compared to 1971-2000 ( Overland et al., 2013), with the warmest summer temperatures in the past 2000 years observed during the $20^{\text {th }}$ century (Kaufman et al., 2009).

Twentieth century increases in temperature contrast a distinct centennial cooling trend observed in proxy records during 1 to 1900 CE (Kaufman et al., 2009). The coolest documented decades in the past 2000 years were from 1600 to 1850 (Kaufman et al., 2009), corresponding with the Little Ice Age cool period (Mann et al., 2002). During the $20^{\text {th }}$ century, high latitude mean annual temperatures were lower from 1940 to 1970 in comparison to 1920 to 1940 and post-1970 (Serreze et al., 2000). The warmest surface 
temperatures in the past 200 years were from 1999 to 2008 (Serreze et al., 2000;

Kaufman et al., 2009).

\subsubsection{Circumpolar Feedbacks}

Globally, vegetation and soil are important terrestrial carbon reservoirs (Matthews et al., 2000; Zimov et al., 2006). Forests store $\sim 45 \%$ of terrestrial carbon (Sellers et al., 1997; Bonan et al., 2008) and are responsible for $\sim 50 \%$ of terrestrial net primary productivity (Roy et al., 2001). Boreal and temperate forests between $30^{\circ} \mathrm{N}$ and $80^{\circ} \mathrm{N}$ alone contain $\sim 80$ Pg of carbon (Thurner et al., 2014). The circumpolar boreal forest region is the largest carbon store of all forest ecosystems, with estimates of carbon storage within the forest and soils of this system ranging from $30-40 \%$ of total terrestrial storage (Matthews et al., 2000; Callaghan et al., 2005; Carlson et al., 2009; WHRC, 2014). Northern boreal forests are important components of global climate and carbon cycling systems due to the role they play in climate feedback processes (Baldocchi et al., 2000; Chapin et al., 2000; Serreze et al., 2000).

With rising temperatures in northern regions, rapid changes in the cryosphere are anticipated, affecting permafrost and snow and ice cover dynamics (Zimov et al., 1997; Serreze and Francis, 2006). Arctic soils affected by permafrost contain a large carbon reservoir estimated to be $\sim 1100 \mathrm{Pg} \mathrm{C}(0-3 \mathrm{~m})$ with roughly $75 \%$ of this carbon perennially frozen (Hugelius et al., 2014). Warming trends in circumpolar regions have been amplified due to a variety of feedback processes (Serreze and Francis, 2006;

Overland et al., 2013). These soil carbon reserves may be sensitive to further warming and could result in the rapid release of carbon dioxide $\left(\mathrm{CO}_{2}\right)$ and methane $\left(\mathrm{CH}_{4}\right)$, providing a positive feedback to climate warming (Zimov et al., 1997; 2006; Callaghan et 
al., 2005). Melting sea ice, an increase in the length of the snow-free season (Dye, 2002), and a $10 \%$ decrease in the extent of snow cover (ACIA, 2005) amplify warming trends in high latitude regions by decreasing the albedo of circumpolar landscapes and increasing the amount of additional heat storage in ice-free sea areas (Overpeck et al., 1997; Serreze and Francis, 2006; Serreze et al., 2009).

\subsection{The Boreal Forest}

\subsubsection{Global Distribution and Composition}

Forests around the world are vital components of the earth-atmosphere system (Overpeck et al., 1997; Matthews et al., 2000). They cover $\sim 30 \%$ of the global terrestrial surface (Volney and Fleming, 2000; Bonan et al., 2008) and provide a variety of valuable services both economically and culturally. These services include nutrient cycling, climate regulation, and the provision of renewable resources (Costanza et al., 1997; Matthews et al., 2000). The boreal forest region alone comprises approximately one third of all forest types, covers $\sim 15 \%$ of the terrestrial surface, and extends across approximately 16 million square kilometers of the northern hemisphere (Runesson, 2011; WHRC, 2014). This region stores more carbon than any other terrestrial system, in both the vegetation and soils (Carlson et al., 2009; Hugelius et al., 2014; Thurner et al., 2014).

Global latitudinal tree-line spans the circumpolar northern hemisphere, forming a band across the northern regions of North America and Eurasia (Hare and Ritchie, 1972). The northern limits of this band have been found to correspond to a mean July temperature isotherm of 10 to $12^{\circ} \mathrm{C}$, and in North America, to the summer position of the Arctic front (Daubenmire, 1954; Hare and Ritchie, 1972; MacDonald and Gajewski, 1992; MacDonald et al., 2000). The Arctic front is defined as the boundary between cold 
and dry Arctic air masses and warm and moist southern air masses (Bryson, 1966). The southern boundary tends to conform to a mean July temperature isotherm of $18^{\circ} \mathrm{C}$ (Kuusela, 1992).

Conifers tend to dominate tree-line due to adaptations which allow them to persist in harsh environments, such as the extreme temperature ranges characteristic of circumpolar regions. These adaptations include a thick cuticle on the leaf surface which protects against water loss and mechanical damage, the ability to photosynthesize year round, and a lower albedo allowing them to absorb incoming solar radiation and thus heat (Oke, 1978; Richardson and Friedland, 2009). Throughout the broad boreal zone, dominance of tree species is limited to four main coniferous genera: pine (Pinus spp.), spruce (Picea spp.), larch (Larix spp.), and fir (Abies spp.) (Hare and Ritchie, 1972). Other, less dominant genera include deciduous genera such as birch (Betula spp.), poplar/aspen (Populus spp.), and willow (Salix spp.) (Hare and Ritchie, 1972). In Canada, tree-line on the northwest coast is most often white spruce while on the east coast tends to be a mixture of white and black spruce (Picea mariana Mill.) (Hare, 1950; MacDonald and Gajewski, 1992). Tree-lines may also be composed of larch on local to regional scales in eastern Canada (MacDonald and Gajewski, 1992).

\subsubsection{Boreal Tree-line}

The boundaries of northern tree growth are determined by both biotic and abiotic factors. These include climate, disturbance regimes, drainage, and biotic interactions (Mather and Yoshoika, 1968; MacDonald and Gajewski, 1992; Körner, 1998). Tree-line is considered a limit beyond which tree growth and reproduction are not possible due to environmental stress (Tranquillini, 1979). Tree-line is widely considered a transition zone 
rather than a well-defined boundary and is also referred to as the 'forest-tundra ecotone' (Hare, 1950; MacDonald and Gajewski, 1992; Körner, 1998). Tree-line occurs where there are thermal, drought, flood, nutrient, or salt stress gradients that inhibit the adaptation of tree growth forms beyond a certain threshold (Körner, 1998). Over the past 400 years of tree-line research (Troll, 1973), many theories about the limits to tree growth have been formulated (Richardson and Friedland, 2009). The abiotic controls to be discussed below include radiation balances, temperature, soil conditions, mechanical damage, physiological stress, and disturbance (Richardson and Friedland, 2009).

\subsubsection{Radiative Controls}

The Arctic tree-line transition zone is believed to correspond to a gradient of surface energy and moisture conditions controlled by radiative heating (Hare and Ritchie, 1972). Transitional trends are widespread across the northern circumpolar boreal forest which suggests a common control - that of the energy balance at these sites (Hare and Ritchie, 1972). The length of the growing season at tree-line can be very short, documented to be approximately 2.5 months at the Arctic-alpine tree-line (Körner, 1998) because of low solar radiation (MacDonald and Gajewski, 1992). The greatest amount of solar radiation receipt is from April through June (Hare and Ritchie, 1972). During the spring, the closed forest has a lower albedo than the tundra due to reduced snow cover and exposed plant matter (Hare and Ritchie, 1972; Epstein et al., 2004). This promotes rapid heating in the forest which slowly spreads northward to thaw tundra regions, affecting temperatures and growing conditions (Hare and Ritchie, 1972). However, treeline covers a broad range of latitudes from north of $68^{\circ}$ to $58^{\circ} \mathrm{N}$ in Canada illustrating that factors other than insolation are also important. 


\subsubsection{Temperature}

The low growth rates of trees at tree-line may be indicative of moisture and temperature stresses (Epstein et al., 2004). Temperature is believed to be the greatest limit to tree growth at both Arctic and alpine boreal tree-lines due to its impact on reproduction, and life-cycle processes (Fritts, 1976; Körner, 1998; Richardson and Friedland, 2009). The establishment of trees has been linked to warm summer conditions (Black and Bliss, 1980; Elliot-Fisk, 1983) as cold temperatures limit seed development and dispersal and seedling germination and establishment (Richardson and Friedland, 2009). Temperature controls necessary physiological processes such as carbon fixation and cell development and maturation (Richardson and Friedland, 2009). Although there might be sufficient carbon at latitudinal tree-line locations, cold temperatures can restrict the use of this carbon for growth and renewal (Richardson and Friedland, 2009). Cool conditions result in reduced photosynthesis and, accordingly, less carbon allocation to wood production (Richardson and Friedland, 2009). The optimal temperature for photosynthesis for trees is $20^{\circ} \mathrm{C}$, below which rates decrease (Grace, 2002).

Temperature may also explain the shift seen from vertical trees to krummholz form. New tissue may be unable to mature before the end of the growing season and may not be able to survive winter conditions above snow depth (Wardle, 1965; Stevens and Fox, 1991). This can damage the stem portion above the snow which may die back, limiting the height of the tree to krummholz mats (Richardson and Friedland, 2009). Temperature limits cell differentiation and division, and a temperature threshold of $5.5^{\circ} \mathrm{C}$ to $7.5^{\circ} \mathrm{C}$ for the production and maintenance of cells has been suggested by Körner (1998). 


\subsubsection{Permafrost and Soil Conditions}

The southern limit of continuous permafrost corresponds loosely with the northern limits of tree-line (Brown and Péwé, 1973). The presence of permafrost has been associated with damage to root systems and restrictions on groundwater flow within the active layer (Brown and Péwé, 1973). It has also been noted that sites with permafrost support fewer trees than sites without (Epstein et al., 2004). Across the Alaskan tree-line, Epstein et al. (2004) observed abrupt tree-line transitions along floodplains resulting from local permafrost distribution. The authors hypothesized that the permafrost active layer was deeper within the floodplains, allowing for the establishment of trees, whereas just off the floodplain tree establishment was hindered due to a shallow active layer (Epstein et al., 2004). Abrupt changes in soil properties have not been found to be linked to treeline boundaries, though they may alter site-specific species composition (Larsen, 1980; Epstein et al., 2004).

\subsubsection{Disturbance}

While climate, particularly temperature, is an important control on the growth of northern trees (Fritts, 1976; D’Arrigo et al., 1992), the distribution of boreal forest ecosystem types (e.g. boreal wetlands and boreal uplands) is strongly linked to topography and disturbance (Chapin et al., 2000). Disturbance events can occur as fire or thermokarst slumps. At the Arctic tree-line, fire may both improve and reduce tree-line species regeneration, although return intervals for fire at tree-line are generally quite long (centuries) (Kasischke et al., 2002). Fire can kill mature trees and seedlings, which has been hypothesized by Payette and Filion (1985) to have caused large scale deforestation in locations where seed banks could not re-establish forest cover. In other cases where 
viable seeds are stored, the post-fire environment can enhance seedling growth conditions and also reduce competition with tundra species (Epstein et al., 2004). In western North America, warming trends have been linked to an increase in boreal forest fires from 1990 to 2000 as compared to 1970 to 1980 (Kasischke et al., 1999).

Thermokarst disturbance, as a result of permafrost thaw, can lead to retrogressive thaw slumps and enhance tree establishment and forest migration where tree-line is locally limited by permafrost (Epstein et al., 2004). Where thaw slumps are formed, nutrients are released, ground temperatures are warmer, and the active layer deepens (Lantz et al., 2009), promoting the establishment of trees.

\subsubsection{Winter Desiccation}

Winter desiccation, also referred to as frost drought, is a phenomenon that occurs in late winter and early spring when soils are frozen and there are high levels of solar radiation (Richardson and Friedland, 2009). The solar radiation stimulates photosynthesis in conifer needles by heating them. The leaf stomata open for carbon intake and at the same time release water vapour to the air. With no means of restoring this water through root uptake from the frozen soil, cell damage and needle death can result from excessive moisture loss (Daubenmire, 1954; Richardson and Friedland, 2009). Growing above the snow depth also leaves stems vulnerable to harsh winter conditions which can destroy needles and stems, predominantly in saplings (Tranquillini, 1979; MacDonald and Gajewski, 1992). There may be an increased risk of frost damage when needles are immature or already damaged by mechanical abrasion (Hadley and Smith, 1983). 


\subsubsection{Reproduction}

Reproduction is closely related to temperatures at tree-line locations. Temperature is important for seed production and germination as these require temperatures of at least $6^{\circ} \mathrm{C}$ (Black and Bliss, 1980; Grace, 2002). Seedlings are highly vulnerable to abiotic stresses and can benefit greatly from growth facilitation (Körner, 1998; Johnson et al., 2004). One of the greatest challenges to seedling development is extending above the krummholz layer (Stevens and Fox, 1991; Körner, 1998). Facilitation by nearby trees and the physical landscape plays an integral role in ensuring seedling maturation to saplings and trees by providing shelter from the sun thus minimizing extreme temperature conditions, including low temperature inhibition of photosynthesis (Smith et al., 2003; Richardson and Friedland, 2009).

\subsubsection{Exceptions}

There are exceptions to the described growth limits, exemplified by forest islands found beyond tree-line limits (Körner, 1998). Forest islands are isolated stands of trees above tree-line extent (e.g. Holtmeier and Broll, 1992). There are several theories which attempt to quantify their existence, of which the 'remnant hypothesis' and the 'shelter hypothesis' are most supported (Körner, 1998). The remnant hypothesis posits that these forest islands are located in sheltered patches left on the landscape from past forests that have since receded. The shelter hypothesis posits that these forests may exist due to the shelter of landscape components (i.e. large rocks) such that they are not disturbed by fire and that they inhabit and maintain a microclimate conducive to survival and growth (Körner, 1998). 


\subsubsection{Summary}

In summary, the Arctic forest-tundra transition zone is limited by factors that affect the growth and reproduction of trees including net radiation, temperature, disturbance, and various stresses. These processes have varying importance on tree-line extent depending on regional and local conditions (Tranquillini, 1979). Trees surviving in this region do so through the allocation of energy resources first to survival and second to growth and reproduction (Elliot-Fisk, 1983).

\subsubsection{Climate-Growth Relationships}

Arctic and boreal ecosystems experience extreme environmental conditions (Elliot-Fisk, 1983), and are sensitive to even slight fluctuations in climate (Chapin et al., 2000). Northern boreal forests are expected to respond to recent high latitude warming with changes in growth trends (Schweingruber et al., 1993; D’Arrigo et al., 2004). Schweingruber et al. (1993) predicted increases in the growth of trees at northern treeline in response to warming temperatures. Recent studies have noted trends contradictory to this prediction, with decreased tree growth in the past few decades of the $20^{\text {th }}$ century even though temperatures are thought to be amongst their warmest during the past several centuries to millennia (e.g. D’Arrigo et al., 2004).

Warming caused by anthropogenic activities are likely to make temperatures higher than they were during the Holocene (Reasoner and Tinner, 2008). The limit of the boreal forest is expected to expand northward in response to climate warming (Körner et al., 1998), and growth rates at tree-line have already been observed to increase (e.g. Andreu-Hayles et al., 2010). If in fact, tree-lines do expand northward, a positive feedback to warming may be initiated as forests have a greater capacity to absorb solar 
radiation than tundra (Oke, 1978; Richardson and Friedland, 2009). A negative feedback would occur if forests increase the carbon sink, although more research is needed to fully ascertain if this is likely (Barber et al., 2000). However, recent research has found indications of a temperature threshold to growth in the form of the divergence problem (see section 2.5) (D’Arrigo et al., 2008). Accurate estimates of carbon storage and feedbacks are essential to predictions of global climate modelling and rely on a knowledge of boreal ecosystem thresholds (Barber et al., 2000; Chapin et al., 2000).

\subsection{Physiology and Growth of Conifers}

\subsubsection{Growth Trends}

Trees are made up of three vegetative components: the stem, roots, and leaves (Pallardy, 2008). The focus of dendrochronology is generally on stem growth. The stems of trees provide mechanical support to the plant body and are responsible for the transportation and storage of water, carbohydrates, minerals, and hormones (Pallardy, 2008). They are composed of two portions: heartwood and sapwood (Kramer and Kozlowski, 1960). The heartwood of a tree is closer to the pith, is often a darker colour, and is made up of dead tracheid cells. The sapwood is the living part of the stem where conduction occurs and is made up of xylem and phloem cells (Pallardy, 2008). Only about $10 \%$ of the cells in the sapwood are alive and these store food (Kramer and Kozlowski, 1960; Pallardy, 2008).

Tree growth proceeds both vertically (apical growth) and horizontally (lateral growth). The primary component of tree growth is a vertical expansion of the stem through the apical meristem resulting in an increase in height, whereas secondary growth is a lateral expansion of the stem through the cambial meristem (Kramer and Kozlowski, 
1960; Morey, 1973; Pallardy, 2008). In coniferous tree species, apical growth is always accompanied by lateral growth (Vaganov et al., 2011), however, the lateral growth of trees tends to last longer than apical growth (Kramer and Kozlowski, 1960).

The vascular region of cell development and expansion in the stem is called the vascular cambium and is located between the xylem and phloem, just behind the bark (Morey, 1973; Pallardy, 2008). Once conditions warm up in the spring and early summer, the cambium begins to produce new xylem and phloem cells. These are formed between older layers of xylem near the pith and older phloem near the bark resulting in radial expansion of the stem (Pallardy, 2008). About $90 \%$ of the xylem of conifers is made up of conducting tracheid cells with the remainder composed of parenchyma and epithelial cells (Morey, 1973; Pallardy, 2008). The new xylem cells will express local environmental conditions in the size and structure of new cells (Hughes, 2011).

\subsubsection{Annual Ring Development}

Annual rings are comprised of radial xylem growth increments (Pallardy, 2008). The formation of xylem cells, or xylogenesis, occurs in 2 phases. The first phase occurs at the beginning of the growing season with the formation of large-diameter cells (earlywood) and transitions to the second, smaller-diameter cells (latewood) later in the growing season, a transition likely triggered by the hormone auxin in the stem (Kramer and Kozlowski, 1960; Morey, 1973; Pallardy, 2008). Over the lifespan of a xylem cell, it will experience rapid growth early in the growing season, cell wall thickening, and later, transition to deadwood in the stem (Vaganov et al., 2011). The final size of xylem cells depends on the environmental conditions during their formation (Vaganov et al., 2011). 
Earlywood and latewood refer to xylem cell types within an annual ring that differ in both their growth phenology and physical properties. In cold region conifers, latewood formation begins in late June continuing until early August (Hoadley, 1990; Meko and Baisan, 2001; Esper and Schweingruber, 2004; Miller et al., 2010; Speer, 2010). The transition between cell types is believed to be governed by internal and external factors (Vaganov et al., 2011). The diameter of cells is controlled by the chemical auxin, which is regulated by factors necessary to photosynthesis including sunlight and water (Kramer and Kozlowski, 1960; Morey, 1973; Vaganov et al., 2011). Latewood formation begins near the base of the tree and gradually moves up the stem (Young, 1952). Hydrologic stress is associated with the shift from earlywood to latewood and may be due to the properties of latewood that restrict water movement to a greater degree than earlywood (Morey, 1973; Kozlowski et al., 1966; Vaganov et al., 2011).

The morphology of earlywood and latewood cells differ as well. Within an annual ring, there are generally a greater number of earlywood cells as growth proceeds rapidly early in the growing season (Kramer and Kozlowski, 1960). Earlywood cells tend to be larger and have thinner cell walls, hence the cells have a lower density than latewood cells (Kramer and Kozlowski, 1960; Morey, 1973; Hoadley, 1990; Speer, 2010). In coniferous species, the thickness of cell walls is closely linked to changes in density as xylem cells tend to be structurally similar and uniform (Pallardy, 2008). Latewood cells are denser than earlywood cells which can be due to thicker cell walls or the formation of smaller diameter cells (Pallardy, 2008). The boundary between these cell types tends to be sharply defined in coniferous species (Pallardy, 2008). The maximum density of cells is determined by the thickness of the cell wall which is in turn controlled by the period of 
xylogenesis and the diameter of the cell prior to cell wall thickening (Vaganov et al., 2011).

The characteristics of ring-width and ring density can vary between trees and within the same tree at different heights (Kramer and Kozlowski, 1960), highlighting the importance of a consistent methodology and replicate sampling. In a similar manner that tree rings become narrower as a tree ages, the density of a ring decreases with distance from the pith (Hughes, 2011). In climate analyses in northern latitudes, ring width correlated well with June, July, and August temperatures while maximum ring density correlated well with temperature from May-September (Briffa et al., 1990; 1992; D’Arrigo et al., 1992).

\subsection{Methods of Dendrochronological Analysis}

\subsubsection{Paleoclimatology, Dendrochronology, and Dendroclimatology}

Paleoclimatology is the study of past climate change, a field that makes use of a wide variety of natural proxy records to provide information about past conditions. Tree ring records are one such proxy that can provide high resolution data about growing season conditions on an annual basis (Bradley, 2011). Compared to other high resolution proxy data, tree rings are among the most highly replicated datasets due to the low cost of sampling and the relative ease by which samples can be collected (Bradley, 2011). The replication of annual series allows researchers to amplify the climate signal present in the proxy and to reduce individual non-climate noise at their study sites, thus providing more accurate estimates of past conditions (Hughes, 2011).

The main methodological and theoretical approaches applied in this research stem from the field of dendrochronology. Dendrochronology refers to the scientific study of 
radial tree growth. Dendroclimatology is a branch of dendrochronology that uses tree rings to study the relationships between tree growth and climate variables and to reconstruct past climate (Fritts, 1976). The use of tree rings to reconstruct past climates is based on the principle of uniformitarianism which states that the physical and biological processes affecting tree growth in the present are similar to those operating in the past (Fritts, 1976). Using this principle, relationships between past climate and tree growth can be inferred from the analysis of tree rings (Fritts, 1976). Tree rings are ideal climate proxies as the environmental controls on tree growth are well understood (Bradley, 2011). The most commonly used tree-ring indices are ring-width and maximum density, which divulge different climate signals (Schweingruber et al., 1993; Hughes, 2011).

Trees growing in temperate regions generally form a growth ring each year and therefore capture climatic conditions at an annual resolution (Fritts, 1976). Trees growing at high northern latitudes are known to be highly sensitive to limiting climatic conditions (Tranquillini, 1979), particularly to summer temperatures (D’Arrigo et al., 1992; Jacoby and D'Arrigo, 1995; Briffa et al., 1998a; Esper and Schweingruber, 2004). Accordingly, trees at the northern tree-line are often used in temperature reconstructions (e.g. Cook and Kairiukstis, 1990; Wilson and Luckman, 2003; Barber et al., 2004; Anchukaitis et al., 2013; Porter et al., 2013). Dendroclimatic reconstructions rely on the strength of climategrowth relationships to reconstruct pre-instrumental climatic conditions, such as temperature, using measurements of tree-ring growth (Cook and Peters, 1997).

\subsubsection{Regional Dendroclimatology}

The climate sensitivity of white spruce near the Northwest Territories boreal treeline has been established by several studies (Szeicz and MacDonald, 1996; Pisaric et al., 
2007; Muise, 2013; Porter et al., 2013a, b). Szeicz and MacDonald (1996) developed a 930-year long white spruce chronology from the Campbell Dolomite Uplands south of Inuvik, NT that exhibited a high sensitivity to moisture stress. Research by Porter et al. (2013a) confirmed the temperature-sensitivity of white spruce in the Inuvik region through the development of a stable oxygen isotope chronology (1850 to 2003) for three spruce trees outside of Inuvik, Northwest Territories. Porter et al. (2013a) found that the oxygen isotope chronology was most significantly correlated to growing season temperatures at Inuvik, which enabled the reconstruction of summer temperatures to 1780 CE.

Evidence of divergence in tree-ring series has also been documented in the Inuvik region (Pisaric et al., 2007; Porter et al., 2013b). Pisaric et al. (2007) noted that all studied white spruce trees exhibited similar responses to temperature during the past 400 years, however this relationship became less coherent during the $21^{\text {st }}$ century (Pisaric et al., 2007). Of their $\sim 650$ samples, only $25 \%$ of trees exhibited positive responses to temperature after $\sim 1930$. A network of 29 white spruce sites developed by Porter et al. (2013b) across the Mackenzie Delta also exhibited divergence, evident as early as $\sim 1900$.

\subsection{The Divergence Problem}

\subsubsection{Definition}

Recent dendroclimatic studies have detected a decoupling between tree-growth indices and instrumental temperature records over the last half of the $20^{\text {th }}$ century across high latitude circumpolar forests, casting uncertainty about the reliability of tree-ring based climate reconstructions (Jacoby and D'Arrigo, 1995; Briffa et al., 1998a; Barber et al., 2000; Briffa et al., 2004; Wilmking et al., 2004, 2005; Pisaric et al., 2007; Wilson et 
al., 2007; D'Arrigo et al., 2008; Grudd, 2008; Porter and Pisaric, 2011). This decoupling, termed the divergence problem, has been the subject of investigation over recent decades (D'Arrigo et al., 2008). The divergence problem tends to be described as one or both of the following: 1) a loss of temperature sensitivity of tree-ring indices in the $20^{\text {th }}$ century leading to temperature underestimations in tree-ring reconstructions (Briffa et al., 1998a) and 2) as the differential response of individual trees to temperature (ranging from positive to negative responses) (Barber et al., 2000; Lloyd and Fastie, 2002; Wilmking et al., 2004; King, 2009; Porter and Pisaric, 2011).

A major concern about the divergence problem is that it may have also happened in the past, affecting the use of tree-ring chronologies in temperature reconstructions and the evaluation of anthropogenic warming in a long-term context (D'Arrigo et al., 2008). Chronologies that diverge from the temperature record cannot be used to compare current warming to past warming events (notably, the Medieval Climate Anomaly (MCA)) as their use may result in underestimation of past temperatures (D'Arrigo et al., 2008). Recent empirical studies suggest that divergence may be unique over the past 700 (Porter and Pisaric, 2011) to 1000 years (Cook et al., 2004). Based on a comparison of northern tree-ring chronologies and extra-tropical Northern Hemispheric chronologies, Cook et al. (2004) found that no periods of divergence other than the current one were present in the record back 1000 years, including the MCA. Porter and Pisaric (2011) found that their northern chronologies also corresponded strongly to Northern Hemisphere temperatures prior to divergence. Several other studies supported these findings and suggested that divergence was a result of recent high temperature anomalies resulting from anthropogenic activity (Briffa et al., 1998a; Wilmking et al., 2005; Pisaric et al., 2007), 
probably warmer than at any time in the past 900 years (Kaufmann et al., 2009;

Anchukaitis et al., 2013).

\subsubsection{Tree Ring Evidence}

\subsubsection{Early Studies}

Small-scale studies in high northern latitude regions have identified divergent trends in tree-ring growth as a loss of temperature sensitivity. Jacoby and D'Arrigo (1995) were among the first to detect a decline in temperature response in white spruce samples taken from 5 sites along the Alaskan tree-line when their TRW and MXD chronologies failed to respond to a renewed warming period in the 1970 s though they had responded to prior warming periods (e.g. 1940's). This phenomenon was further investigated by Briffa et al. (1998a) in an extensive $~ 300$-site study examining the growth trends of multiple tree species across the circumpolar northern latitudes. They discovered a divergent trend as all TRW and MXD chronologies were highly temperature sensitive over the common 1881 to 1940 period, but stopped tracking temperatures after 1960 (Briffa et al., 1998a). When temperatures peaked in the 1980s, tree growth indices were as low as those recorded for the cool 1880s period (Briffa et al., 1998a). Based on their data, Briffa et al. (1998a) defined divergence as beginning in the 1930s and becoming more widespread until a peak in the late 1980 s to early 1990 s, a development also noted in later research (e.g. Pisaric et al., 2007). These studies proposed site-specific factors such as moisture stress and hemispheric influences such as changes in UV-B and solar radiation amounts as potential causes of divergence (Jacoby and D’Arrigo, 1995; Briffa et al., 1998a) 
A study conducted by Kirchhefer (2001) in Norway examining Scots pine (Pinus sylvestris L.) spanning the period from AD 1700 to 1992, with a chronology end date comparable to those of Briffa et al. (1998a) and Jacoby and D'Arrigo (1995) did not find the decline in temperature sensitivity characteristic of other studies. Kirchhefer (2001) stated that growth trends began to differ from a consistent response to summer temperature to site-specific climate responses after 1910, but did not find evidence of the development of divergence identified in Briffa et al. (1998a) and Jacoby and D'Arrigo (1995). It is possible that divergence was not found at these sites as a result of local oceanic climate forcings due to the maritime aspect of the study sites (Kirchhefer, 2001). These early studies raise questions about the scope of divergence in temperature reconstructions and the corresponding consequences for global climate models relying on tree-ring reconstructions (Briffa et al., 1998a).

The impact of the divergence problem is not limited to certain species as discussed by Lloyd and Bunn (2007). In a circumpolar study of the temperature-growth response of trees in the boreal forest from 1901 to 2002, the authors found that all species examined (Larix spp., Picea spp., Pinus spp., and Tsuga spp.) exhibited variability in response to climate, and especially temperature. Negative growth responses to temperature were primarily noted in spruce species, namely, Picea abies, Picea glauca, Picea mariana, and Picea obovata. This was attributed to the often dry, continental interiors in which spruce are common in North America (Lloyd and Bunn, 2007).

\subsubsection{Divergence in the $20^{\text {th }}$ century}

Divergence in the most recent half of the $20^{\text {th }}$ century has been described in numerous studies as a hemisphere-wide occurrence at both site-level (e.g. Barber et al., 
2000; Lloyd and Fastie, 2002; Andreu-Hayles et al., 2011) and individual tree-level (e.g. Wilmking et al., 2004; 2005; Pisaric et al., 2007; Porter and Pisaric, 2011). Barber et al. (2000) analysed TRW and MXD chronologies from 20 sites across the Alaskan boreal forest and found strong correlations between TRW and instrumental temperature from 1909 to 1996, although the relationship was negative from 1970 onward (Barber et al., 2000). Alternatively, the MXD chronologies sustained a positive relationship with temperature throughout the 76-year study period from 1918 to 1994 (Barber et al., 2000). Barber et al. (2000) state that their samples' TRW exhibited no declines in temperature sensitivity, only changes in the sign of the relationships after 1970 from positive to negative. Contrasting results were also found elsewhere in Alaska by Lloyd and Fastie (2002), who found divergent responses to temperature between their study sites, with declining growth after 1950. Declines in TRW were observed after 1950 at sites below tree-line while those at tree-line were positively correlated with summer temperatures throughout the study period (1923 to 1996) (Lloyd and Fastie, 2002). Both studies suggested that temperature may be limiting tree growth after a certain temperature threshold is reached, with moisture stress effects increasing for temperature stressed sites (Barber et al., 2000; Lloyd and Fastie, 2002; Wilmking et al., 2004).

Evidence of a temperature threshold was also discussed by Wilmking et al. (2004; 2005). Wilmking et al. (2004) identified subpopulations of white spruce based on their response to climate after 1950. Individual trees that tracked instrumental temperatures were positive responders, those with decreases in growth were negative responders, and a third subpopulation was identified that had no significant response (Wilmking et al., 2004). This extensive study sampled from $\sim 1500$ trees at tree-line sites in Alaska and 
used instrumental data from 1906 to 2000 to extract the climate-growth relationship (Wilmking et al., 2004). Strong relationships with temperature were found amongst the majority of trees, with a greater number of negative responders than positive responders (Wilmking et al., 2004).

Pisaric et al. (2007) and King (2009), in studies similar to that of Wilmking et al. (2004) and both in the Mackenzie Delta region in the Northwest Territories also found distinct subpopulation signals at their study locations. In both studies, the majority of trees were identified as negative responders with regards to instrumental temperatures, supporting the findings of Wilmking et al. (2004). These opposing growth trends (negative and positive) at the subpopulation level may explain observations of decreased temperature sensitivity over time at study sites as the combined response of positive and negative responders could confuse the observed relationship with temperature (e.g. Jacoby and D'Arrigo, 1995) (Wilmking et al., 2004, 2005; Pisaric et al., 2007; King, 2009). Wilmking et al. (2005) observed that temperature sensitivity had actually increased during the $20^{\text {th }}$ century compared to the 300 years preceding.

Later studies also found indications of widespread divergence across the high northern hemisphere latitudes. Similar to earlier studies, Porter and Pisaric (2011) found evidence of widespread divergence in temperature response among individual white spruce trees and that divergence began in the 1930s across a 23 -site network in Yukon Territory. A peak in growth was observed in all TRW chronologies in the 1930s after which negative responders declined in growth and positive responders increased in growth (Porter and Pisaric, 2011). Another study conducted by Andreu-Hayles et al. (2011) developed white spruce TRW and MXD records at tree-line in Firth River, 
Alaska. Their TRW chronology was not significantly correlated with temperature from 1951 to 2001, while their MXD chronology continued to give a stable temperature response throughout the $20^{\text {th }}$ century. Interestingly, their trees produced wider and denser rings, contrary to the declines in ring-width described by earlier studies (Barber et al., 2000; Lloyd and Fastie, 2002; Pisaric et al., 2007; Andreu-Hayles et al., 2011).

Although these studies were conducted in similar environments, there were conflicting results and different points of view about the nature of divergence. Briffa et al. (1998a) detected a decline in temperature sensitivity while other researchers detected strong negative and positive correlations with temperature (e.g. Barber et al., 2000; Porter and Pisaric, 2011). This can partly be explained by the scale of the studies. Those researchers who analysed tree-ring data by site observed either consistent trends (e.g. Briffa et al., 1998a) or no response to climate (e.g. Andreu-Hayles et al., 2011) after $\sim 1950$, while those who separated trees on an individual basis identified divergence in growth trend, (e.g. Wilmking et al., 2004), though not in all cases. The grouping of negative and positive responders by study site could mask the individual signals. Another difference between studies is in the responses displayed by the TRW and MXD chronologies constructed from the same samples to temperature. In Briffa et al. (1998a, b), both records showed divergence but in others, MXD showed no divergence while TRW did (Grudd, 2008; Andreu-Hayles et al., 2011).

\subsubsection{Potential Causes of Divergence}

The causes of divergence in TRW are thought to be widespread across the extratropical northern hemisphere due to the scope and synchronicity of observations (D’Arrigo et al., 2008). This excludes causes such as insect infestations (Briffa et al., 
1998a) and suggests factors such as pollution effects and changes in solar radiation (Briffa et al., 1998b; Büntgen et al., 2006). If divergence is determined to be due uniquely to anthropogenic causes, this will give assurance that no similar event influenced tree growth in the past, though it will need to be considered in predictions of future temperature response (D’Arrigo et al., 2008).

\subsubsection{Temperature-induced drought stress}

Recent increases in global temperatures have been influencing tree growth (Esper and Schweingruber, 2004). Higher temperatures have been linked with increasing tree growth in the early half of the $20^{\text {th }}$ century, but with declines in growth and temperature sensitivity in the later half (see section 2.5.1). One of the most widely accepted explanations is that the high temperatures of the $20^{\text {th }}$ century are affecting tree growth through moisture stress (Barber et al., 2000; Grudd, 2008; Anchukaitis et al., 2013).

Increases in temperature may negatively impact tree growth by increasing evapotranspiration and decreasing available soil moisture (Brooks et al., 1998; Barber et al., 2000). The positive and negative responders documented in several studies are likely responding individually to microclimate moisture conditions at individual sites, causing divergent responses between trees (Wilmking et al., 2004; King, 2009; Porter and Pisaric, 2011). In a study from Alaska, negative responders were found at sites with high stem densities and limitations on water transport, possibly leading to competition for water and inducing further water stress (Wilmking et al., 2004). Additionally, in regions where soil moisture was already limiting, rising temperatures reduced the amount of soil moisture

present (Barber et al., 2000). The thickness of the organic soil layer has also been found to be important as thicker moss layers have been found to support trees with positive 
growth responses as the thicker moss layers limited moisture loss (King, 2009). A temperature threshold of mean July temperatures $\left(11^{\circ} \mathrm{C}\right.$ to $\left.12^{\circ} \mathrm{C}\right)$ was suggested by Wilmking et al. (2004) for their Alaskan sites, after which TRW growth is limited. This may be indicative of a non-stationary response between tree growth and climate (Anchukaitis et al., 2013). Several studies have noted moisture stress responses as well (e.g. Jacoby and D’Arrigo, 1995; Barber et al., 2000; Lloyd and Fastie, 2002; Wilmking et al., 2004; 2005; Büntgen et al., 2006; Porter and Pisaric, 2011).

\subsubsection{Standardization and End Effects}

The standardization of tree-ring series is an integral step in converting tree-ring measurements into local and regional chronologies composed of many series (Fritts, 1976). Also referred to as detrending, this process involves the removal of the natural age-related trend in an individual tree-ring series as there is a tendency for the production of relatively wider rings when a tree is younger which become more narrow as the tree continues to age (Fritts, 1976; Cook, 1985). The traditional and most commonly used method of detrending in tree-ring studies applies either a negative exponential curve or a horizontal line to individual tree-ring series using program ARSTAN (Cook, 1985). This process may result in a loss of low frequency variability which has been identified as a possible cause of divergence (Briffa et al., 1998a; b; Grudd, 2008). Many of the early studies on divergence used this method to standardize their data (e.g. Kirchhefer, 2001; Lloyd and Fastie, 2002; Wilmking et al., 2004).

Some issues arise in the use of detrending methods, namely the segment length curse (Cook et al., 1995) and trend distortion (Melvin, 2004). The segment length curse described by Cook et al. (1995) refers to the issue with traditional detrending methods in 
that they do not account for the possibility that trends in climate or stand-level ageing can last longer than the length of series. Thus, climate signals with periodicities longer than that of individual segments will not be resolved in the resulting standardized chronologies. Cook et al. (1995) states that the shorter the length of the segments, the greater the loss of climate data.

Another cause may be due to trend distortion, which refers to chronologies with biased representations of growth due to higher sample replication late in the $20^{\text {th }}$ century (Melvin, 2004; Grudd, 2008; Melvin and Briffa, 2008; Porter and Pisaric, 2011). As described by Melvin (2004), trend distortion is the removal of some medium frequency (decadal-centennial) climate data from chronologies due to the use of inflexible fitted detrending curves (i.e. least-squares-fitted straight line). It can also occur when using data-adaptive curves (modified negative exponential and smoothing spline) when there is "variance in the common signal at frequencies lower than that of the flexibility of the detrending curve" (Melvin and Briffa, 2008, p. 3). Trend distortion is pronounced when multiple series end in the same year (Melvin and Briffa, 2008). The high replication of samples in the late $20^{\text {th }}$ century could result in over-emphasis on negative growth trends, causing divergent trends to emerge (Melvin, 2004; D'Arrigo, 2008). Thus, it is important to consider the age structure of all samples in a chronology prior to standardization.

\subsubsection{Other Causes}

Several other causes of divergence have been suggested, from global dimming to increases in ultraviolet radiation (D'Arrigo et al., 2008; Büntgen et al., 2006). Global dimming refers to a decrease in the amount of solar radiation reaching Earth's surface in recent decades (D'Arrigo et al., 2008) as a result of aerosol output of volcanic eruptions 
and from pollutants released from anthropogenic activities (Stanhill and Cohen, 2001; Stine and Huybers, 2013). The combination of these aerosols reduced the penetration of light to the ground surface by reflecting and absorbing incoming radiation over the study period from 1950 to 1994 in Arctic regions, with the greatest amount of dimming observed from 1955 to 1975 (Stanhill and Cohen, 2001; Stine and Huybers, 2013). Since the 1980 s, there appears to have been a decrease in dimming resulting from the efforts of industrial nations to reduce air pollution (Wild et al., 2007; D’Arrigo et al., 2008). Atmospheric pollution may also be important as increasing levels of $\mathrm{CO}_{2}$ and other chemicals are exchanged with terrestrial systems (Briffa et al., 1998a).

Increases in UV-B radiation may be inhibiting the photosynthesis of higher plants due to its damaging effects to photosynthetic processes (Briffa et al., 1998a; Briffa et al., 2004). There are few long-term measurements of the atmosphere, so Briffa et al. (2004) tested this by comparing ozone concentrations to MXD residuals from a regression with summer temperatures and found that reduced ozone was positively correlated with reduced MXD residual values. With a reduction in the ozone, a greater amount of UV-B radiation is transmitted to the surface, negatively impacting tree growth.

\subsubsection{Developing Divergence-free Reconstructions}

With a better understanding of divergence, researchers began to attempt to build reliable temperature reconstructions by a) excluding negative responders from reconstructions, b) implementing updated statistical methods, and c) using alternate tree indices such as MXD. Wilmking et al. (2005) suggested that accurate temperature reconstructions could still be calculated if tree ring series were separated prior to chronology development by including only positive responders. This sorting was 
implemented by Wilson et al. (2007) who chose samples based on the strength of their representation of local and regional temperatures and made sure there was sufficient replication in each period. The authors succeeded in creating a divergence-free chronology for the extra-tropical northern hemisphere using a compilation of published and unpublished tree-ring data (Wilson et al., 2007). This divergence-free reconstruction spanned the period from 1750 to 2000 and generally agrees with instrumental temperature records though there is a slight under prediction of temperatures after 1988 that was attributed to homogenization corrections (Wilson et al., 2007).

A longer reconstruction was created by Grudd (2008) using Scots pine (Pinus sylvestris L.) samples from northern Sweden which spanned from 500 to $2004 \mathrm{CE}$. This reconstruction was based on the premise that divergence is caused by non-environmental standardization and age-trend related factors (Melvin, 2004; Grudd, 2008; Melvin and Briffa, 2008). They excluded young trees from their analysis and standardized their samples to remove growth trends using a detrending method called regional curve standardization (RCS) (Esper et al., 2003). RCS aligns individual tree-ring series based on their cambial age and calculates an average growth curve to which the individual samples are then standardized and realigned by calendar year (Esper et al., 2003). It is very important to have replication throughout the time period of interest for RCS detrending in order to minimize bias (Grudd used a cut off of 25 samples) (Grudd, 2008). RCS improves upon traditional negative exponential curve detrending by preserving long-term variability while still removing the age-related growth trend (Esper et al., 2003). Results of the reconstruction illustrated a difference between the TRW and MXD chronologies in the first half of the $20^{\text {th }}$ century (Grudd, 2008). Grudd (2008) concluded 
that this is likely due to forest regeneration during this period which affected the form of the RCS curve.

Anchukaitis et al. (2013) also created a divergence-free MXD chronology using samples from 103 trees at the Firth River, Alaska; a location where TRW chronologies had previously been found to have low temperature sensitivity (see Andreu-Hayles et al., 2011). The authors tested 3 detrending methods: the traditional method of Cook (1985), RCS (Esper et al., 2003), and a signal-free method (SF) using a pseudo-proxy MXD dataset (Melvin and Briffa, 2008). The SF method iteratively removes the common growth signal present in individual ring-width and density series, allowing growth curves to be fit while retaining a strong climate signal (Melvin and Briffa, 2008; Anchukaitis et al., 2013). Anchukaitis et al. (2013) used the signal-free detrending method to reconstruct temperatures from $\mathrm{AD} 1100$ to 2002 as it was deemed to contain the least amount of bias of the 3 tested methods.

While the SF detrending method utilized by Anchukaitis et al. (2013) did remove the divergence effect in their TRW, it was also used by Porter and Pisaric (2011) to compensate for end effects, but did not remove the divergence effect in their TRW series. Andreu-Hayles et al. (2011) also did not attribute divergence in their samples to detrending or end effects as their results showed decreased sensitivity to high frequency (2-3 years) climate variation rather than the loss of low frequency variation that can be caused by detrending.

In terms of placing $20^{\text {th }}$ century warming into a centennial-scale context, the research of Anchukaitis et al. (2013) and Grudd (2008) agrees. Based on their reconstruction, Anchukaitis et al. (2013) found that temperatures are highest at the end of 
the $20^{\text {th }}$ century, as compared to the past 900 years. The only period Grudd (2008) specifies as likely being warmer than in recent decades is a 200 -year long warm period around AD 1000, where no divergence between their TRW and MXD was found. Based on multiple reconstructions and many studies, divergence is widely believed to be unique to the $20^{\text {th }}$ and $21^{\text {st }}$ centuries and to northern forests and thus there should be no concern about its use as a temperature proxy as it is thought to be a response to anomalously high temperatures caused by anthropogenic activities (Briffa et al., 1998a; Cook et al., 2004; Wilmking et al., 2005; Pisaric et al., 2007).

\subsubsection{Maximum Tree Ring Density}

A comparison of 7 ring-width indices (earlywood, latewood, total ring-widths, mean earlywood, mean latewood, and minimum and maximum ring density) by Schweingruber et al. (1993) concluded that total ring-width and maximum ring density were the tree-ring indices most strongly related to temperature. As the densest cells tend to be formed at the end of the growing season, maximum density is considered synonymous to maximum latewood density (Schweingruber et al., 1993). It has been suggested that latewood chronologies are more robust and sensitive to climatic variability, making them more suitable for climate reconstructions (Lebourgeois, 2000; Meko and Baisan, 2001; Henderson and Grissino-Mayer, 2009). Thus, chronologies composed of TRW and/or MXD measurements are the indices most commonly used in dendroclimatic investigations as they have been deemed the most sensitive to growing season climatic conditions (Schweingruber et al., 1978; Schweingruber et al., 1993; Esper and Schweingruber, 2004). 
Further research has suggested that MXD tends to correlate better and more consistently with climate than other ring-width indices (D'Arrigo et al., 1992; Briffa et al., 1998a; Frank and Esper, 2005; Andreu-Hayles et al., 2011). Andreu-Hayles et al. (2011) suggested that MXD performs better as a climate proxy as it exhibits lower autocorrelation with previous year conditions, indicating that the formation of MXD is controlled primarily by current year conditions. TRW is primarily composed of earlywood cells which are highly reliant on carbohydrate reserves from the previous growing season (Glerum, 1980; Loescher et al., 1990) while latewood is relatively independent of this trend (Andreu-Hayles et al., 2011). Frank and Esper (2005) and Andreu-Hayles et al. (2011) also concluded that MXD is better correlated with temperature data and is largely independent of site conditions. The primary reason for this phenomenon may be as a result of the difference in cell activity during the formation of the earlywood and latewood portions of xylem cells. Earlywood formation is a period of cell division and cell enlargement directly linked to environmental conditions whereas latewood is the maturation of pre-existing xylem cells through cell wall thickening and lignification triggered by conditions that cause the cessation of active cambial cell division (Morey, 1973; Kozlowski et al., 1996; Andreu-Hayles et al., 2011; Vaganov et al., 2011). The shift from earlywood to latewood formation can be caused by site conditions, such as moisture stress, but also resulting from seasonal changes in photoperiod, nutrients, water, and temperature (Vaganov et al., 2006). For this reason, latewood density is relatively independent of moisture stress and other site conditions and is dependent instead on favourable temperature conditions promoting a longer period of cell thickening. This is supported by Anchukaitis et al. (2013) who created a divergence- 
free MXD chronology using samples from a location where TRW chronologies had previously been found to be affected by the divergence problem (see Andreu-Hayles et al., 2011). It is difficult to conclusively evaluate the differential responses of MXD and TRW as fewer MXD chronologies have been created for high northern latitudes (D'Arrigo et al., 2008), however, there is a growing pool of evidence supporting the use of MXD in producing divergence-free temperature reconstructions.

\subsubsection{Conclusions}

The divergence problem observed in high latitude and high elevation forests by numerous studies has been described both as a decline in temperature sensitivity and a divergence in growth trend between individual trees (Briffa et al., 1998a; Barber et al., 2000; Lloyd and Fastie, 2002; Wilmking et al., 2004; King, 2009; Porter and Pisaric, 2011). This phenomenon is widespread across the extra-tropical northern hemisphere and is important because of the significance of tree-ring reconstructions in global climate and carbon cycling models (Chapin et al., 2000). Attempts to understand this issue have led to increased research into the environmental factors influencing tree growth at these temperature-limited sites (Wilmking et al., 2004; King, 2009) as well as to advances in standardization methods (Esper et al., 2003; Melvin and Briffa, 2008) and the use of alternate proxy records such as $\mathrm{O}_{18}$ isotope analysis and MXD. These advances have allowed the creation of reliable tree-ring temperature reconstructions extending back hundreds of years (e.g. Grudd, 2008; Anchukaitis et al., 2013; Porter and Pisaric, 2013).

The cause(s) of the divergence problem remain uncertain though temperatureinduced moisture stress, detrending, and end effects are most commonly cited as possible reasons. Further research into temperature thresholds and non-linear growth-climate 
responses would improve current understanding of the divergence problem (Wilmking et al., 2004; Anchukaitis et al., 2013). Several recommendations have been suggested, namely the need for increased sample replication in the past and in recent decades (Wilson et al., 2007; D’Arrigo et al., 2008; Grudd, 2008; Porter and Pisaric, 2011), the need for the creation of additional MXD chronologies to compare with TRW (D'Arrigo et al., 2008), and further research into the effects of micro-climate conditions on treegrowth. 


\section{Chapter 3 - Methods}

\subsection{Study Site}

\subsubsection{Study Region}

The study region is located in the Taiga Plains High Subarctic (HS) region of the Northwest Territories (Figure 3.1), in the Mackenzie Delta HS area (Ecosystem Classification Group, 2009). The dominant vegetation types are closed canopy white spruce and black spruce forests that give way to open white spruce stands with increasing latitude. The forest understory consists of green alder (Alnus viridis Chaix) and willow to the south of the ecoregion and dwarf birch (Betula nana L.) and low mats of green alder and willow further north and at higher elevations. The ground tends to be level or hummocky glacial and lacustrine till with boulder deposits, interspersed with bedrock outcrops (Ecosystem Classification Group, 2009). The soils in this zone are coarsetextured and well-drained Brunisols and Cryosols, specifically Regosolic Turbic Cryosols with little to no soil horizon development (Ecosystem Classification Group, 2009). This region is underlain by continuous permafrost. The northern boundary of the HS region is the Tundra Plains Southern Arctic region, coincident with approximate tree-line extent (Ecosystem Classification Group, 2009).

Tuktoyaktuk and Husky Lakes are found in the Tundra Plains Southern Arctic region (Figure 3.1), in the Tuktoyaktuk Coastal Plain Low Arctic north (LA $n$ ) region of the Northwest Territories (Ecosystem Classification Group, 2012). The LAn landscape is characterized by a "low elevation undulating to hummocky till plain" (Ecosystem Classification Group, 2012, p. 48). This region is very moist as it is covered in wetlands, ponds, and lakes and is underlain by continuous permafrost. The regional soil types are 
Turbic Cryosols overtop glacial tills with a high ice content. The vegetation is primarily comprised of low shrubs consisting of willow, green alder, and dwarf birch and sedge (Cyperaceae) in wetlands. South of Husky Lakes, stunted, open canopy white spruce grow near the Taiga Plains ecoregion boundary (Ecosystem Classification Group, 2012). 


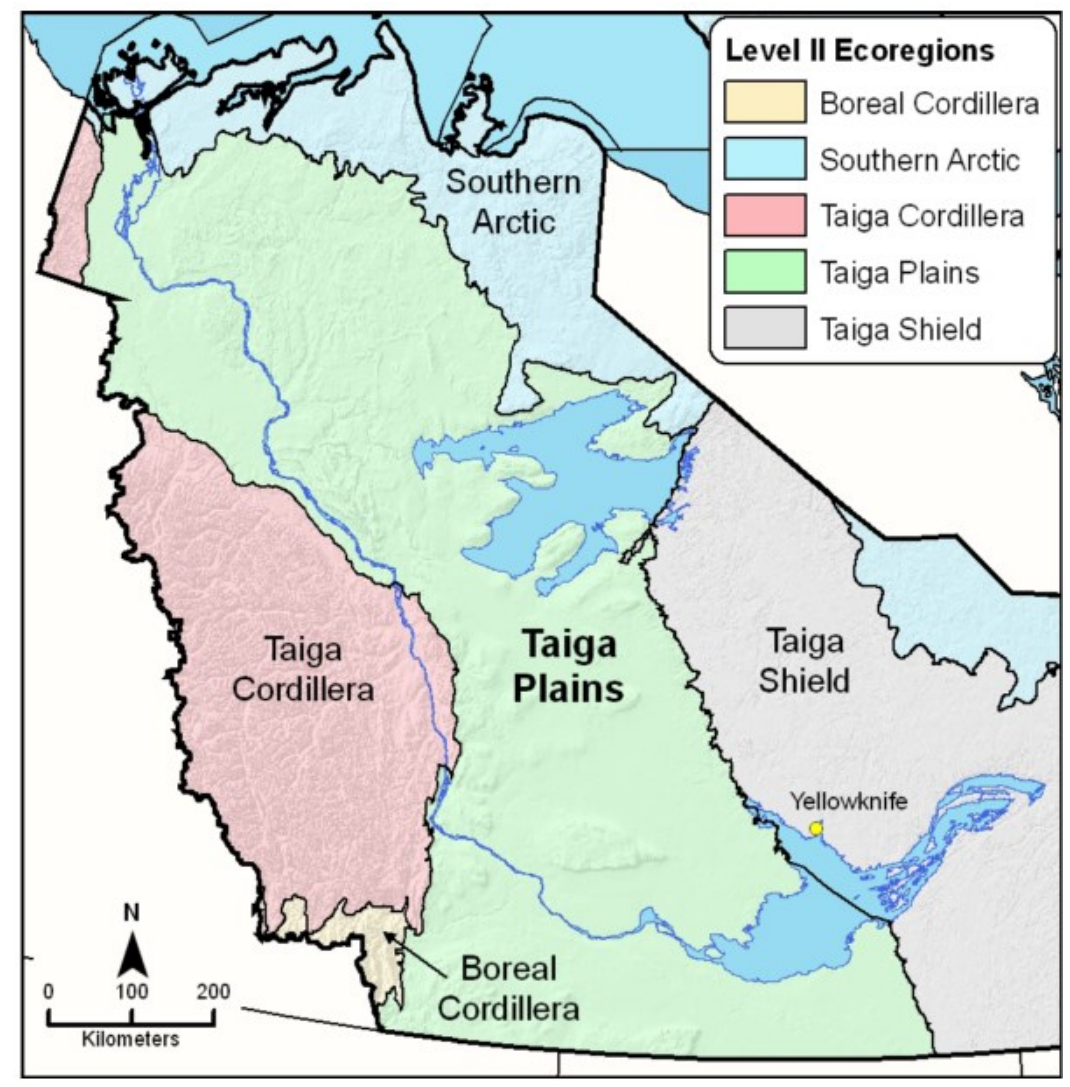

Figure 3.1 - Ecoregions of the Northwest Territories as of 2007 (reproduced from Ecosystem Classification Group, 2009). 


\subsubsection{Climate}

The sampling locations for this research were nearest to climate stations in Inuvik and Tuktoyaktuk. Inuvik, located at $68^{\circ} 18^{\prime} 14.0^{\prime \prime} \mathrm{N}$ and $133^{\circ} 28^{\prime} 59.0^{\prime \prime} \mathrm{W}$ is the closest climate station to sites on the Campbell Dolomite Uplands and is at an elevation of $68 \mathrm{~m}$ a.s.1.. Tuktoyaktuk is nearest to sampling sites near the Husky Lakes and is located at $69^{\circ} 26^{\prime} 00.0^{\prime \prime} \mathrm{N}$ and $133^{\circ} 01^{\prime} 00.0^{\prime \prime} \mathrm{W}$ and $5 \mathrm{~m}$ a.s.1.. These station locations have instrumental records for temperature and precipitation dating back to 1957 (Adjusted and Homogenized Canadian Climate Data (AHCCD), 2014) and are separated from each other by $120 \mathrm{~km}$. Seasonal climate indices are based on those used by the AHCCD and are broken up into: March, April, May (spring), June, July, August (summer), September, October, November (autumn), and December, January, February (winter). The minimum, mean, and maximum monthly values were used for the temperature analysis, while the total monthly precipitation was used. Some annual data is missing from the AHCCD records and is left blank in the corresponding figures. In order to calculate the significance values of the trends, missing values were replaced by the average of the two values preceding and two values following the missing value.

Inuvik is further inland than Tuktoyaktuk with a tendency for warmer temperatures and more precipitation (Figures 3.2-3.7). Inuvik and Tuktoyaktuk both experience short, cool summers with temperatures above $0^{\circ} \mathrm{C}$ for only 5 months of the year (May-Sept) and cold, dry winters. Winters in Tuktoyaktuk are very long and cold, longer than in Inuvik (Figures 3.3; 3.6; Ecosystem Classification Group, 2012). The greatest amount of solar input for both regions is in June ( $22 \mathrm{MJ} / \mathrm{m}^{2} /$ day) (Ecosystem Classification Group, 2009; 2012). Based on annual records of mean monthly 
temperature from 1957 to 2012 , the average annual temperature in Inuvik is $-8.8^{\circ} \mathrm{C}$ and in Tuktoyaktuk is $-10.2^{\circ} \mathrm{C}$. The month with the coldest mean temperature in Inuvik is January $\left(-28^{\circ} \mathrm{C}\right)$ and the mean warmest month is July $\left(14^{\circ} \mathrm{C}\right)$. Tuktoyaktuk is colder than Inuvik in the winter months from November through January, with February being the coldest month on average $\left(-27^{\circ} \mathrm{C}\right)$. The warmest month in Tuktoyaktuk is also July, with a mean temperature of $11^{\circ} \mathrm{C}$. Inuvik is warmer during the growing season than Tuktoyaktuk, with the greatest difference between the locations in June $\left(5^{\circ} \mathrm{C}\right)$. Warming trends over the length of the record are most pronounced in the winter and least in the summer in Inuvik (Figures 3.2; 3.4). In Tuktoyaktuk the greatest warming trend is also in the winter with similar but lesser amounts of warming during the spring, summer, and autumn (Figures 3.3; 3.6). Summer temperatures in Tuktoyaktuk are highly variable from year to year (Figure 3.6c). At treeline north of Inuvik, a growing season of approximately 575 growing degree days (mean temperature $>5^{\circ} \mathrm{C}$ ) was determined by Burn (1997), decreasing with increasing latitude to 315 growing degree days at Tuktoyaktuk (Burn, 1997).

Inuvik receives a third more precipitation annually than Tuktoyaktuk, though both locations experience a similar pattern of precipitation with over half falling during the summer and autumn as compared to the winter and spring $(60 \%$ in Inuvik and $70 \%$ in Tuktoyaktuk). Snow remains on the ground into the month of June in Tuktoyaktuk, later than in more southern regions (Burn and Kokelj, 2009). Approximately equal amounts of precipitation fall during the summer and autumn and in the winter and spring at both locations. Annual precipitation is on average $340 \mathrm{~mm}$ in Inuvik from 1957 to 2012 and $225 \mathrm{~mm}$ in Tuktoyaktuk from 1957 to 2007. In Tuktoyaktuk, winter precipitation has 
increased, while in all other seasons it has decreased with the most striking decrease during the summer (Figure 3.7; AHCCD, 2014). Tuktoyaktuk experiences climate conditions affected by its proximity to the Beaufort Sea, with coastal influences extending $70 \mathrm{~km}$ inland as of 1995 (Burn, 1997). With coastlines documented to be moving southward in the western Arctic at a rate of about $7 \mathrm{~m} / \mathrm{a}$ during the Holocene (Burn, 1997), these effects are likely to continue to extend further inland over time. 


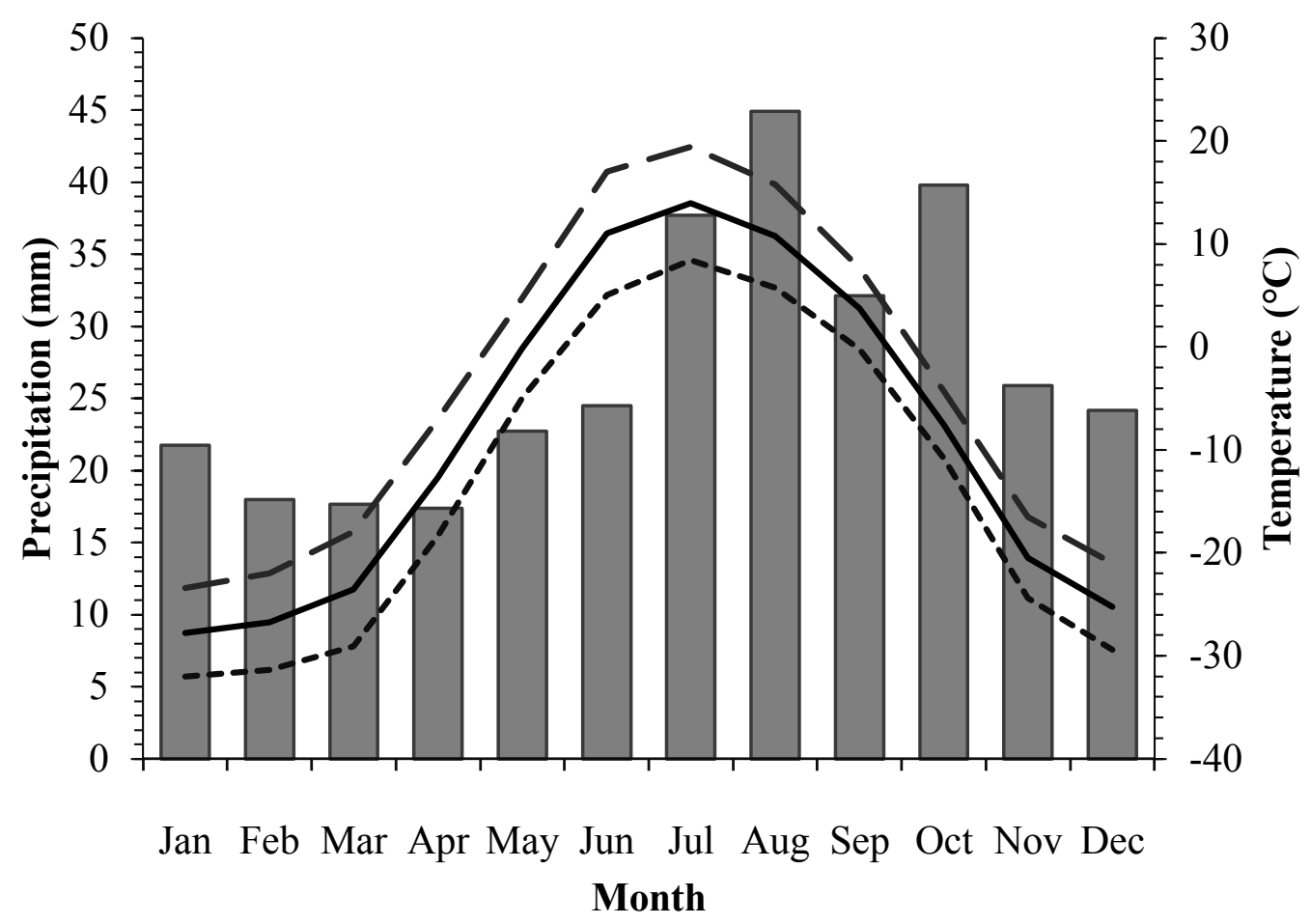

Figure 3.2 - Average Inuvik instrumental temperature and precipitation from 1957 to 2012 (AHCCD, 2014). The shaded bars represent average monthly precipitation totals, the solid line represents average mean monthly temperature, the long dashed line is the average maximum monthly temperature, and the short dashed line is the average minimum monthly temperature. All monthly values were averaged over the length of the instrumental record. 


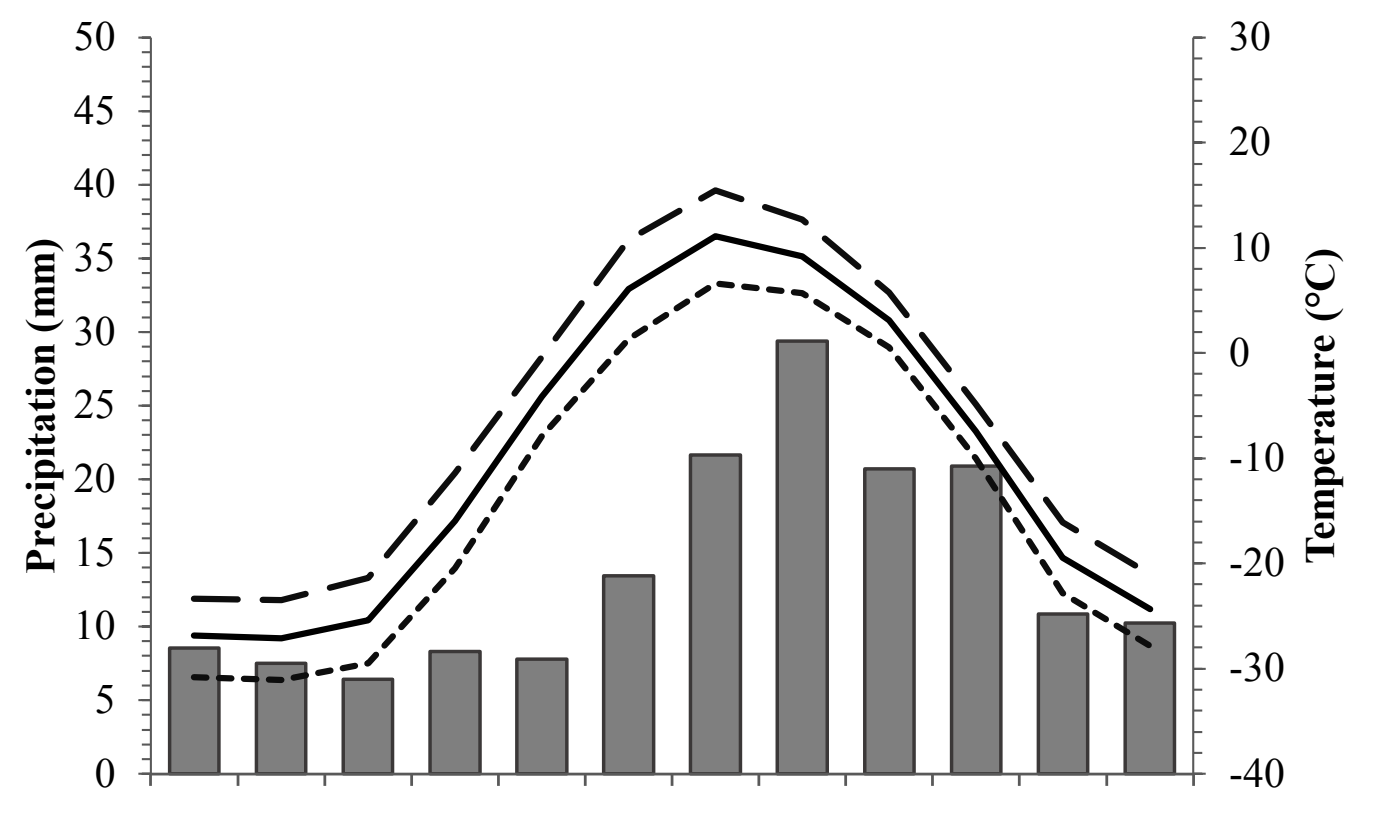

Jan Feb Mar Apr May Jun Jul Aug Sep Oct Nov Dec Month

Figure 3.3 - Average Tuktoyaktuk instrumental temperature and precipitation from 1957 to 2012 (AHCCD, 2014). The bars represent average monthly precipitation totals, the solid line represents average mean monthly temperature, the long dashed line is the average maximum monthly temperature, and the short dashed line is the average minimum monthly temperature. All monthly values were averaged over the length of the instrumental record. 

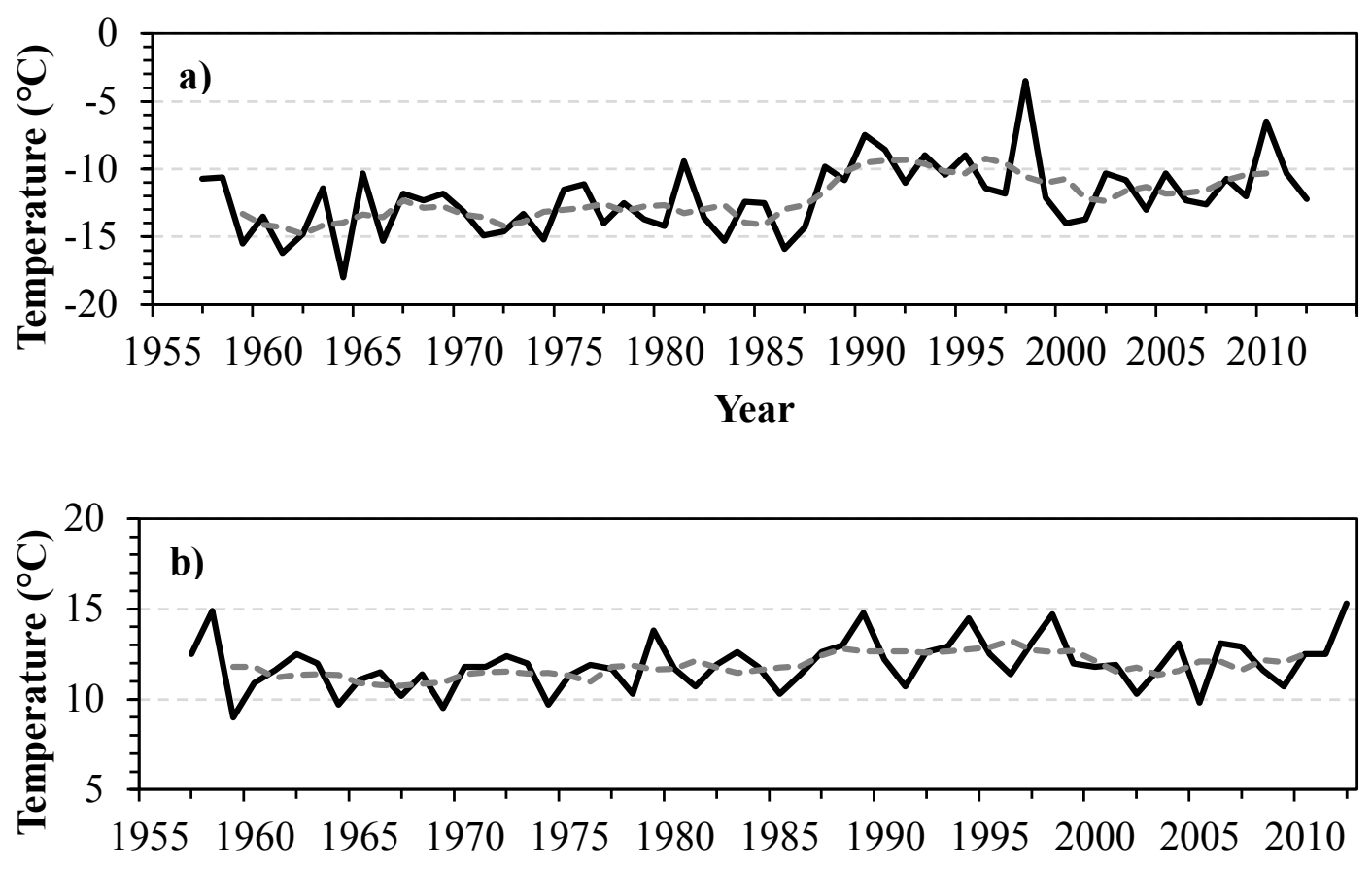

Year
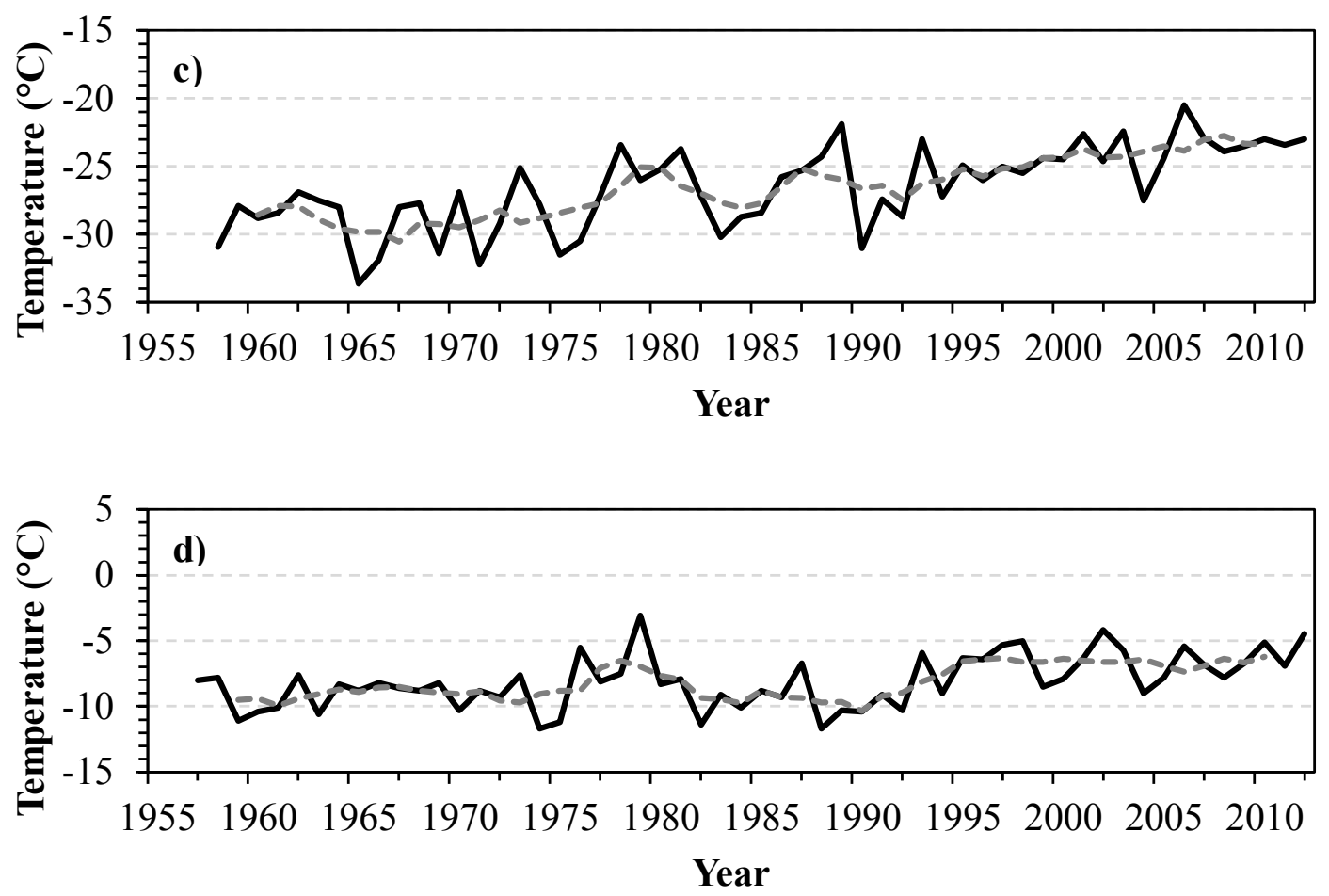

Figure 3.4 - Inuvik seasonal mean temperature (black lines) and 5-year moving average (dashed grey lines) during a) winter, b) spring, c) summer, and d) autumn from 1957 to 2012 (AHCCD, 2014). 

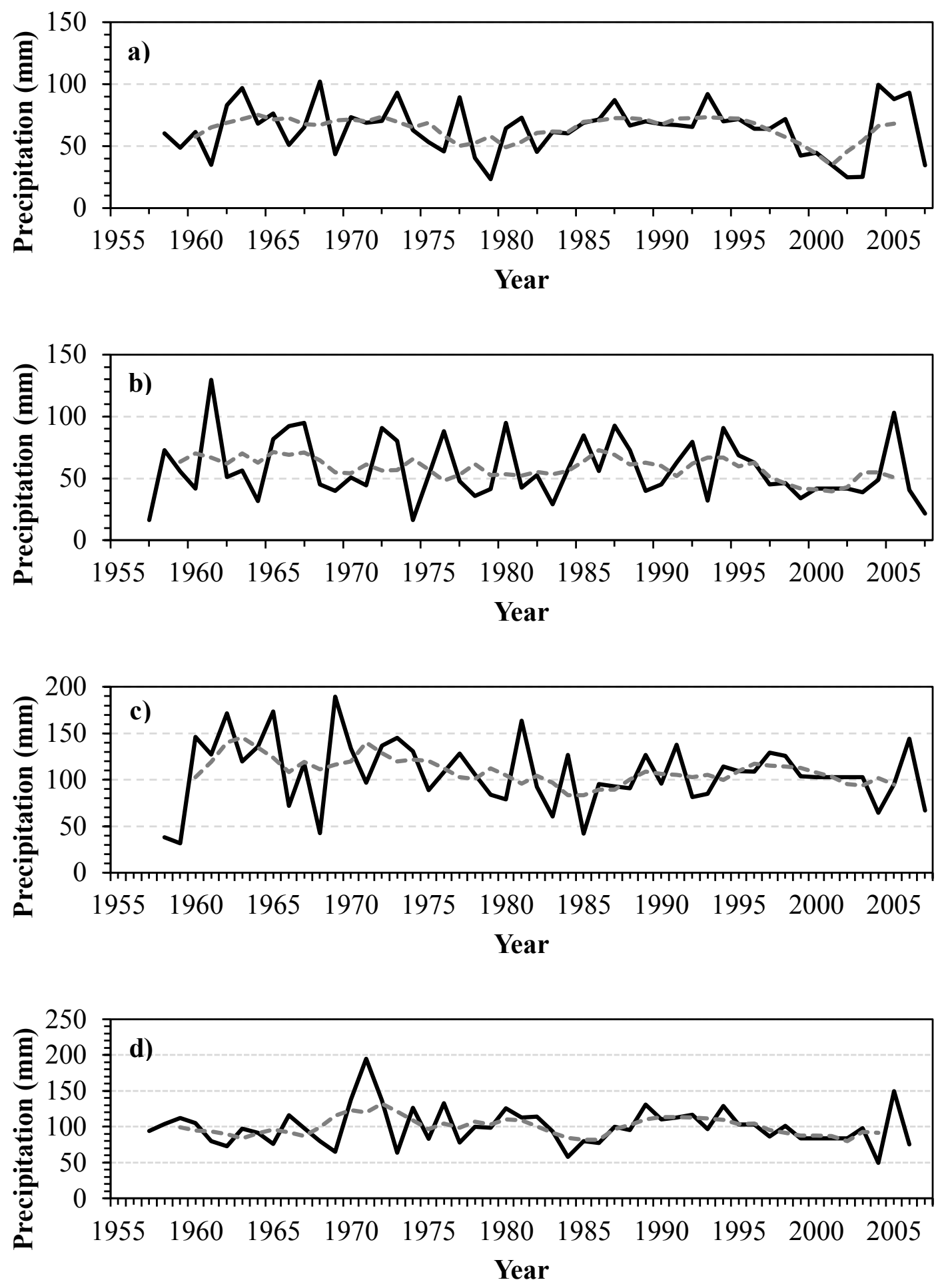

Figure 3.5 - Inuvik total seasonal precipitation (black lines) and 5-year moving average (dashed grey lines) during a) winter, b) spring, c) summer, and d) autumn from 1957 to 2012 (AHCCD, 2014). 

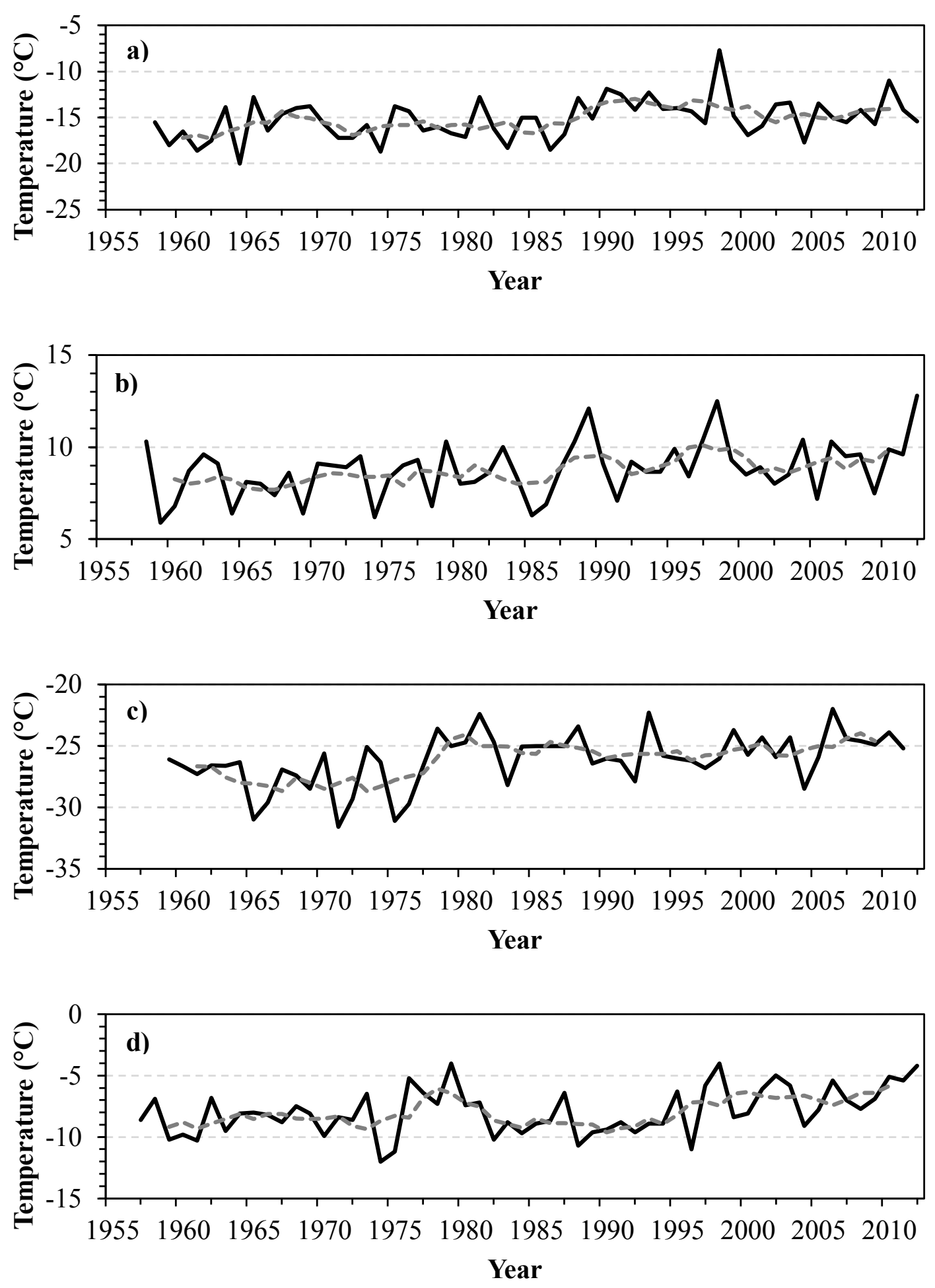

Figure 3.6 - Tuktoyaktuk seasonal temperature (black lines) and 5-year moving average (dashed grey lines) during a) winter, b) spring, c) summer, and d) autumn from 1957 to 2012 (AHCCD, 2014). 

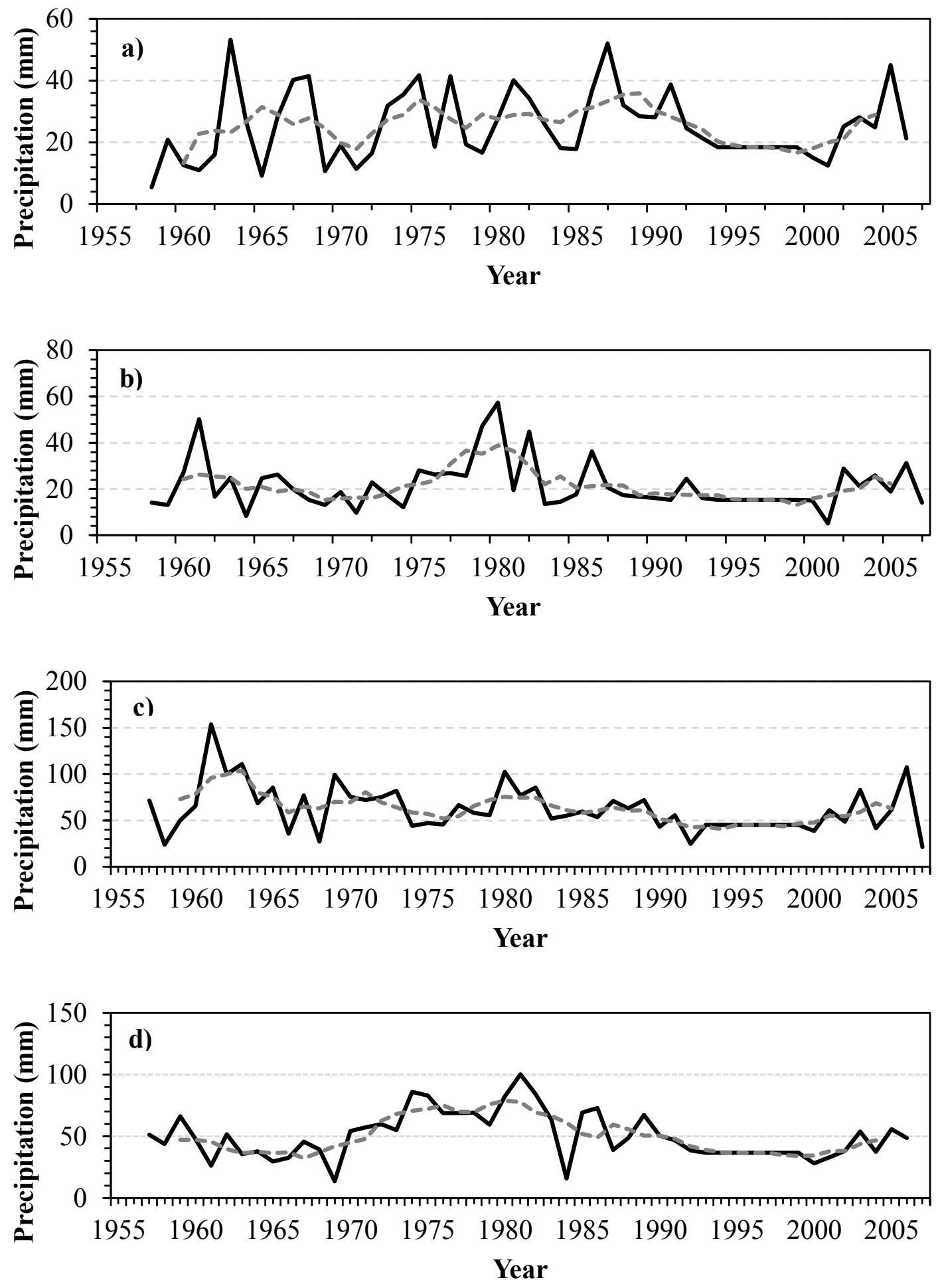

Figure 3.7 - Tuktoyaktuk total seasonal precipitation (black lines) and 5-year moving average (dashed grey lines)during a) winter, b) spring, c) summer, and d) autumn from 1957 to 2007 (AHCCD, 2014). 


\subsubsection{Sample Sites}

The fieldwork for this research was undertaken at five sites in two locations in the Northwest Territories: at the Campbell Dolomite Uplands (CDU) (Figure 3.8) and Husky Lakes (HL) (Figure 3.9). CDU is located $14 \mathrm{~km}$ south of Inuvik and is comprised of an exposed carbonate bedrock uplift formed in the late Precambrian period (Ritchie, 1977). The soil is very thin $(1-10 \mathrm{~cm})$ and well drained (Ritchie, 1977). The site has sparse ground cover in exposed locations, often only lichen or bare rock. Gullies shelter the growth of shrubs and trees; white spruce, dwarf birch, aspen (Populus tremuloides Michx), and willow were observed, with most samples being found on dry cliff sides at this location. White spruce was found growing across the Campbell Dolomite Upland on flat areas, not being restricted to sheltered locations. At this site, plant access to moisture during the growing season is probably limited to snow melt run-off and growing season precipitation.

The HL area is $45 \mathrm{~km}$ south of Tuktoyaktuk and the Arctic Ocean. The HL sites are generally flat with hummocks in drier, slightly upland areas and all are within a maximum of $4 \mathrm{~km}$ of each other. This is a region interspersed with numerous and differently sized water bodies. Standing water and/or a moist topsoil layer was observed at these sites, to a depth of about $20 \mathrm{~cm}$ between hummocks. The active layer depth in the Tuktoyaktuk region where white spruce stands are present has been documented to range between 30 to $60 \mathrm{~cm}$ (McLeod, 2001), similar to the 40 to $60 \mathrm{~cm}$ range observed by Burn (1997) in hummocky tundra in this region. Similar active layer thicknesses were observed at the Husky Lake sites. At HL1, white spruce trees are spaced out and the understory consists of low brush with abundant moss (Sphagnum spp.), lichen, and blueberries 
(Vaccinium spp.). At HL2, shrub cover is tall and consists primarily of alders. The ground cover is made up of dwarf willow shrubs and lichen. HL3 is much wetter than the other sites as standing water was observed during sampling. There are low hummocks, abundant snags, grasses (Gramineae), Labrador tea (Ledum palustre; now referred to as Rhododendron tomentosum), and a few shrubs. Sphagnum moss is the predominant ground cover. 


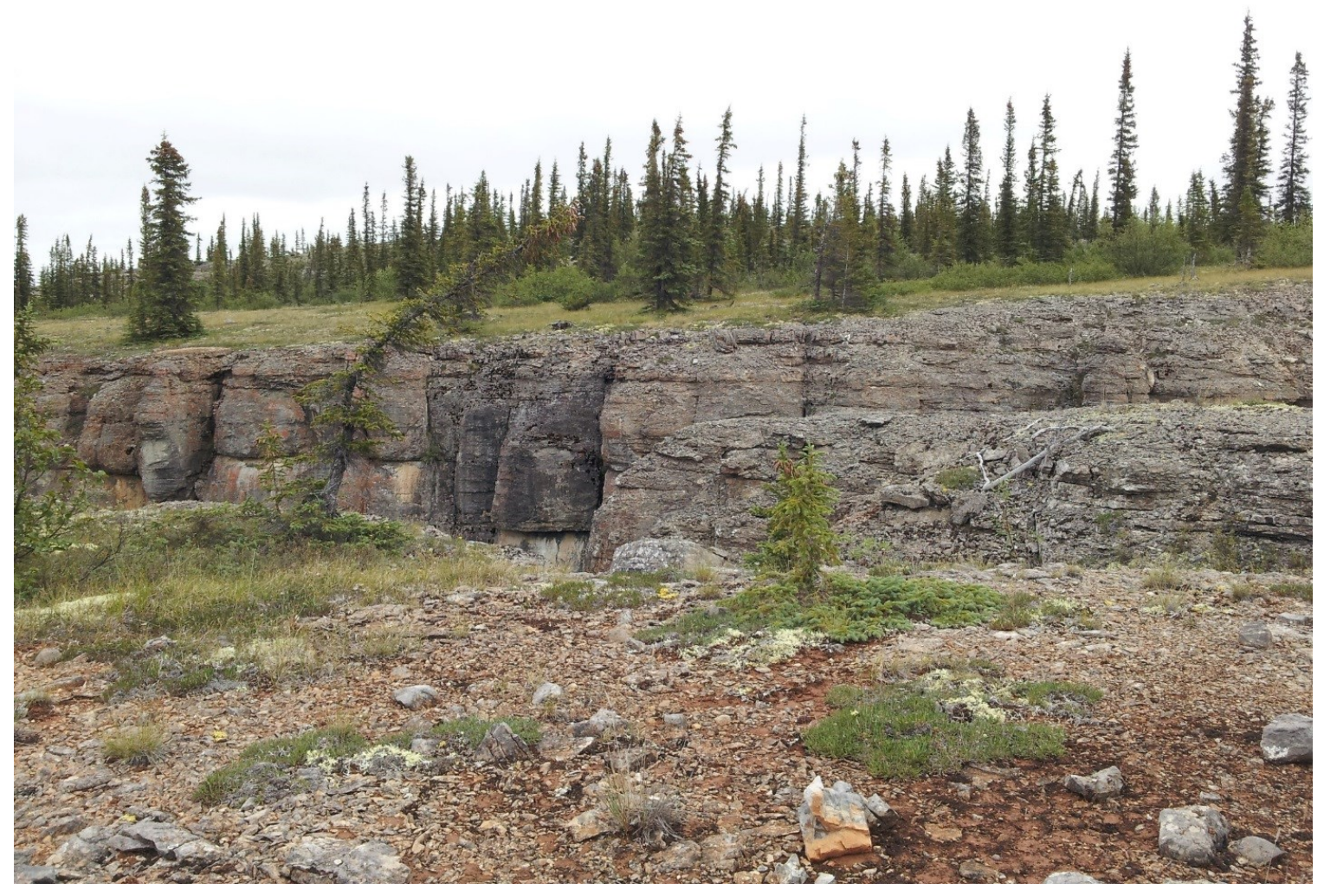

Figure 3.8 - Study site at the Campbell Dolomite Uplands at CDU1 illustrating the rocky bedrock substrate and open canopy white spruce trees. These site characteristics are shared by CDU2. 


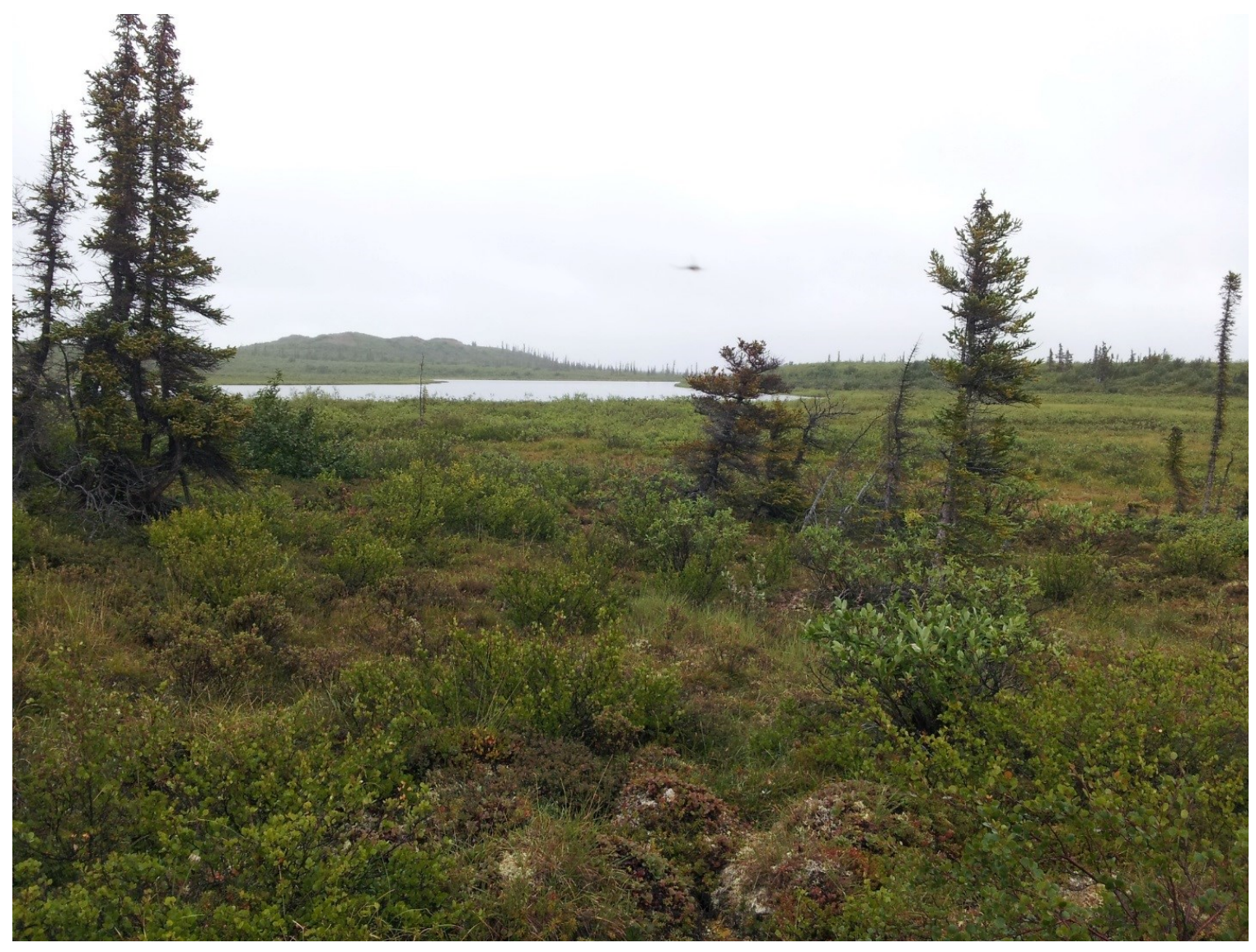

Figure 3.9 - Study site at Husky Lakes at HL3 illustrating the hummocky, moist growing conditions. These site characteristics are representative of HL1 and HL2 as well. 


\subsection{Sample Collection}

White spruce samples were collected from five locations near tree-line in the Northwest Territories using standard dendrochronological techniques (Figure 3.10; Table 3.1) (Stokes and Smiley, 1968; Speer, 2010). At each site, living trees were sampled at breast height using $5.2 \mathrm{~mm}$ and $12 \mathrm{~mm}$ Haglöf increment borers. The larger core samples were required for measurements of density (Schweingruber et al., 1978) and the smaller cores to verify the density chronologies. Living trees were selected based on physical characteristics associated with age such as crooked and contorted canopy branching patterns and stunted appearance. Additional subfossil wood samples were collected in situ at the study locations to extend the living chronology as far into the past as possible. Subfossil wood refers to deadwood that has been preserved (i.e. in situ or in lakes or sediments) and not yet fossilized. Subfossil wood samples were selected on the basis of structural integrity and physical characteristics associated with age. These characteristics were surficial pitting likely caused by ice abrasion and wind blasting as well as the absence of bark or branches (Porter, 2013, pers. comm.). The Campbell Dolomite Uplands and Husky Lakes are both areas where researchers have in the past collected samples with pith dates more than 1000 years old (Bégin et al., 2000; Porter and Pisaric, 2011). 


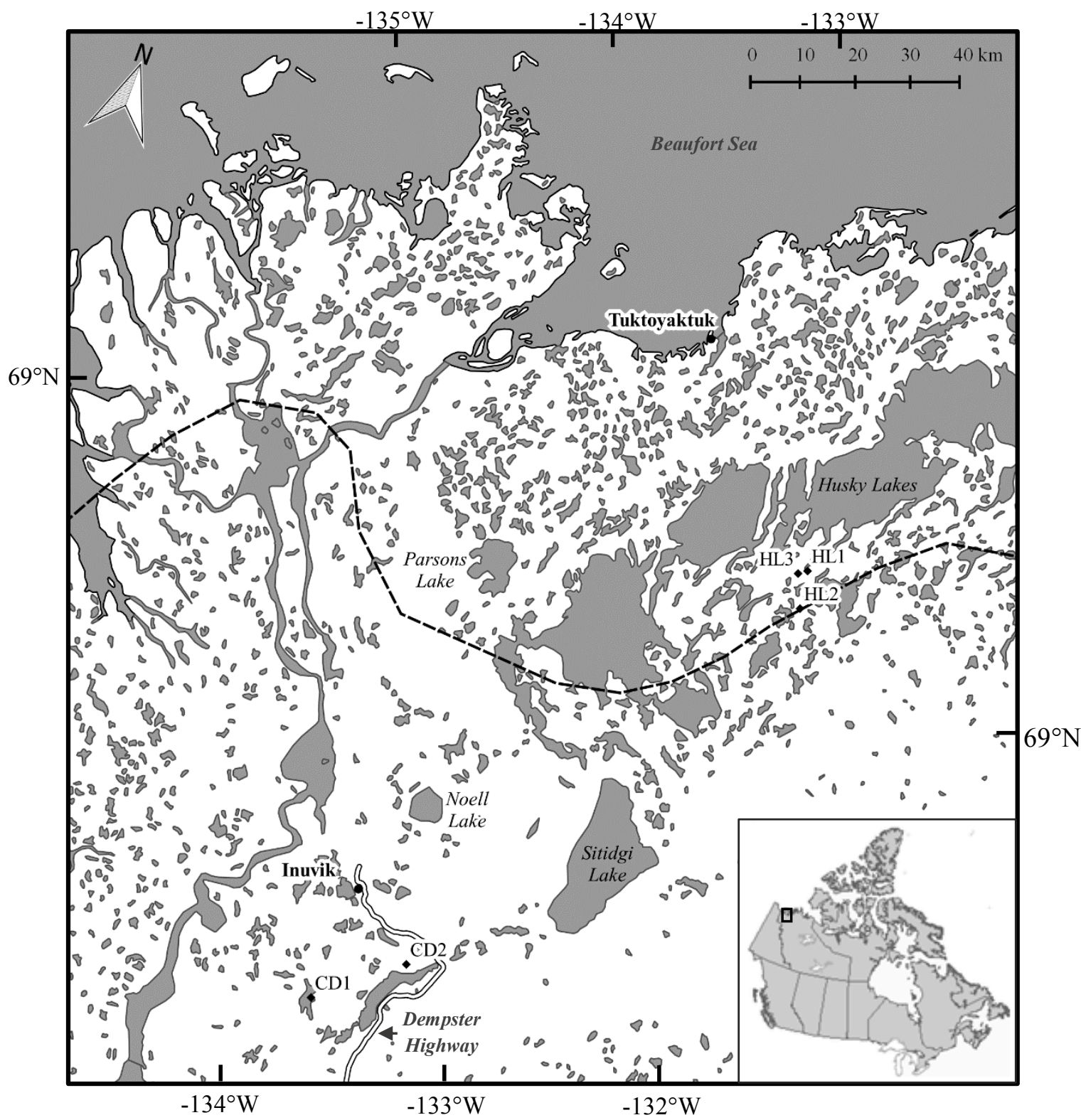

Figure 3.10 - White spruce sampling locations, Northwest Territories, Canada (NRCAN, 2014). The dashed line indicates the approximate position of tree-line based on Brown et al. (2001). The inset on the bottom right illustrates the location of the study region in the northwestern Northwest Territories, Canada. 
Table 3.1 - The coordinates and elevation (m) of the 5 white spruce sample sites, Northwest Territories, Canada and the number of each sample type collected at each site.

\begin{tabular}{ccccccc}
\hline Site & Latitude & Longitude & $\begin{array}{c}\text { Elevation } \\
(\mathrm{m} \text { a.s.1. })\end{array}$ & $\begin{array}{c}\text { No. of } \\
5.2 \mathrm{~mm} \\
\text { cores }\end{array}$ & $\begin{array}{c}\text { No. of } \\
12 \\
\mathrm{~mm} \\
\text { cores }\end{array}$ & $\begin{array}{c}\text { No. of } \\
\text { subfossil } \\
\text { samples }\end{array}$ \\
\hline HL1 & $6^{\circ} 09^{\prime} 22.7^{\prime \prime}$ & $132^{\circ} 14^{\prime} 01.1^{\prime \prime}$ & 11 & 54 & 40 & 35 \\
HL2 & $69^{\circ} 08^{\prime} 30.0^{\prime \prime}$ & $132^{\circ} 12^{\prime} 39.0^{\prime \prime}$ & 13 & 6 & 4 & 8 \\
HL3 & $69^{\circ} 06^{\prime} 49.4^{\prime \prime}$ & $132^{\circ} 16^{\prime} 21.1^{\prime \prime}$ & 29 & 16 & 40 & 32 \\
CDU1 & $68^{\circ} 09^{\prime} 39.0^{\prime \prime}$ & $133^{\circ} 45^{\prime} 55.0^{\prime \prime}$ & 44 & 0 & 44 & 29 \\
CDU2 & $68^{\circ} 16^{\prime} 07.0^{\prime \prime}$ & $133^{\circ} 24^{\prime} 22.0^{\prime \prime}$ & 89 & 0 & 44 & 27 \\
\hline
\end{tabular}




\subsection{Sample Preparation and Analysis}

\subsubsection{Ring-Width Measurements}

The samples were brought back to the Carleton University Paleoecology Laboratory for further processing. The $5.2 \mathrm{~mm}$ samples collected from living trees were glued onto wooden mounts with the tracheids perpendicular to the mount to best expose the annual rings. They were then sanded with progressively finer (80-400 grit) sand paper using a belt sander in order to increase the visual clarity of the annual rings. The subfossil samples were sawed flat in order to expose the surface perpendicular to the direction of apical growth. They were then sanded in the same manner as the $5.2 \mathrm{~mm}$ samples.

For each sample, the radial width of each annual ring was measured to an accuracy of $0.001 \mathrm{~mm}$ using a Velmex measuring system (Velmex Inc., Bloomfield, NY, USA) attached to a SMZ-1000 Nikon microscope and saved using the measuring program MeasureJ2X (VoorTech Consulting, Holderness, NH, USA). The last incomplete year of growth of a living tree was identified as its sampling date, while the first year of growth was determined by counting backwards to the pith. For the $5 \mathrm{~mm}$ samples, the last year of growth was usually 2012 as the samples were collected partway through the formation of the 2013 ring. For the subfossil samples, the minimum last year of growth was determined through pattern matching of the ring-width series against the living samples collected for this study and several previously dated ring-width chronologies from the region (Porter, 2012). The patterns of the undated samples were crossdated visually and statistically using characteristic wide and narrow rings. Pattern matching relied on living and subfossil chronologies collected by Porter (2013b) in 2008 from the Campbell Dolomite Uplands. All samples were crossdated both visually using 
marker ring analysis (the "List method" of Yamaguchi, 1991) and statistically using the computer program COFECHA in order to ensure the correct dating of samples and the identification of missing rings (Holmes, 1983; Grissino-Mayer, 2001).

\subsubsection{Density Measurement}

The $12 \mathrm{~mm}$ living white spruce samples were mounted onto boards with the tracheids parallel to the board. Once the ring-width measurements had been taken, the subfossil samples were sliced to extract a central $12 \mathrm{~mm}$ wide strip, leaving two outer pieces (Figure 3.11). This was done so that the subfossil samples would be the same size as the $12 \mathrm{~mm}$ cores to allow for processing for density measurement. An additional 23 samples from the Campbell Dolomite Uplands from Trevor Porter, were added to the density analysis (Porter, 2013b) resulting in a total of 131 subfossil wood samples. 


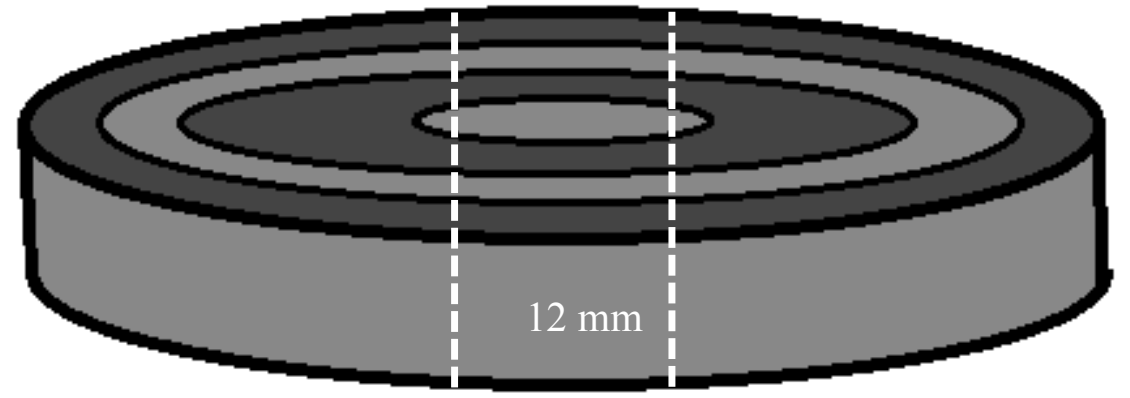

Figure 3.11 - Graphic illustrating the further processing of subfossil samples to extract a $12 \mathrm{~mm}$ wide central strip for density analysis. The area removed for density analysis encompassed a strip from bark to pith to bark across the diameter of each sample. 
Densitometric analysis was undertaken at the University of Victoria's Tree Ring Laboratory (UVTRL) in May, 2013 (pilot study) and in October, 2013. Each core and subfossil sample was further sliced from $12 \mathrm{~mm}$ pieces into $2 \mathrm{~mm}$ lathes using a Waltech high-precision twin-bladed saw (Figure 3.12; Haygreen and Bowyer, 1996). The next steps involved the removal of water and resin from the samples to provide unbiased density measurements. First, the samples were soaked overnight for about 16 hours in a solution of propanol to remove the water. Next, the samples were run through a Soxhlet extraction process where boiling acetone soxhlet was repeatedly run over the cores for a total of 7.5 hours, with the cores being flipped over halfway through (Figure 3.13) (Schweingruber et al., 1978). 


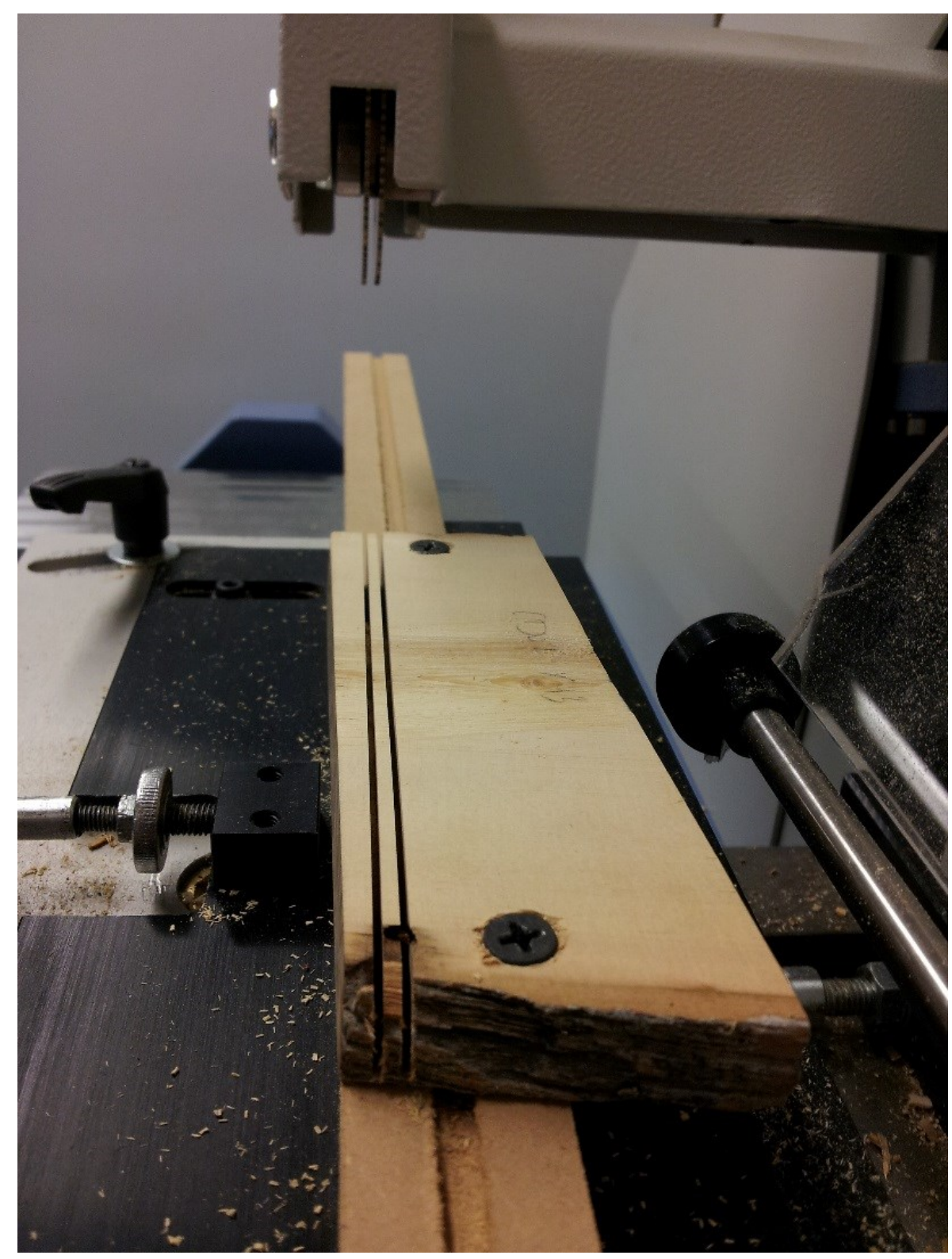

Figure 3.12 - The Waltech high precision twin-bladed saw illustrating the lathe cut from a $12 \mathrm{~mm}$ subfossil sample. The same process was used with the $12 \mathrm{~mm}$ living tree core samples. 


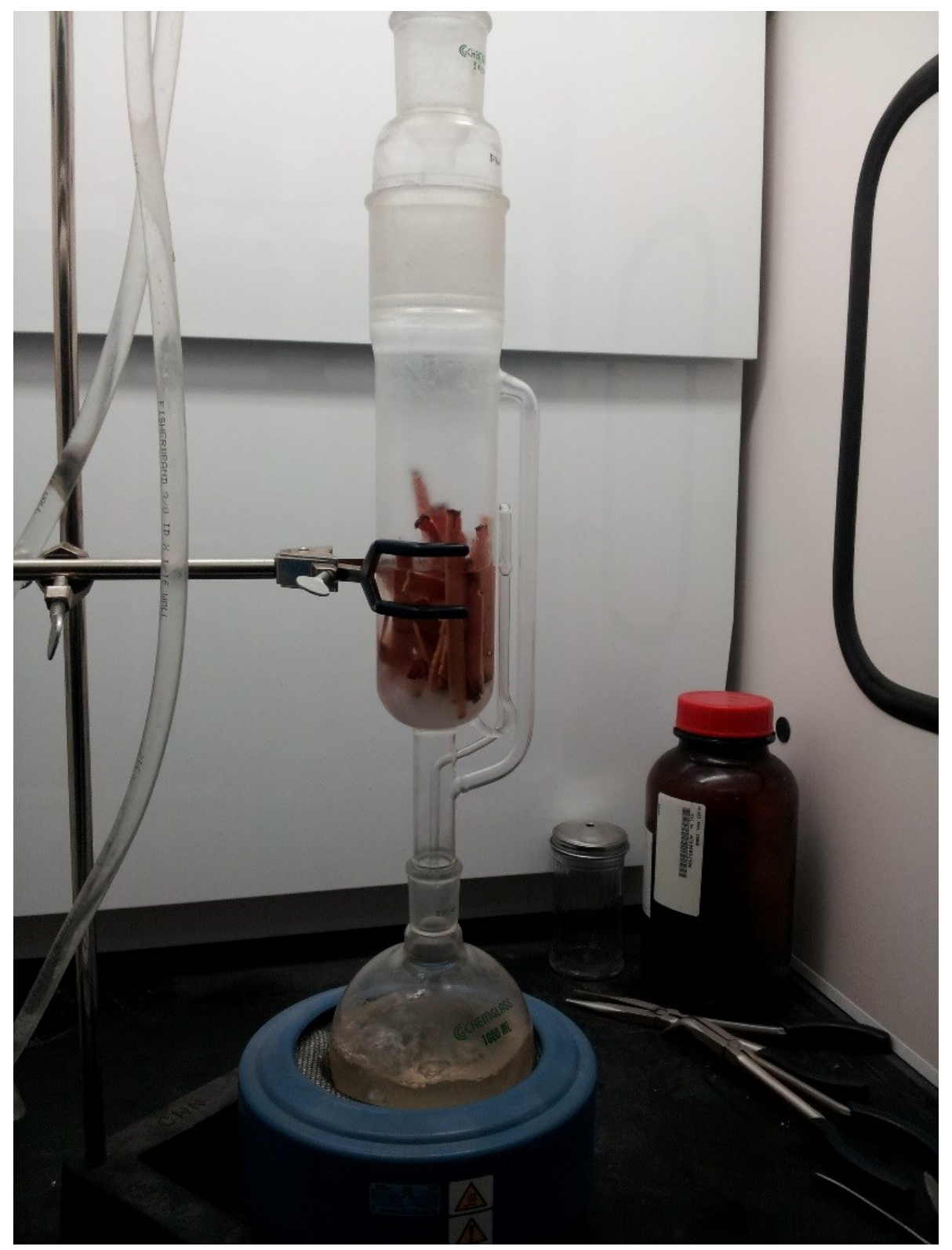

Figure 3.13 - The Soxhlet extraction apparatus set up. The samples were placed into a glass Fredrichs condenser and boiling acetone, seen below the condenser, cycled through the apparatus, filling the flask through condensation and soaking the samples. 
Following the extraction process, the samples were laid flat to dry overnight. In groups of 8-10, lathes were mounted onto needles and inserted into the ITRAX scanning densitometer (Ver. 2008g) (Regent Instruments Inc. 2008) (Figure 3.14; Schweingruber et al., 1978). The x-ray densitomer was calibrated using a plastic block of known density with density values being manually assigned according to the calibration manual for this device. The scanning densitometer exposed the samples to an x-ray beam and the density in $\mathrm{g} \mathrm{cm}^{-3}$ was determined by measuring the amount of radiation required to penetrate each ring using a measurement interval of $25 \mu \mathrm{m}$. Scanning was done at a voltage of $30 \mathrm{kV}$, a current value of $55 \mathrm{~mA}$, and an exposure time of $20 \mathrm{~ms}$ (White, 2010). The images were analysed and crossdated against the previously developed ring-width series (see section 3.3.1) using Windendro 2009b, c (Regent Instruments Inc., 2009) to ensure that the density measurements were correctly placed in time. In some cases, multiple paths were measured for a single core to avoid areas of indistinguishable ring boundaries. Each path was called a 'segment' for ease of processing. This process produced minimum, mean, and maximum density values for individual rings as well as annual ring-width values for a total of 207 samples. Maximum density in this case refers to the single largest density value measured for a given annual ring over the user-chosen measurement path. 


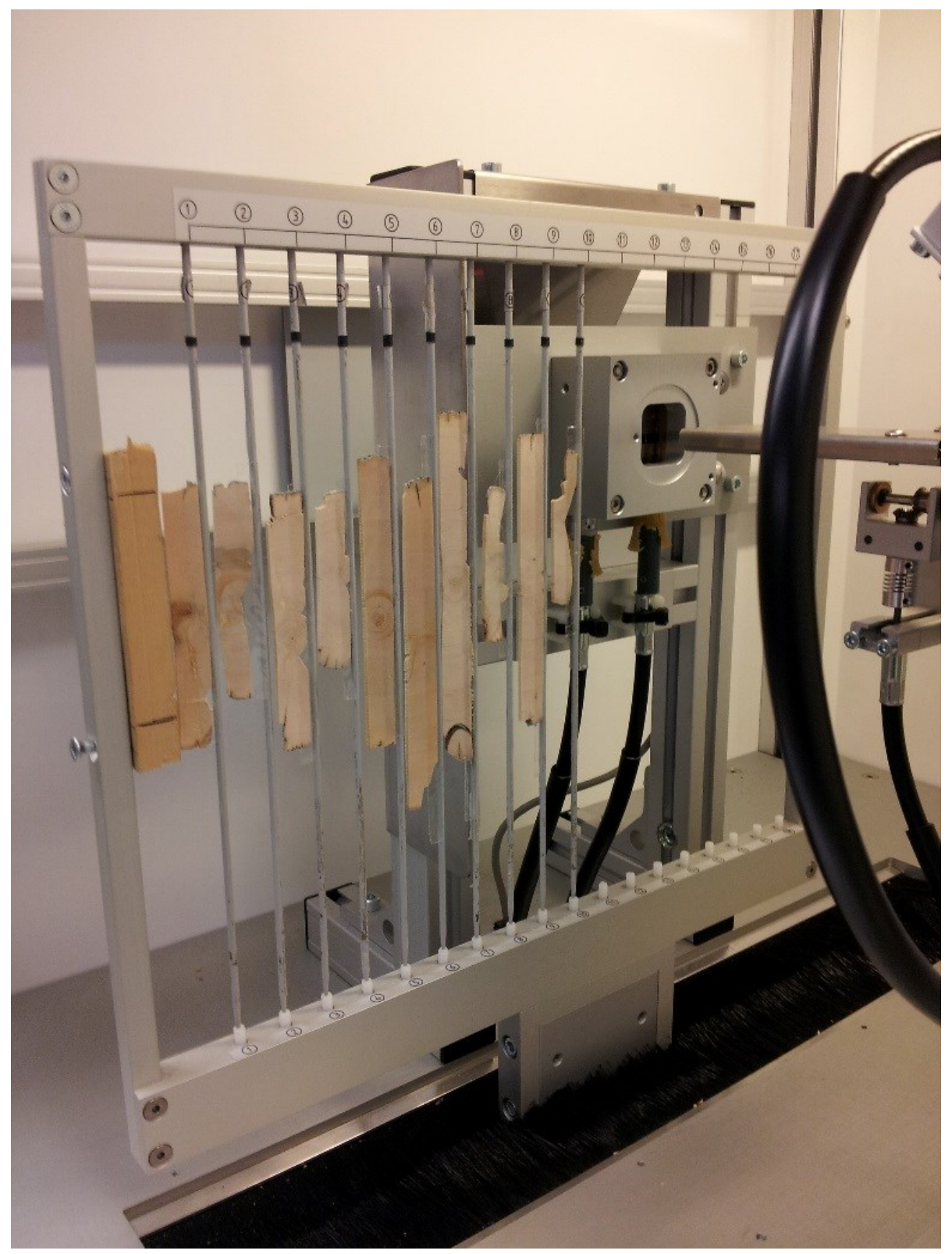

Figure 3.14 - Ten $2 \mathrm{~mm}$ by $12 \mathrm{~mm}$ sample lathes mounted in the x-ray densitometer apparatus at the University of Victoria Tree Ring Laboratory. 


\subsection{Site Analysis}

\subsubsection{Standardization and Chronology Development}

Following the measurement of ring width and density, individual series were standardized and aggregated in order to produce site-level chronologies. Standardization, also referred to as detrending, is an important and necessary step in chronology building as it removes the age-related growth trend inherent in tree ring series and allows for comparison among differently aged series (Cook, 1985; Fritts, 2001). Chronologies developed using detrending methods are representative of the common growth signal among trees at a given site (Fritts, 1976). There are several methods used to detrend treering series. A negative exponential or modified negative exponential curve (NEXP) is a conservative model commonly used in dendrochronology (Fritts, 1976; Bunn, 2008; Speer, 2010). The modified negative exponential curve applies a growth model:

$$
G_{t}=a e^{-b t}+k
$$

where $G_{t}$ is the growth trend as a function of time, e is the base of the natural log, and the coefficients are $a, b$, and $k$, which may vary between series (Fritts, 1969; Fritts, 1976; Bunn, 2008). The coefficient $a$ is the intercept, $b$ is the slope, $k$ is the asymptote and $t$ is time (Cook et al., 1995). This curve describes the decrease in ring width with distance from the pith that results from the addition of cells on an expanding stem (Speer, 2010). In some cases, this model does not fit the ring-width series and instead a horizontal line through the mean is fit (Fritts, 1976). The NEXP method has been found to be inadequate for trees growing in closed canopy conditions with few disturbances $(\mathrm{Cook}, 1985)$ and in some northern regions by several studies (Esper et al., 2003; Melvin and Briffa, 2008; Anchukaitis et 
al., 2013).

A second detrending method involves the use of a cubic smoothing spline, found to be more effective in regions where the negative exponential curve is inappropriate, such as forest interiors (Cook and Peters, 1981; Speer, 2010). This method commonly applies a smoothing spline with a frequency response of $50 \%$ at a wavelength of $2 / 3$ of the series length (Cook et al., 1990), though these defaults may be altered. The trees sampled for this research were in open canopy conditions outside of contiguous forest so this method was not applied. Melvin (2004) asserts that the aforementioned standardization models do not perform well in preserving variance at time-scales longer than the length of the individual series (p. 12), referred to as the "segment length curse" (see section 2.5.3.2) (Cook et al., 1995).

Recently developed detrending methods such as regional curve standardization (Esper et al., 2003) and the signal free model (Melvin and Briffa, 2008) compensate for deficiencies in earlier curve fitting models. Regional curve standardization (RCS) is one such method that is geared toward dendroclimatic studies by maintaining low frequency variability in the ring-width series and providing a more flexible model fit (Briffa et al., 1992; Speer, 2010). RCS is a method whereby tree-ring series are aligned based on their cambial age rather than by their calendar age to produce a site-specific growth curve that is then applied to individual series (Esper et al., 2003; Speer, 2010). It is also intended to account for the segment length curse by assuming that there is a common biological signal for a species at a site that can be removed without compromising low frequency climatic information (Briffa et al., 1992; Cook et al., 1995). This method requires that the pith measurement be year 0 and a minimum replication of 5 series. This method is less 
effective in the face of the divergence problem whereby a single site may contain trees with differing biological growth trends and thus offset each other in the development of a common growth curve (Esper et al., 2003). When dealing with long chronology time spans, the RCS curve may be biased as it does not account for the possibility that the biological growth trend of the trees may have changed over longer temporal scales (Cook et al., 1995).

The signal free (SF) method developed by Melvin and Briffa (2008) is another method intended for dendroclimatological research that iteratively calculates and removes an estimated common growth signal from each measurement series (Anchukaitis et al., 2013), allowing growth curves to be fit while retaining a strong climate signal and compensating for trend distortion (Melvin and Briffa, 2008). As described by Melvin and Briffa (2008), for each tree, an index is produced through detrending with the modified exponential curve method whereby:

$$
\text { Tree Index = Ring Width/Expected Growth }
$$

An initial chronology is developed by averaging all tree indices into a single detrended chronology. The next step is the creation of signal-free measurements by dividing the original ring widths into the initial chronology:

$$
\text { Signal-Free Measurement }=\text { Ring Width/Chronology Index }
$$

These measurements are estimates of tree growth in a scenario where climate is constant but the growth curve and medium-high frequency variability are retained (Melvin and Briffa, 2008). The signal-free measurements are detrended once again and the process proceeds iteratively until the final signal-free chronology contains zero variance. This gives a final unbiased curve that is then applied to the ring-width measurements. The 
final growth curve contains no external growth forcing signal and retains the desired climate signal (Melvin and Briffa, 2008). Thus, SF is less biased for series length, sample size, and growth trajectory (Anchukaitis et al., 2013).

Due to the success of the SF method in removing end effects and in enhancing low frequency variability (Melvin and Briffa, 2008; Anchukaitis et al., 2013), samples were detrended using this method using the beta program TOMB, developed by Ed Cook (courtesy of Trevor Porter, pers. comm.). Using TOMB, a signal-free curve-fitting exponential/negative exponential line was applied using a biweight robust mean that excludes outliers (Cook et al., 1990). When using SF detrending, sample replication is an important consideration and should be evaluated when detrending (Melvin and Briffa, 2008). Due to sample depth limitations throughout the record, the density series at CDU1 and CDU2 and those at HL1, HL2, and HL3 were combined to give four ring-width chronologies and two density chronologies. To justify this detrending choice, results of SF NEXP detrending were compared to results obtained through standardizing using SF RCS and traditional NEXP models. Evaluation of the methods was done by comparing the detrended chronologies statistically using Pearson product-moment correlation.

Once standardized, the individual series were aggregated and averaged by site to give a single chronology for each index. The aggregation of series into site-level chronologies is common in dendrochronology as it gives a clearer climate signal (Fritts, 1976; Cook and Briffa, 1990). In this case, divergence is assumed to be present in the ring-width series but there will be no separation of negative or positive responders in order to evaluate the ability of TRW and MXD to track temperature variability over time. 


\subsubsection{Signal Strength}

Based on past research, an annual sample depth of 25-50 trees is recommended to produce reliable temperature reconstructions (Cook et al., 2004; Grudd, 2008), although reconstructions have been found to be statistically reliable with as few as 7-14 samples (Davi et al., 2003; Cook et al., 2004). The strength of the climate signal within chronologies can be assessed by evaluating the effective chronology signal and the Expressed Population Signal.

The common chronology signal was evaluated by calculating the effective chronology signal, or $\bar{r}_{\text {eff }}$ using 50 -year moving windows lagged by 25 years (Cook and Kariukstis, 1990). The $\overline{\bar{r}}_{\text {eff }}$ is an estimate of the common growth signal for multiple cores per tree, and is equivalent to the $\bar{r}_{\mathrm{mt}}$, the mean tree correlation value (Cook and Kariukstis, 1990). This term estimates the chronology signal using both within- and between-tree correlations:

$$
\overline{\bar{r}}_{\mathrm{eff}}=\bar{r}_{\mathrm{bt}} \bar{r}_{\mathrm{wt}}+\left(1-\bar{r}_{\mathrm{wt}}\right) / \mathrm{c}_{\mathrm{eff}}
$$

where $\bar{r}_{\mathrm{bt}}$ is the between tree correlation, $\overline{\bar{r}}_{\mathrm{wt}}$ is the within tree correlation, $\mathrm{c}_{\mathrm{eff}}$ is the effective number of cores used when an unequal number of cores per tree is present, and $t$ is the number of trees (Cook and Kariukstis, 1990).

To estimate the chronology confidence, or strength, the Expressed Population Signal (EPS) was calculated using a 50-year moving window lagged by 25 years (Cook and Kariukstis, 1990; Melvin and Briffa, 2008). The EPS quantifies the relationship between the number of samples and the common variance of a given tree-ring chronology, with a suggested threshold cut-off value of 0.85 (Wigley et al., 1984):

$$
\mathrm{EPS}=\bar{r}_{\mathrm{bt}}+\left(1-\overline{\bar{r}}_{\mathrm{bt}} / \mathrm{t}\right)
$$


where $\bar{\square}_{\mathrm{bt}}$ is the mean between tree correlation (Cook and Kariukstis, 1990). The EPS is sensitive to sample replication with values increasing when going from 1 to 10 samples (Cook and Kariukstis, 1990).

The $\overline{\bar{r}}_{\text {eff }}$ and EPS were calculated using the dendrochronology package dplR (Bunn, 2008; 2013) within the R program workspace (R Core Team, 2014). The input chronologies were individually SF detrended ring-width and density series. Within R, series were read based on an id mask so that a tree with multiple series would have those series averaged and would only be included once in the analysis. A running window of 50 years lagged 25 years (Wigley et al., 1984) and another of 30 years lagged 15 years was used to identify sections with low signal strength within the chronologies. The use of a running mean is important because the signal strength can vary over the length of a chronology (Cook and Kariukstis, 1990).

\subsubsection{Regional Representation}

In order to establish that the samples in this research were representative of local growth trends, the ring-width chronologies were statistically compared to 46 TRW chronologies from the Northwest Territories from Porter (2013) using a Pearson productmoment correlation matrix. The density chronologies were statistically compared to two chronologies collected from the Campbell Dolomite Uplands and accessed from the ITRDB database using Pearson correlation analysis.

\subsection{Climate Analysis}

\subsubsection{Climate Data}

An archival temperature composite spanning 1890 to 2010 for the Northwest Territories from Porter et al. (2013) was used to evaluate the regional temperature 
response of the tree-ring indices. A temperature composite was also used by Kaufman et al. (2009) to improve the observed climate signal in their research across the circumpolar Arctic. The period of analysis spanned from 1910 to 2010 using climate data from Inuvik, Tuktoyaktuk, Fort McPherson, Norman Wells, Aklavik, and Fort Good Hope, NT. Local as opposed to regional precipitation records were used as precipitation is not considered spatially homogenous in this region (Porter, pers. comm., 2014). The 1910 to 2010 time span also encompasses the period when divergence has been identified in some records from northwestern Canada and parts of Alaska (Briffa et al., 1998; Wilmking et al., 2004; Pisaric et al., 2007; Andreu-Hayles et al., 2011; Porter and Pisaric, 2011).

Local temperature and precipitation data were also used to evaluate the local response, using climate data from Inuvik and Tuktoyaktuk. The data used for the local climate analyses was retrieved from Environment Canada's Adjusted and Homogenized Canadian Climate Data (AHCCD) website and spans from 1957 to 2012 for temperature and from 1957 to 2007 for precipitation in Inuvik and from 1957 to 1992 in Tuktoyaktuk for precipitation. Additional data from Environment Canada's historical weather website extended the precipitation record to 2012 in Tuktoyaktuk. Seasonal indices were created as well, to attempt to improve the climate signal within the chronologies by averaging growing season monthly values using the composite temperature data.

\subsubsection{Stationary Correlation}

As is common in dendroclimatological research, Pearson product-moment correlations were calculated between the ring-width and density chronologies and the local and regional climate variables to assess the climate-growth relationships. The regional analysis using the composite record spanned from 1910 to 2010 as this was the 
range with the most climate stations providing data. The local analysis was from 1957 to 2012, the period for which instrumental climate records are available for the Inuvik and Tuktoyaktuk regions. A 16-month window spanning from May of the previous year to August of the current year was used to test for autocorrelation within the ring-width chronologies. In addition to the statistical analysis, the relationships were plotted for visual assessment.

\subsubsection{Moving Window Analysis}

Moving window analyses were next performed to test the temporal stability of the climate-growth relationships over the length of the instrumental records. For the composite temperature record, a window length of 24 years lagged 1 year was used to calculate the relationship over time using DendroClim2002 (Biondi and Waikul, 2004) over a 100 year span from 1910 to 2009 using minimum, mean, and maximum temperature. For the local climate variables, 20-year moving windows were calculated for minimum, mean, and maximum temperatures in R rather than in DendroClim 2002 because of missing values in the datasets. 


\section{Chapter 4 - Results}

\subsection{Tree-Ring Processing}

\subsubsection{Tree-Ring Sample Collection}

Dendrochronological sampling at the Campbell Dolomite Uplands (CDU) and Husky Lakes (HL) resulted in the collection of 76 living $5 \mathrm{~mm}$ cores from 38 trees, 172 living $12 \mathrm{~mm}$ cores from 86 trees, and 131 subfossil cross sections from the 5 sites, giving a total of 255 trees. This section presents the results of the chronology-building process and indicates when the removal of samples was deemed necessary to preserve chronology strength.

\subsubsection{Ring-Width Measurement}

Using the $5 \mathrm{~mm}$ cores and viable subfossil samples, ring-widths were measured from the 5 sites: CDU1, CDU2, HL1, HL2, and HL3 and subsequently visually crossdated and checked using the computer software COFECHA (Holmes, 1983; Grissino-Mayer, 2001). Of the 169 samples collected for ring-width measurement, 142 were retained for further statistical analysis (Table 4.1). Cores were excluded for a variety of reasons including: the presence of reaction wood, core warping, core decay and/or breakage, and interseries correlations below 0.328 (at $\mathrm{p}=0.05)(\mathrm{e} . \mathrm{g}$. Szeicz and MacDonald, 1996) as calculated by COFECHA. Interseries correlations are a measure of the stand-level signal, calculated iteratively between each core and the average site chronology (Speer, 2010). At HL, one $5 \mathrm{~mm}$ core was removed because of reaction wood $(2.7 \%)$ and five more because of core breakup (13.5\%). These were removed because of the potential they pose for inaccuracy in the ring-width measurement values. No $5 \mathrm{~mm}$ cores were sampled at CDU. Overall, sample removal resulted in the exclusion of $10 \%$ of 
the living tree cores and $18 \%$ of the subfossil samples (primarily of decayed samples). Cores that met the above criteria, but contained less than 30 rings, were also excluded due to the statistical consideration that shorter samples may erroneously correlate well in several time periods due to their length (Briffa et al., 1984) and thus may not be reliable estimates of growth. 
Table 4.1 - The number of $5.2 \mathrm{~mm}$ cores and subfossil samples retained in relation to the number collected at each of the 5 sample sites. The fraction of the number of trees $(\mathrm{N}$ Trees) and the number of cores (N Cores) retained versus collected is presented.

\begin{tabular}{|c|c|c|}
\hline Name & N Trees & N Cores \\
\hline \multicolumn{3}{|c|}{ Living Cores (5 mm) } \\
\hline HL1 & $25 / 27$ & $49 / 54$ \\
\hline HL2 & $2 / 3$ & $4 / 6$ \\
\hline HL3 & $7 / 8$ & $11 / 16$ \\
\hline Total & $34 / 38$ & $64 / 76$ \\
\hline \multicolumn{3}{|c|}{ Subfossil Samples } \\
\hline HL1 & $29 / 35$ & $\mathrm{~N} / \mathrm{A}$ \\
\hline HL2 & $6 / 8$ & $\mathrm{~N} / \mathrm{A}$ \\
\hline HL3 & $24 / 32$ & $\mathrm{~N} / \mathrm{A}$ \\
\hline CDU1 & $25 / 29$ & $\mathrm{~N} / \mathrm{A}$ \\
\hline CDU2 & $24 / 27$ & $\mathrm{~N} / \mathrm{A}$ \\
\hline Total & $108 / 131$ & N/A \\
\hline
\end{tabular}


The minimum, mean, and maximum ring-width values were similar among the ring-width sites. Minimum ring-width values were $0.31 \mathrm{~mm}$ at CDU1, $0.35 \mathrm{~mm}$ at CDU2, $0.27 \mathrm{~mm}$ at HL1, and $0.25 \mathrm{~mm}$ at HL3. The average ring-width measurement was 0.97 $\mathrm{mm}$ at CDU2, HL1, and HL3, and $0.96 \mathrm{~mm}$ at CDU1. The maximum values were also very similar and were $2.75 \mathrm{~mm}$ at CDU1, $2.53 \mathrm{~mm}$ at CDU2, $2.69 \mathrm{~mm}$ at $\mathrm{HL} 1$, and the highest value of $3.63 \mathrm{~mm}$ at HL3.

\subsubsection{Maximum Density Measurement}

Of the samples collected ( $5 \mathrm{~mm}$ cores, $12 \mathrm{~mm}$ cores, and subfossil wood), 207 were cut into lathes for ring density measurement. Following the water and resin extraction phases, some lathes had broken up into numerous segments and were run through the densitometer individually. A segment refers to a measurement path, of which there may be multiple for a single core. The x-ray densitometer passed an x-ray beam through each segment to produce a calibrated image of the wood density along the lathe. Each density image had a measurement path manually laid down using Windendro 2009b,c (Regent Instruments Inc., 2009). Thirty-seven of these lathes produced irreparably blurry visual images and so no viable measurement path could be placed. Of the 207 samples, a total of 170 lathes proceeded to the measurement stage of analysis. Ring-width and density measurements were taken concurrently along a chosen measurement path. The ring-width measurements obtained using this method were crossdated against the originally measured ring-width values at those sites. As suggested by Schweingruber (1993), the parameter maximum latewood density was chosen as the optimal output measurement for further analysis. 
Throughout crossdating, the removal of lathe segments followed a strict protocol. Of the 309 segments measured from the 207 lathes, 134 segments were retained. Fourteen segments were removed because of unreliable density measurement readings (1270 max outs), 11 because of issues with wood decay/preservation, 55 because of poor image quality resulting from ring alignment issues, 20 because of indecipherably narrow sections, 20 segments were short ( $<35$ years), 47 would not crossdate with their original ring-width measurement series, and 2 contained reaction wood. This amounts to the exclusion of 176/309 segments (57\%).

Further image analysis and crossdating removed an additional 29 segments. Every removal was based on a detailed examination of the density image and only those sections whose removal was visually justified were removed (Figure 4.1). Issues with image quality were directly related to the ability of the $\mathrm{x}$-ray beam to penetrate each ring on a path parallel to the $12 \mathrm{~mm}$ wide face of the lathe. From a detailed examination of the samples, these errors tended to be linked to sections of samples with decay, as well as sections with exceedingly narrow rings. This is likely because of changes in the angle of ring growth along the length of the segment, a property that is very difficult to adjust along a core with narrow rings.

Of the 207 cores originally scanned, 123 cores were retained in the final chronologies (59\%). The CDU density chronology (CDUMXD) contains 70 segments from 65 cores, representing 50 trees. The HL density chronology (HLMXD) contains 64 segments from 58 cores, representing 42 trees. The density measurements were very similar between the CDU density chronology (CDUMXD) and the HL density chronology (HLMXD). The average density value at CDUMXD was $0.99 \mathrm{~g} \mathrm{~cm}^{-3}$ and at 
HLMXD was $1.0 \mathrm{~g} \mathrm{~cm}^{-3}$. The maximum and minimum CDUMXD values were $1.32 \mathrm{~g}$ $\mathrm{cm}^{-3}$ and $0.73 \mathrm{~g} \mathrm{~cm}^{-3}$ while at HLMXD they were $1.64 \mathrm{~g} \mathrm{~cm}^{-3}$ and $0.65 \mathrm{~g} \mathrm{~cm}^{-3}$. HLMXD has a higher range of variability in density measurement. 

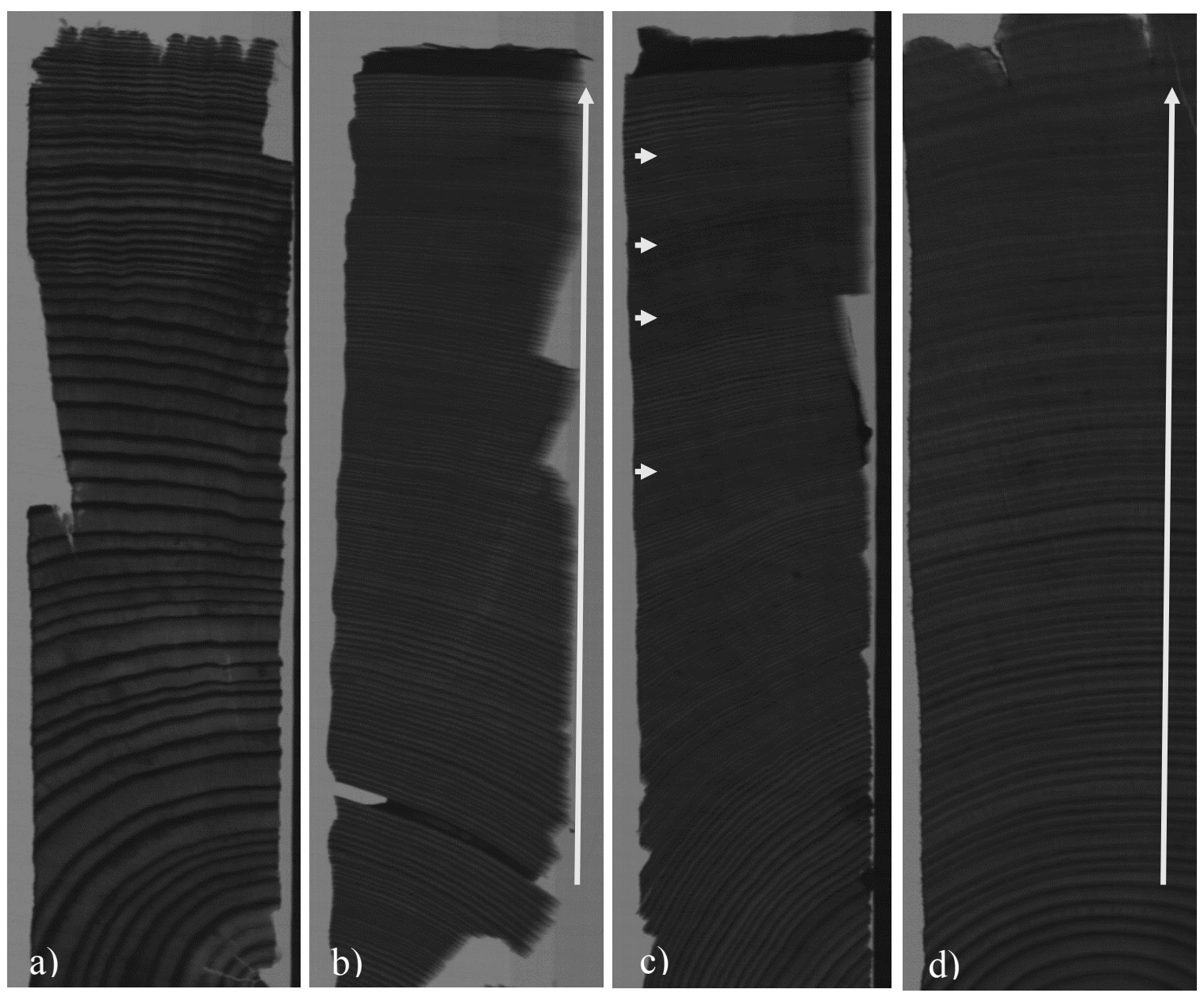

Figure 4.1 - Illustrations of the range of density images produced through $x$-ray densitometry. In a) a good image is shown, with distinct ring boundaries (C1D05A); b) the appearance of decay in a sample increasing toward the bark (H1L08A); c) narrow sections of samples cannot be resolved by the x-ray beam (H1L11A); d) the ring angle of the sample becomes more twisted toward the bark of the sample, such that the $\mathrm{x}$-ray beam is penetrating multiple rings at once (H1D14A). 


\subsection{Chronology Development}

\subsubsection{Series Standardization}

Following the measurement and crossdating of TRW and MXD, the series were detrended to create site chronologies. Three detrending methods were tested to evaluate how appropriate they were for this dataset. The three detrending models tested were signal free (SF), signal free regional curve standardization (SF RCS) and traditional negative exponential (NEXP). A chronology was developed for each site using each of the three methods. The resulting chronologies were then statistically compared to one another using Pearson product-moment correlation.

\subsubsection{Ring-Width Series Detrending}

Within the ring-width chronologies, SF and NEXP were found to be most similar at all sites $(r>0.900, p<0.05)$ while the SF RCS differed notably (Table 4.2). The difference in the SF RCS chronology is likely because of pith offset, where not all series begin at year zero of growth (i.e. the first year of tree growth). The SF model was considered to be most appropriate as it captures the greatest amount of climate signal (Melvin and Briffa, 2008), while still producing a growth curve similar to the NEXP model. Anchukaitis et al. (2013) also chose the SF model as most appropriate for detrending their density series from northeastern Alaska. 
Table 4.2 - Correlation coefficients from the statistical comparison of the three detrending methods (SF, SF RCS, and NEXP) tested at each ring-width site (CDU1, CDU2, HL1, and HL3). Correlations are significant at the $95 \%$ confidence interval.

\begin{tabular}{lccc}
\hline & SF-SF RCS & SF RCS-NEXP & NEXP-SF \\
\hline HL1TRW & 0.574 & 0.615 & 0.946 \\
HL3TRW & 0.659 & 0.660 & 0.969 \\
CDU1TRW & 0.600 & 0.575 & 0.959 \\
CDU2TRW & 0.552 & 0.542 & 0.937 \\
\hline
\end{tabular}




\subsubsection{Density Series Detrending}

Among the MXD chronologies, similar results were observed to those of the TRW detrending, although the SF RCS method was not tested because of the segmentation of the samples during density processing. For CDUMXD, the correlation between results of the SF and NEXP models was 0.976 and for HLMXD was 0.990 ( $p=$ $<0.05)$. It is important to note that for the HLMXD chronology, there is a gap in chronology coverage from 1357 to $1413 \mathrm{CE}$. There is still high confidence in the temporal placement of samples older than 1413 as they were crossdated against the ringwidth record which contains no gaps and sufficient sample depth for crossdating purposes.

\subsubsection{Chronology Summary Statistics}

Following SF detrending, the series were aggregated using a biweight robust mean into a single master chronology for each site. The HL2 series were added to the HL1 site chronology because there were only 11 trees sampled at this site. Summary statistics for the sites indicate that relatively higher correlations are found at the more northern sites compared to the Campbell Dolomite Upland sites near Inuvik (Tables 4.3 and 4.4).

\subsubsection{Ring-Width Chronologies}

The ring-width chronologies contain a total of 536 series and span the period from 1025 to 2012 . A total of 219 ring-width series were developed from HL and 317 from CDU (Table 4.3). The series intercorrelation (SI) values are consistently higher at HL for the TRW chronologies. The CDU1 and CDU2 TRW chronologies have a large number of samples, more than 50 from $\sim 1800$ to $2007 \mathrm{CE}$ (Figure 4.2). Standardized ring-width 
values have a large range at CDU, between $0.310 \mathrm{~mm}$ and $2.75 \mathrm{~mm}$. However, ring-width index values are much more variable at HL1 and HL3 than at CDU with measurement values between $0.25 \mathrm{~mm}$ and $3.65 \mathrm{~mm}$. Sample depth is low at HL near the beginning of the record and increases consistently throughout the record at HL1 while at HL3 it is typically stable between 20 and 40 samples (Figure 4.2). 
Table 4.3 - Summary site statistics for the ring-width chronologies describing the number of series in each chronology, the chronology length, the temporal span of the chronology, the series intercorrelation value (SI), the mean sensitivity (MS) and the mean length of series (MLS).

\begin{tabular}{lcccccc}
\hline & \# Series & Length (Years) & Range (CE) & SI & MS & MLS (Years) \\
\hline HL1TRW & 142 & 692 & $1321-2012$ & 0.575 & 0.260 & 160 \\
HL3TRW & 77 & 630 & $1383-2012$ & 0.573 & 0.263 & 180 \\
CDU1TRW & 141 & 855 & $1158-2012$ & 0.500 & 0.239 & 174 \\
CDU2TRW & 176 & 988 & $1025-2012$ & 0.500 & 0.266 & 200 \\
\hline
\end{tabular}



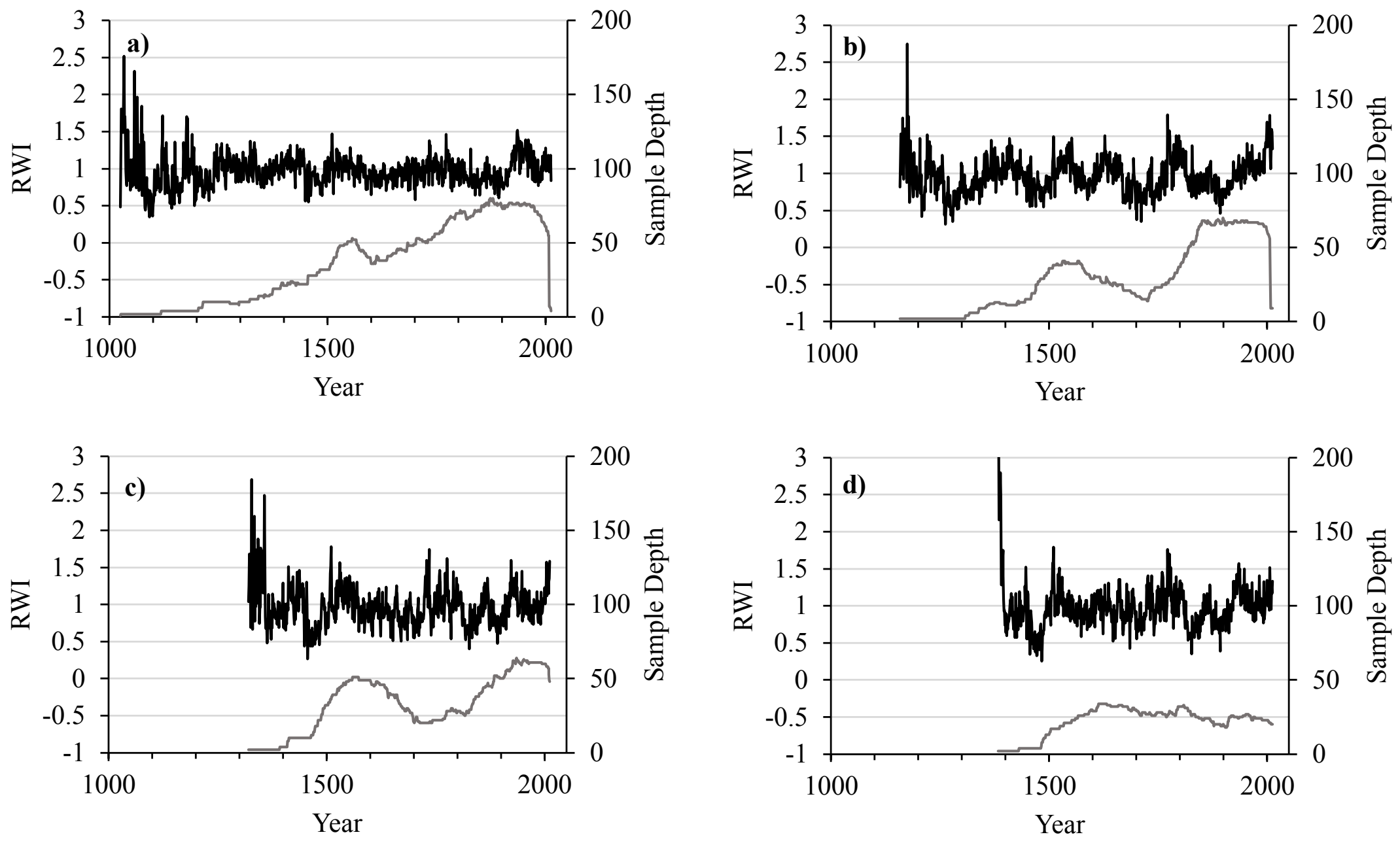

Figure 4.2 - Ring-width index (RWI) (in black) and sample depth (in grey) of a) the CDU1TRW chronology (1158 to 2012); b) the CDU2TRW chronology (1025 to 2012); c) the HL1TRW chronology (1321 to 2012); and d) the HL3TRW chronology (1383 to 2012). 


\subsubsection{Maximum Density Chronologies}

The maximum density chronologies contain 134 samples and span from 1321 to $2012 \mathrm{CE}$, due to the elimination of samples as required throughout the density chronology building process (Table 4.4). For CDUMXD, standardized MXD values ranged from 0.730 to $1.321 \mathrm{~g} \mathrm{~cm}^{-3}$, with greater variability during periods of low sample depth (i.e. $~ 1642$ to $1760 \mathrm{CE}$ ) (Figure 4.3). The HLMXD chronology has a range of values close to that of CDUMXD, from 0.649 to $1.636 \mathrm{~g} \mathrm{~cm}^{-3}$ (Figure 4.3). 
Table 4.4 - Summary site statistics for the ring density chronologies describing the number of series in each chronology, the chronology length, the temporal span of the chronology, the series intercorrelation value (SI), the mean sensitivity (MS) and the mean length of series (MLS).

\begin{tabular}{lcclllc}
\hline & \# Series & Length (Years) & Range & SI & MS & MLS (Years) \\
\hline HLMXD & 64 & 692 & $1321-2012 \mathrm{CE}$ & 0.552 & 0.084 & 75 \\
CDUMXD & 70 & 705 & $1308-2012 \mathrm{CE}$ & 0.472 & 0.078 & 101 \\
\hline
\end{tabular}



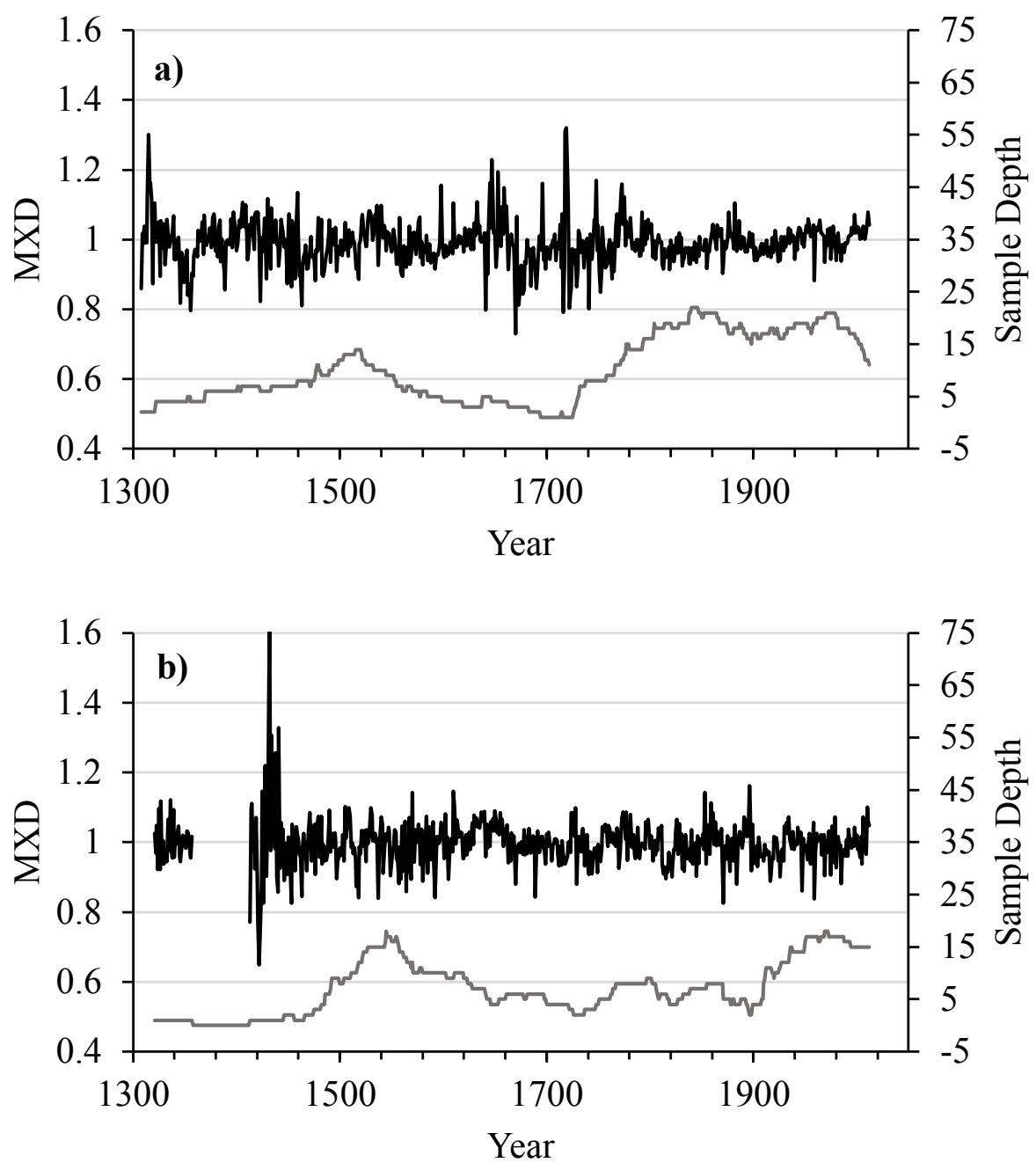

Figure 4.3 - Detrended maximum density chronology (in black) and sample depth (in grey) of a) the CDU density chronology (1308 to 2012) and b) the HL density chronology (1321 to 2012). 


\subsubsection{Growth Trends}

A correlation matrix was used to display the relationship between the SF detrended ring-width chronologies (Table 4.5). All of the study sites correlated positively with each other above the $95 \%$ confidence interval with $r$ values $=0.394$ to 0.587 and $p<$ 0.05. Due to these high correlation values, these sites are similarly responsive to environmental conditions. 
Table 4.5 - Correlation matrix between the ring-width SF chronologies with correlation coefficients displayed. All correlations are significant at the $95 \%$ confidence interval.

\begin{tabular}{lllll}
\hline & HL1TRW & HL3TRW & CDU1TRW & CDU2TRW \\
\hline HL1TRW & 1 & & & \\
HL3TRW & 0.587 & 1 & & \\
CDU1TRW & 0.497 & 0.484 & 1 & \\
CDU2TRW & 0.499 & 0.474 & 0.394 & 1 \\
\hline
\end{tabular}


The MXD SF chronologies correlate positively with each other with an r-value = 0.330 and $\mathrm{p}<0.05$. The MXD chronologies also correlate above the $95 \%$ confidence interval with all of the TRW SF chronologies, although with lower, positive correlation coefficients. These correlations are higher when comparing the density and ring-width chronologies developed from the same site. At CDU, CDUMXD has a correlation of 0.281 with CDU1TRW and 0.255 with CDU2TRW (Figure 4.4). At HL, HLMXD has a correlation of 0.238 with HL1TRW and 0.241 with HL3TRW (Figure 4.5). When CDUMXD and HLMXD are plotted against each other, they appear to have similar maximum density trends in growth as depicted using a 10-year smoothing average (Figure 4.6). 


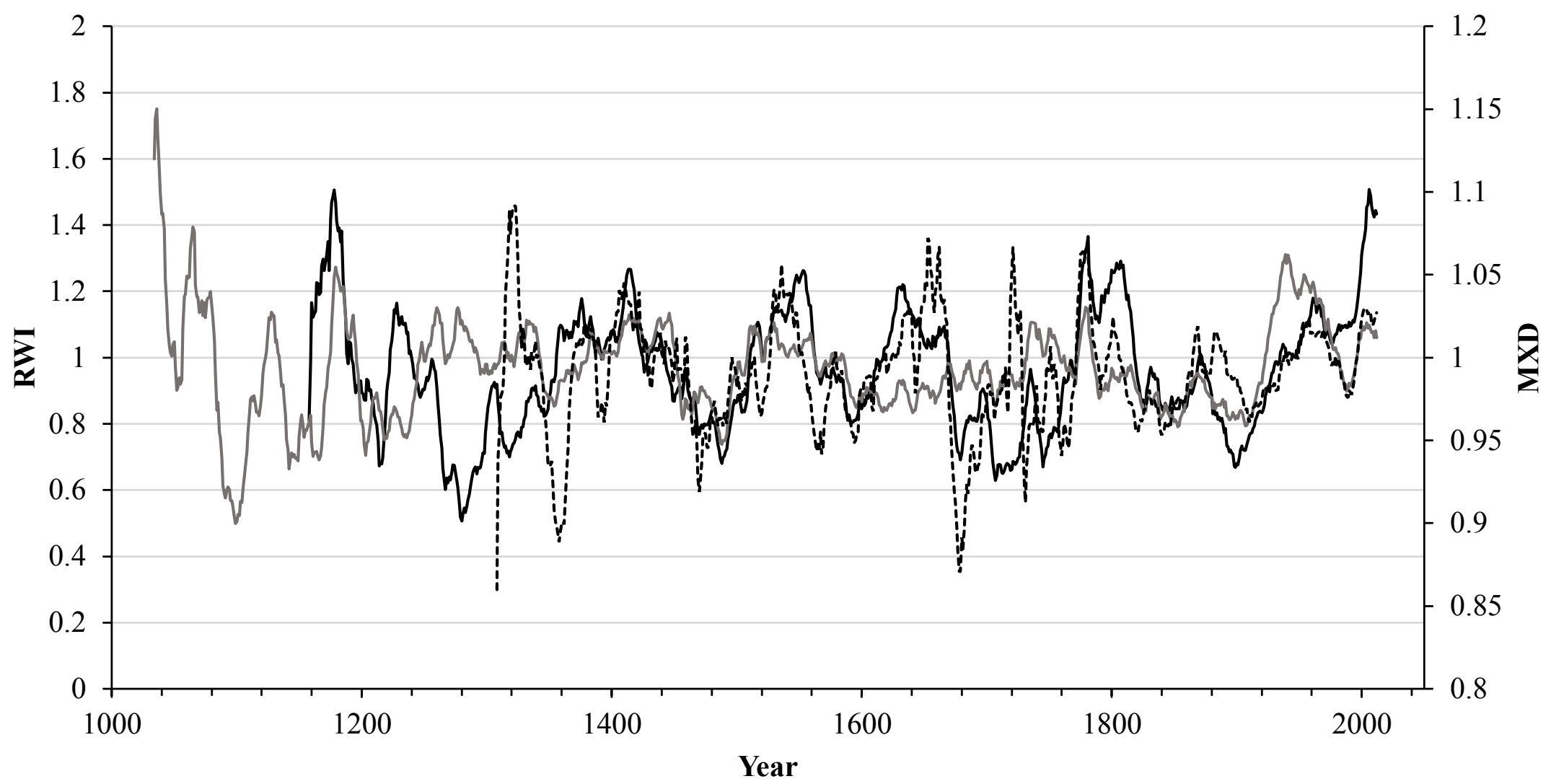

Figure 4.4 - Time series plots of the ring-width (RWI) and maximum density (MXD) chronologies at CDU smoothed using a 10-year moving average. The solid black line is CDU1TRW RWI, the solid grey line is CDU2TRW RWI, and the dashed black line is CDUMXD. 


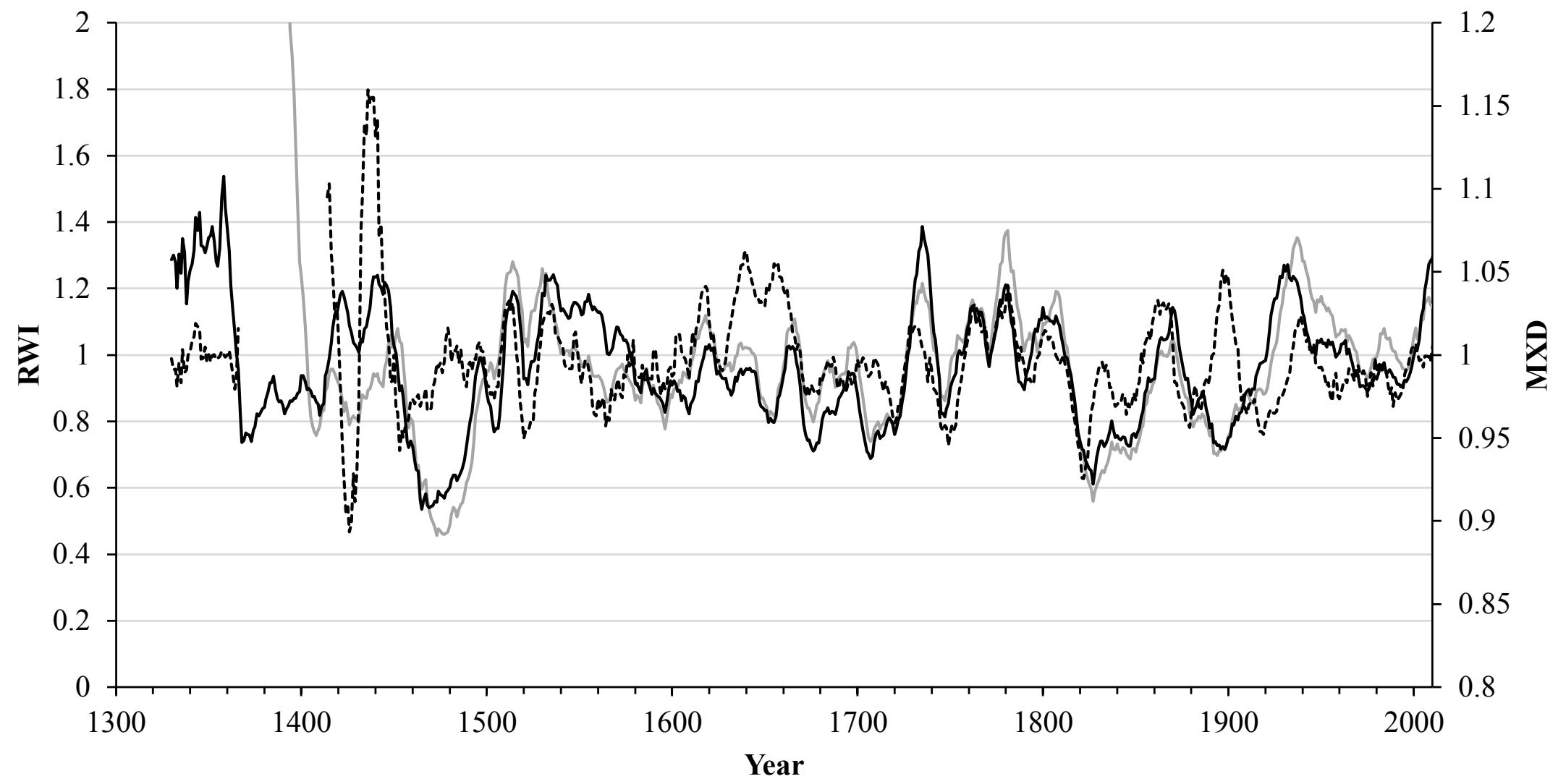

Figure 4.5 - Time series plots of the ring-width (RWI) and maximum density (MXD) chronologies at HL smoothed using a 10-year moving average. The solid black line is HL1TRW RWI, the solid grey line is HL3TRW RWI, and the dashed black line is HLMXD. 


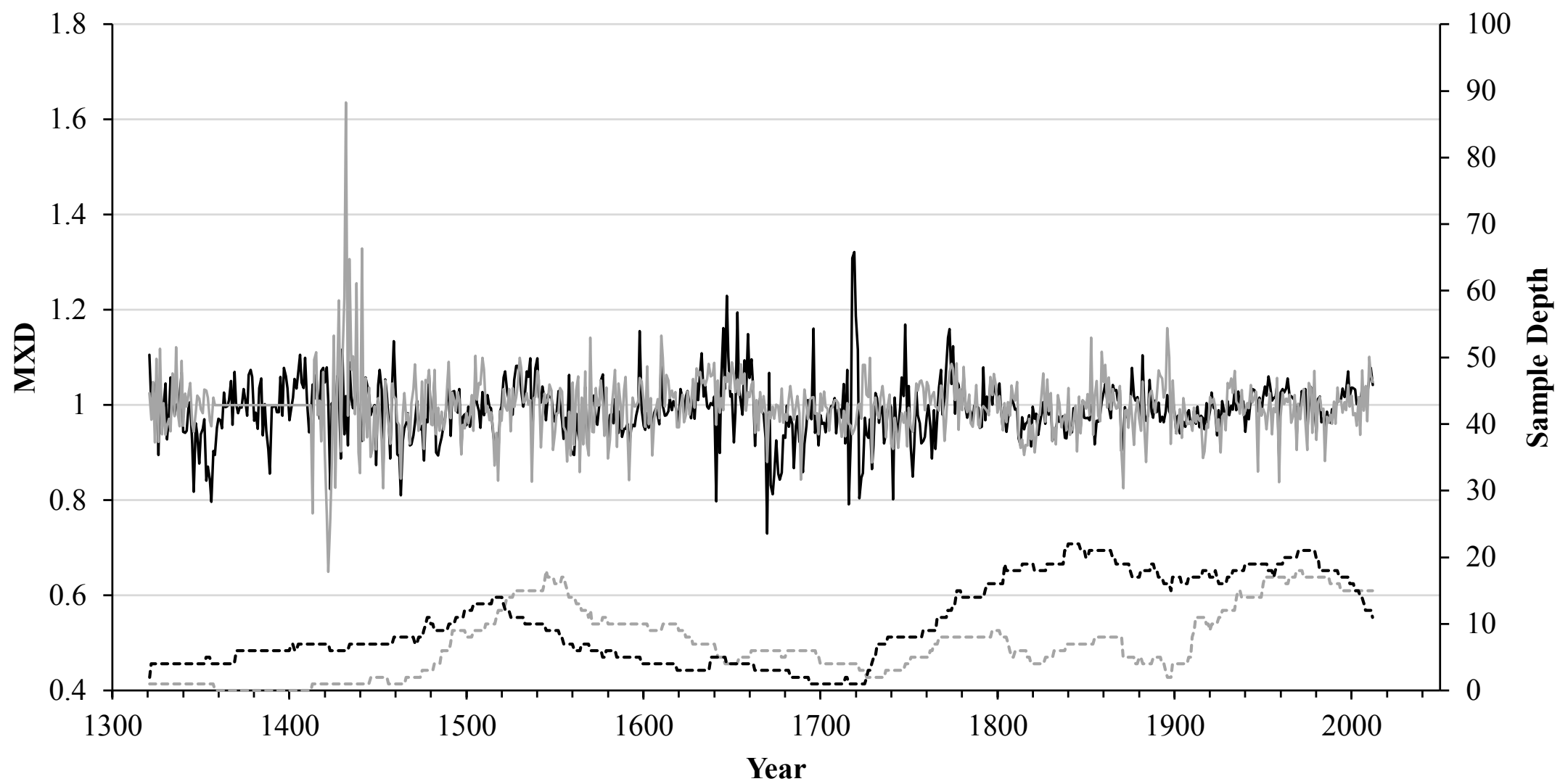

Figure 4.6 - The standardized density chronologies plotted against each other. The MXD index for CDUMXD is the narrow black line and for HLMXD is the narrow grey line. Sample depth is displayed for CDUMXD as the dotted black line and for HLMXD as the dotted grey line. 


\subsection{Regional Representation of Chronologies}

\subsubsection{Ring-Width Records}

The TRW chronologies were next evaluated for their representation of regional growth trends by statistically comparing them to 46 ring-width chronologies developed by Trevor Porter for the northern Northwest Territories (pers. comm., 2014). The majority of sites $(78 \%)$ were correlated positively and significantly with the CDU and HL chronologies. The average correlation between all Porter's sites and those collected for this research was $r=0.428$, with a range of correlation coefficients from -0.371 to 0.958 . There were only three negative correlations, two of which were with CDU1TRW and one with CDU2TRW, suggesting that trees sampled from CDU may not be as representative of regional growth trends.

\subsubsection{Density Records}

The density chronologies were compared to two chronologies (CANA172 and CANA173) developed by Schweingruber from the Campbell Dolomite Uplands, nearest to the CDU2 site (Table 4.6), available online from the International Tree-Ring Databank (ITRDB). Together the Schweingruber chronologies cover the period from 1175 to 1992. Correlation analysis indicates that CDUMXD and HLMXD are coherent with other regional density chronologies (Table 4.6). A lower correlation is seen between CDUMXD and the Schweingruber chronologies, possibly resulting from conflicting signals within CDUMXD as CDU1 and CDU2 may have differing climate responses. 
Table 4.6 - Correlation coefficients between CDUMXD, HLMXD, CANA172, and CANA173. All correlations are significant at 95\% confidence interval.

\begin{tabular}{lllll}
\hline & CDUMXD & HLMXD & CANA172 & CANA173 \\
\hline CDUMXD & & & & \\
HLMXD & 0.323 & & & \\
CANA172 & 0.438 & 0.388 & & \\
CANA173 & 0.295 & 0.444 & 0.438 & \\
\hline
\end{tabular}




\subsection{Signal Strength}

\subsubsection{Effective Chronology Signal}

The common chronology signal was estimated by calculating the effective chronology signal, or $\bar{r}_{\text {eff }}$ (Cook and Kariukstis, 1990), an indicator of the signal strength present within the tree-ring series at a site using the package dplR in the $\mathrm{R}$ workspace (Bunn, 2008). Values of $\overline{\bar{r}}_{\text {eff }}$ greater than 0.5 point toward a common signal between trees at a site (Briffa and Jones, 1990). The $\overline{\bar{r}}_{\text {eff }}$ was assessed for each of the TRW and MXD chronologies using a 50-year window lagged by 25 years. Values for $\overline{\bar{r}}_{\text {eff }}$ averaged 0.260 for CDUMXD, 0.256 for CDU1TRW, 0.196 for CDU2TRW, 0.355 for HLMXD, 0.341 for HL1TRW, and 0.359 for HL3TRW. The $\bar{r}_{\text {eff }}$ of the CDU chronologies was lower than those of the HL chronologies by about 0.1 . The $\bar{r}_{\text {eff }}$ values were consistently below the threshold of 0.5 and thus cannot be said to be completely representative of the local signal over the length of the chronologies.

\subsubsection{Expressed Population Signal}

The expressed population signal (EPS) represents the signal-to-noise ratio. The signal strength of each chronology was evaluated using the SF detrended and standardized indices produced using the package dplR in R (Bunn, 2008). Two moving window lengths were tested to observe the effect of window length on the EPS values: 50-years lagged 25 years (Figures 4.7 and 4.8) (Wigley et al., 1984) and 30-years lagged 15 years (not shown). The 50-year window lagged 25 years was chosen to best represent the long term trends in signal strength in the chronologies. Broken lines in the graphs indicate where N/A values were deleted, as the result of an insufficient mean number of trees for the EPS calculation. 


\subsubsection{Ring-Width Population Signal}

For CDU1TRW, the signal strength is above the threshold cut-off during the 50year windows around 1487 to 1562 and from 1737 to 1987 , the last window analysed (Figure 4.7). The average sample depth for periods of above threshold signal confidence is 27 series. The minimum number of trees above the threshold is 12. For CDU2TRW, windows above the cut-off value occur between 1487 to 1512 and from 1687 to 1987 (Figure 4.7). The minimum number of trees is 16 for significant periods for CDU2TRW. The mean EPS values are 0.774 for CDU1TRW and 0.687 for CDU2TRW over the length of the chronology.

At HL, the TRW chronology strength is more stable over time than at CDU. A higher overall signal strength is observed at HL as opposed to CDU for both the TRW and MXD chronologies. High signal confidence in HL1TRW occurs between 1462 to 1987 and for HL3TRW for the 50-year windows at 1487 and between 1562 to 1862, and from 1912 to 1987 (Figure 4.7). The average and minimum numbers of trees for confidence are 29 and 7 for HL1TRW and 17 and 5 for HL3TRW. The average EPS for HL1TRW is 0.872 and at HL3TRW is 0.867 . There is higher signal confidence for the HL chronologies. 

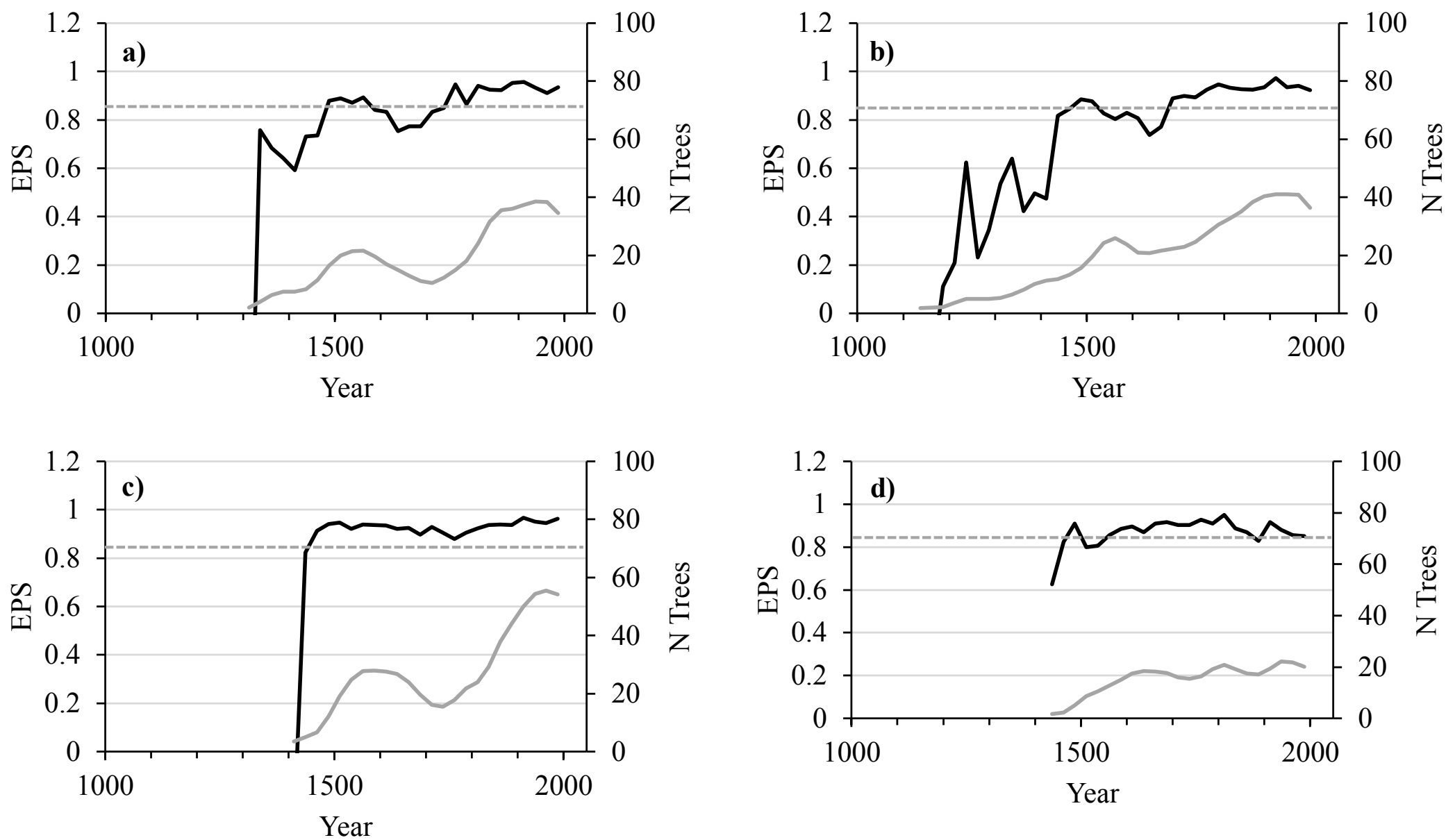

Figure 4.7 - The EPS of the ring-width chronologies and the number of trees used to calculate the EPS over a 50-year window, lagged by 25 years for a) CDU1TRW; b) CDU2TRW; c) HL1TRW; and d) HL3TRW. The black lines are the EPS values and the grey lines are the average number of trees used to calculate a specific EPS value. The dashed line illustrates EPS $=0.85$. 


\subsubsection{Density Population Signal}

For CDUMXD, the average sample depth over the 50-year moving window is $\sim 15$ trees. The EPS values are consistently below the EPS confidence threshold of 0.85 (Wigley et al., 1984) for the length of the record (Figure 4.8). The highest EPS values are calculated from 1762 to 1987 , the middle of the last window analysed. The average EPS value for the entire period is 0.691 , while the minimum value is 0.431 and the maximum value is 0.831 (Figure 4.8). The EPS values of HLMXD are on average higher than those of CDUMXD. The mean EPS value is 0.772 , ranging from 0.573 to 0.865 . Values are above the threshold cut-off from 1537 to 1587 and the 50-year windows around 1887 and 1962 (Figure 4.8). 

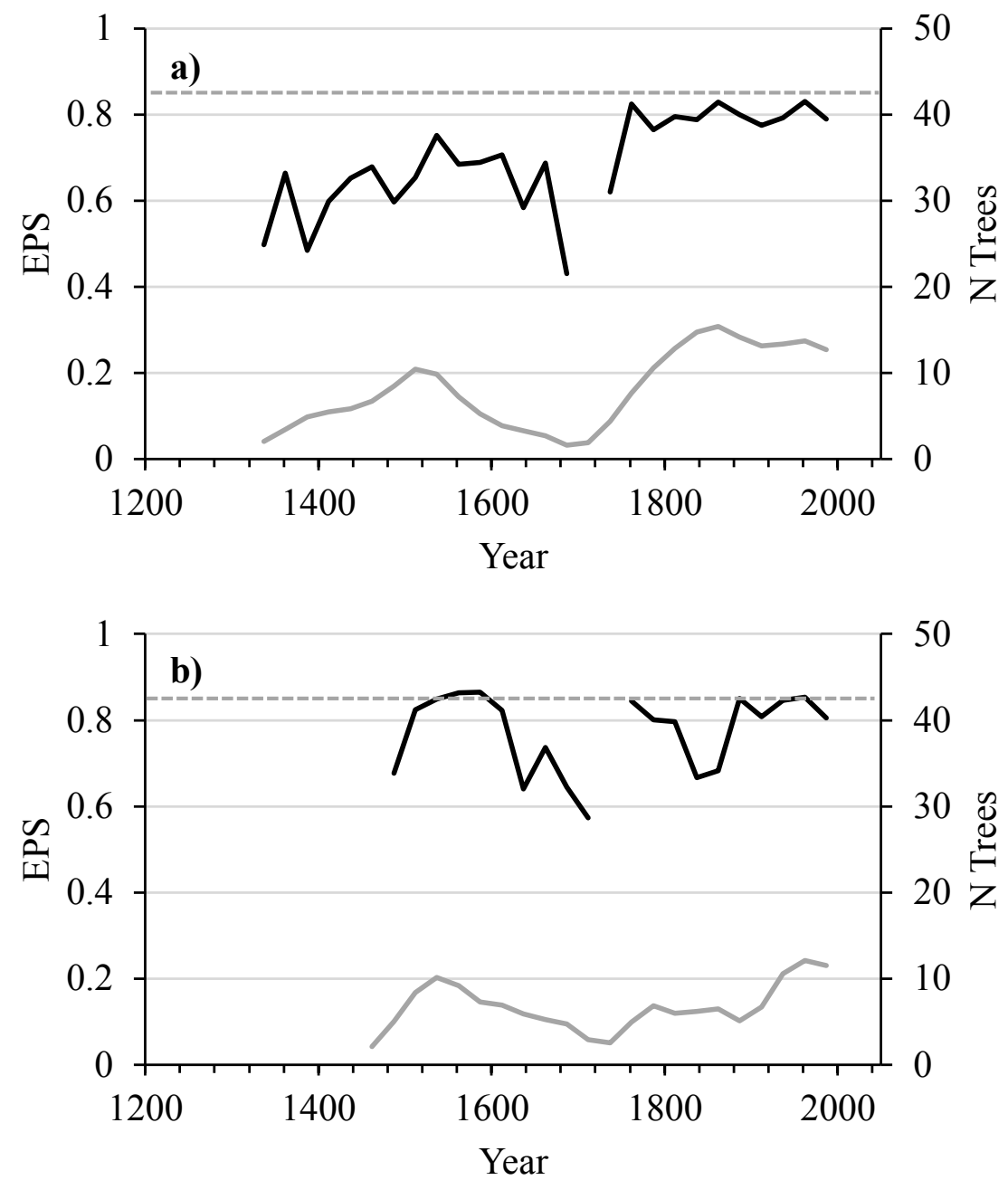

Figure 4.8 - The EPS of a) the CDUMXD chronology and b) the HLMXD chronology and the number of trees used to calculate the EPS over a 50-year window, lagged by 25 years. The black lines are the EPS values and the grey lines are the average number of trees used to calculate a specific EPS value. The dashed line illustrates EPS $=0.85$. 


\subsubsection{Recent Ring-Width Signal Stability}

The recent stability of the EPS over the past century or so (1900 to 2012) was examined using 20-year windows lagged 19 years. A shorter window was chosen to examine finer scale changes in the variance of the common signal. All of the ring-width chronologies remain above the 0.85 cut-off for the duration of the past 112 years (Figure 4.9). 

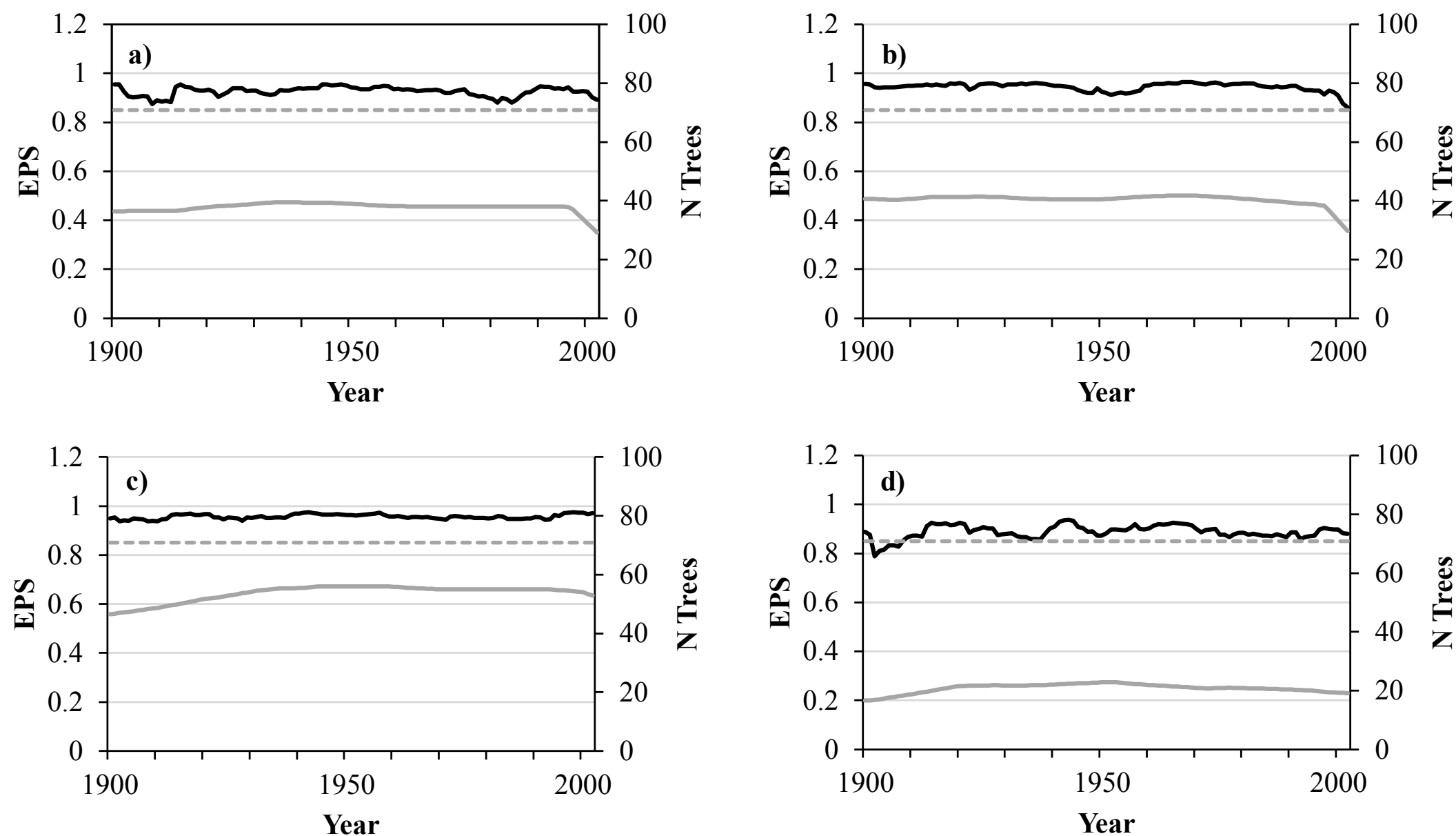

Figure 4.9 - The EPS values for the ring-width chronologies are plotted for the past 110 years along with the average number of trees used to calculate the statistic for a) CDU1TRW; b) CDU2TRW; c) HL1TRW; and d) HL3TRW. The black lines are the EPS values and the grey lines are the number of trees used to calculate a specific EPS value. The dashed line illustrates EPS $=0.85$. 


\subsubsection{Recent Density Signal Stability}

The density chronologies exhibit a higher degree of variance over the period of interest (Figure 4.10). From 1900 to 2002, CDUMXD is above the threshold cut-off from 1949 to 1968 , with several shorter periods above the threshold prior to 1950 (Figure 4.10). The signal in the CDUMXD chronology is fairly stable as it fluctuates between 0.7 and 0.9 , rarely going above or below this range. The mean EPS value is 0.802 and the maximum and minimum values are 0.916 and 0.622 , respectively. The HLMXD chronology is variable, more so with decreasing sample number. HLMXD remains above 0.85 from 1949 to 1968 and from 1975 to 1984 . Over the 112 year period, HLMXD EPS values are within 0.499 and 0.929 with the single exception of the 1911 window where the EPS is 0.119. The average EPS value for HLMXD is 0.788 for the span 1900 to 2012. 

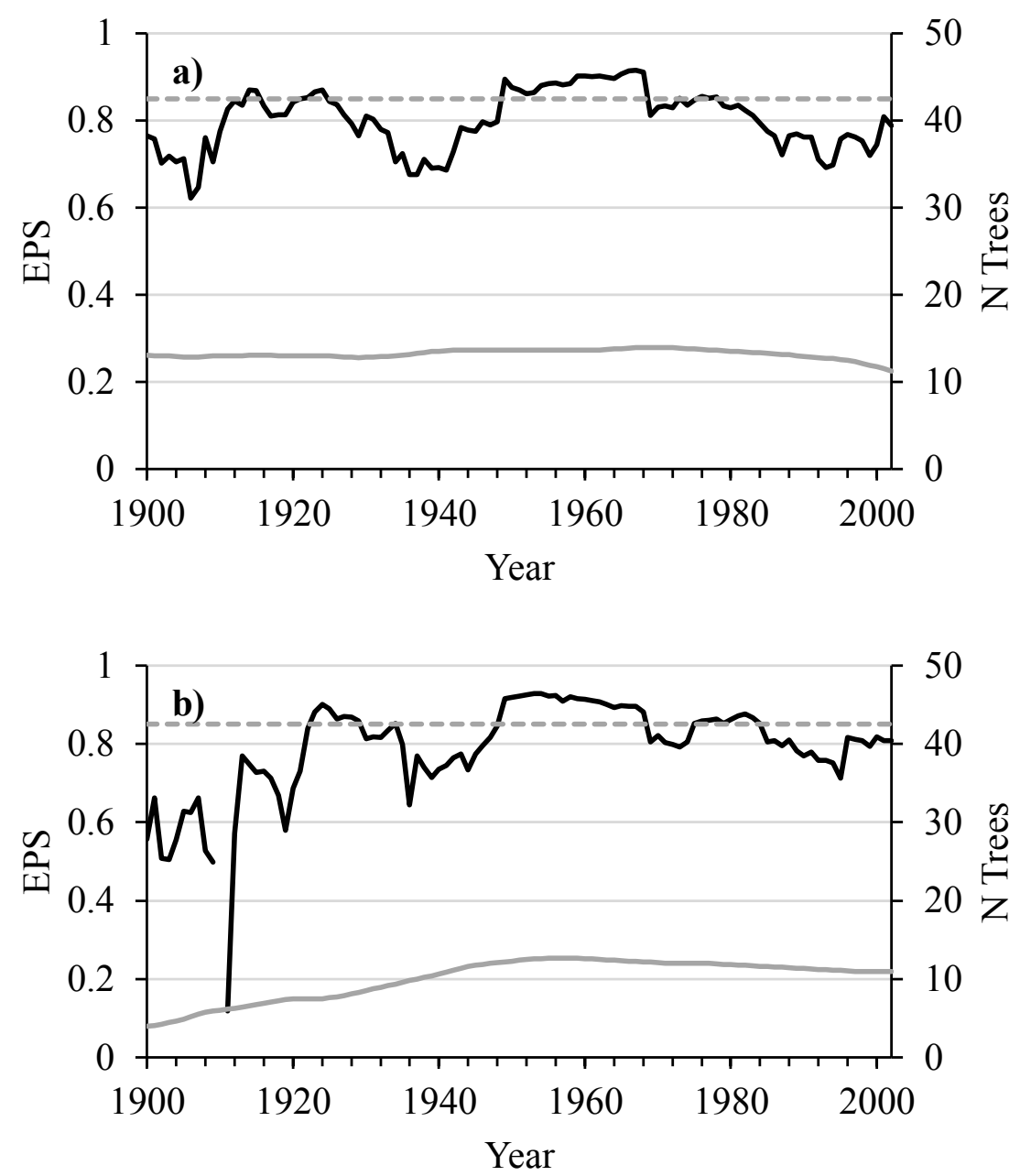

Figure 4.10 - The EPS values for the density series are plotted for the past 110 years along with the average number of trees used to calculate the statistic for a) CDUMXD and b) HLMXD. The black lines are the EPS values and the grey lines are the average number of trees used to calculate a specific EPS value. The dashed line illustrates EPS = 0.85 . 


\subsection{Climate-Growth Relationships}

A climate-growth analysis was conducted at the site level to examine the factors that most influence tree growth. A reduction in the climate sensitivity of tree-ring series was used as an indication of the presence of divergence as this is an outcome of the blending of differing climate signals. This blending may occur when trees expressing different climate signals are aggregated into chronologies. The chronology signal thus would poorly represent climate trends and would appear as a decrease in climate sensitivity. This first indication of divergence in the early studies of Jacoby and D'Arrigo (1995) and Briffa et al. (1998a) was a decrease in the climate sensitivity of their northern tree chronologies.

The chronologies were statistically compared to composite temperature records produced by Porter (2013) spanning 1910 to 2010 and local records from Inuvik and Tuktoyaktuk spanning 1957 to 2012 for temperature and from 1957 to 2007 (Inuvik) and 1957 to 1992 (Tuktoyaktuk) for precipitation. Only correlations between the chronologies and corresponding local precipitation and temperature are considered; HL is compared to Tuktoyaktuk and CDU is compared to Inuvik. Unfortunately, the length of the local precipitation records only encompasses the period after which divergence has been noted in ring-width series. A 16-month window from May of the previous growing season to December of the current growing season was used to capture the influence of climate in the previous growth year on tree growth during the current growing season. Three separate correlation analyses (minimum, mean, and maximum temperature) were calculated using Pearson product-moment correlation to analyse the response of the TRW 
and MXD chronologies to climate variables. Only correlations significant at the $95 \%$ confidence interval are presented.

\subsubsection{Stationary Climate Analysis}

\subsubsection{Stationary Climate Record and Ring-Width}

Upon examination of the stationary climate-growth results matrices, a single consistent correlation with TRW chronologies is noted. The only relationship common among the four TRW chronologies are negative correlations with composite maximum July temperature of the previous growing season $(r=-0.351$ to -0.203$)$ and local maximum July temperature of the previous growing season $(-0.475$ to -0.289$)$. The strongest correlations with local temperature at each site are here noted: CDU1TRW with minimum JAS index temperature (0.413), CDU2TRW with maximum previous July temperature (-0.340), HL1TRW with minimum June temperature $(\mathrm{r}=0.318)$, and HL3TRW with maximum previous July temperature (-0.475). Slight differences in highest correlation values with the composite temperature record are noted as well: CDU1TRW with minimum June temperature (0.458), CDU2TRW with maximum previous June temperature (-0.327), HL1TRW with maximum previous July temperature $(-0.321)$, and HL3TRW with maximum previous July temperature $(-0.351)$. There are some negative correlations between fall precipitation and some TRW chronologies, however, tree growth has probably ceased by this point in the season and thus those relationships are considered spurious.

\subsubsection{Stationary Climate Record and Maximum Density}

The MXD chronologies exhibit positive relationships with summer temperature conditions when correlated against the composite and local records. CDUMXD and 
HLMXD are both sensitive to growing season temperatures, namely to minimum June, July, and August temperatures and mean July and August temperatures. The strongest composite temperature correlation with CDUMXD and HLMXD is with minimum August temperature $(r=0.351$ and $r=0.397$, respectively). The HLMXD chronology also responds positively to composite mean June temperatures, but CDUMXD does not.

The relationships between MXD and local temperature during the growing season are stronger than at the regional level. The MXD chronologies both correlate with minimum July, August, September, and November temperatures, mean August temperatures, and maximum August and November temperatures. The strongest composite temperature correlations with CDUMXD are with minimum and mean August temperatures $(r=0.448, r=0.403)$. HLMXD has high correlations with minimum and mean August temperatures as well $(r=0.536, r=0.515$, respectively). The highest composite correlations with HLMXD are with maximum July temperature $(\mathrm{r}=0.611)$, mean July temperature $(\mathrm{r}=0.582)$, and mean previous July temperature $(\mathrm{r}=0.581)$. The MXD chronologies also respond well to growing season precipitation. At CDUMXD, the correlation with June precipitation in Inuvik is $r=0.473$ and at HLMXD it is $r=0.404$ with previous year July precipitation at Tuktoyaktuk.

\subsubsection{Seasonal Indices}

Seasonal indices were created to amplify the climate signal using the composite and local temperature records. Seasonal indices were developed based on the highest correlations in section 4.4.1. For the composite record, monthly values were averaged for minimum June, July, and August (min JJA), mean June, July, August (mean JJA), and maximum July, August temperatures (max JA) (Table 4.7). The highest HLMXD and 
CDUMXD composite index correlations are with minimum JJA $(r=0.392 ; r=0.471)$

(Table 4.7). For the local record, the minimum July, August, September (min JAS), mean July, August, September (mean JAS), and maximum July, August (max JA) temperatures were averaged (Table 4.8). Locally, the highest MXD index correlations are with minimum JAS at CDUMXD $(r=0.481)$ and maximum JA at HLMXD $(r=0.610)($ Table $4.8)$. 
Table 4.7 - Correlation coefficients for tree growth and the seasonal indices based on the monthly correlation values from the composite record. Correlations shown are significant at the $95 \%$ confidence interval.

\begin{tabular}{|c|c|c|c|c|c|c|}
\hline & \multicolumn{4}{|c|}{$\overline{T R W}$} & \multicolumn{2}{|c|}{ MXD } \\
\hline & $\overline{\text { HL1 }}$ & $\overline{\text { HL3 }}$ & CDU1 & $\overline{\text { CDU2 }}$ & $\mathrm{CDU}$ & $\overline{\mathrm{HL}}$ \\
\hline MIN JJA & & & 0.424 & & 0.392 & 0.471 \\
\hline MEAN JJA & & & 0.271 & & 0.319 & 0.464 \\
\hline MAX JA & & & & & 0.224 & 0.393 \\
\hline
\end{tabular}


Table 4.8 - Correlation coefficients for tree growth and the seasonal indices based on the monthly correlation values with local station records in Inuvik and Tuktoyaktuk.

Correlations shown are significant at the $95 \%$ confidence interval.

\begin{tabular}{lcccccc}
\hline & \multicolumn{3}{c}{ TRW } & \multicolumn{2}{c}{ MXD } \\
\hline & HL1 & HL3 & CDU1 & CDU2 & CDU & HL \\
\hline MIN JAS & 0.314 & 0.288 & 0.413 & & 0.481 & 0.487 \\
MEAN JAS & 0.304 & 0.305 & & & 0.459 & 0.421 \\
MAX JA & & & & & 0.405 & 0.610 \\
\hline
\end{tabular}




\subsubsection{Moving Window Analysis}

The results of the stationary correlation analysis illustrate a low sensitivity of TRW chronologies to climate variables. To further understand the climate-growth relationship, a moving interval correlation analysis was run on local minimum, mean, and maximum temperature in an attempt to track changes in the climate-growth relationship over the span of the local instrumental record using a 20 -year evolutionary moving interval. For this analysis, the significance threshold is $r=0.444$ at a $95 \%$ confidence interval. For the composite record, a 24-year evolutionary moving window was used to assess changes in the temperature-growth relationship using DendroClim2002 (Biondi and Waikul, 2004). Only the variables with the highest temperature correlations with local and composite temperature records, including seasonal indices, are shown.

\subsubsection{Ring-Width and Local Temperatures}

Moving interval analysis of the local temperature records was restricted to graphical representation in Excel because of limitations of the program DendroClim2002 in processing missing values. These records were also shorter (1957 to 2010) so a 20-year moving interval was used to observe changes in trends over time. The analysis illustrates a fluctuation in the relationships between tree growth and temperature over time, which for the most part is below the $\mathrm{p}=0.05$ significance threshold (Figure 4.11). At CDU, CDU1TRW and minimum JAS temperature are very weakly correlated; for CDU2TRW, the correlation with maximum previous July temperature is consistently negative. At HL, HL1TRW has a tendency for a positive relationship with minimum June temperature while HL3TRW has a weakly negative relationship with maximum previous July temperature 

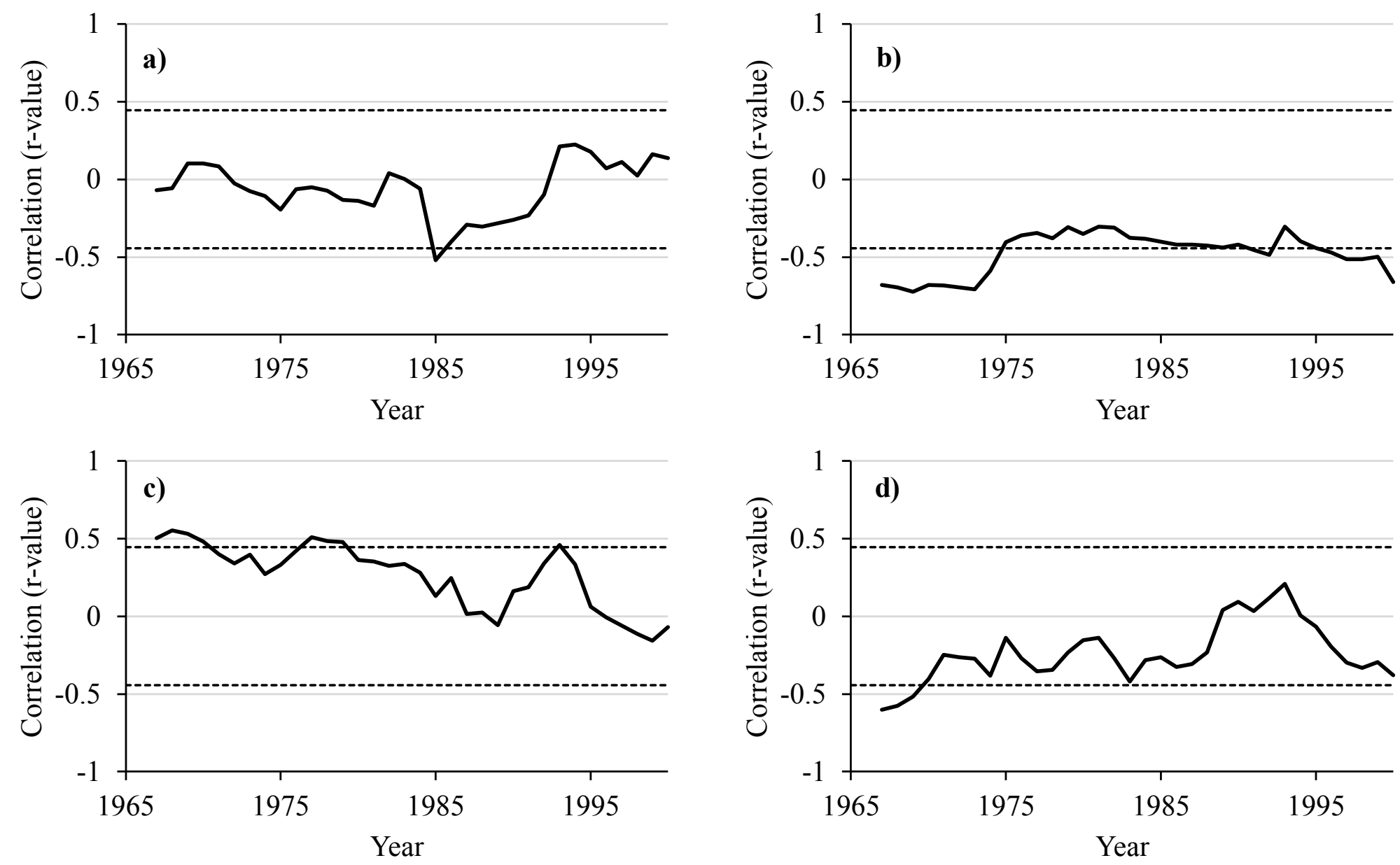

Figure 4.11 - Moving 20-year interval analysis of a) CDU1TRW and minimum JAS temperature; b) CDU2TRW and maximum previous July temperature; c) HL1TRW and minimum June temperature; and d) HL3TRW and maximum previous July temperature. The black lines illustrate the correlation over time and the dashed lines illustrate the bounds of significant values $(r=0.444$ to -0.444$)$. 


\subsubsection{Maximum Density and Local Temperatures}

The best relationship with local temperature is at HLMXD with an average moving correlation of $r=0.610$ with maximum July temperature (Figure 4.12 ). The average correlation value for CDUMXD over the moving correlation is $r=0.439$ (Figure 4.12). HLMXD is a better density record than CDUMXD in terms of the strength of the climate-growth relationship, though both are consistently positive and above the $p=0.05$ significance threshold. 

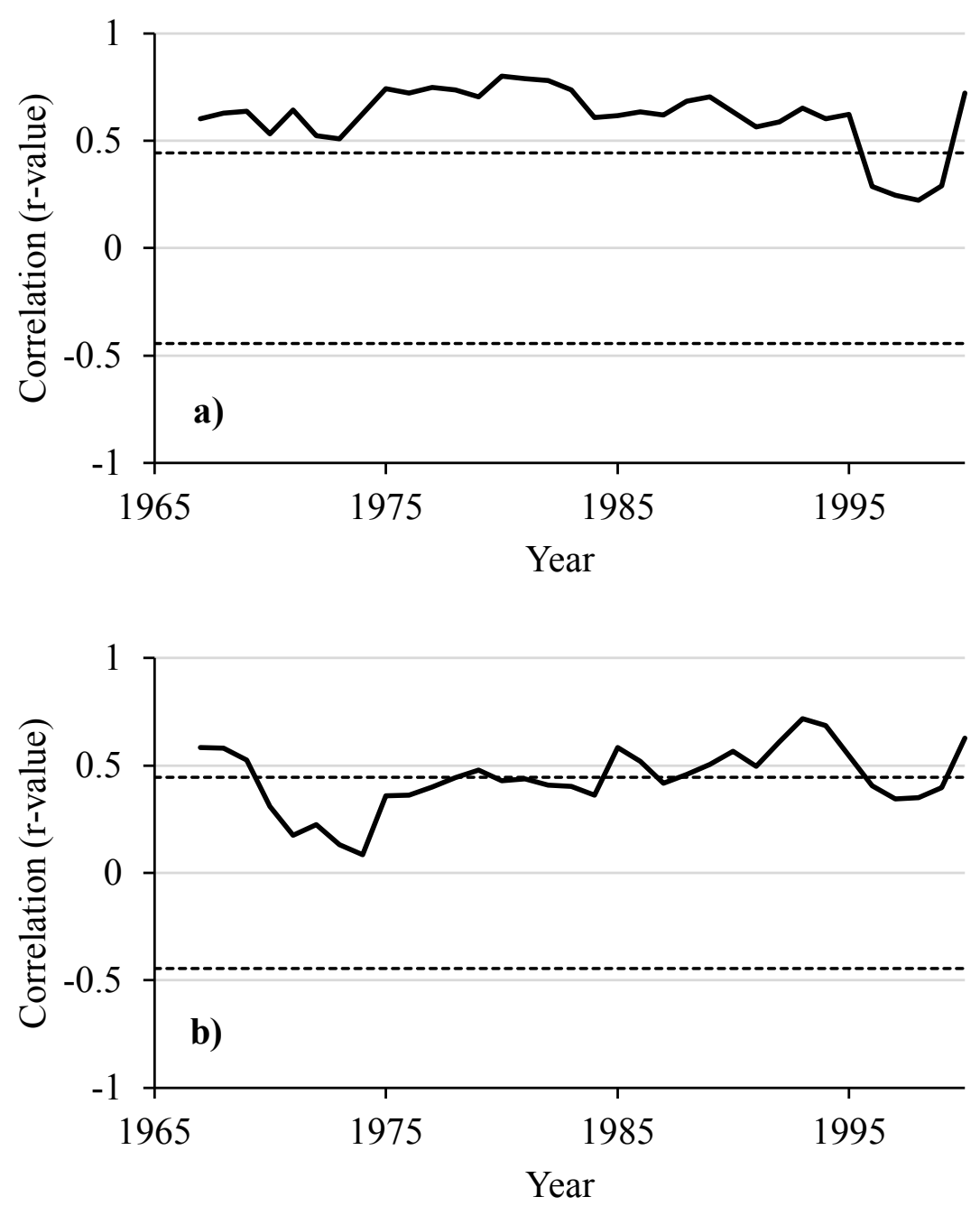

Figure 4.12 - Moving 20-year interval analysis between a) CDUMXD and minimum JAS temperature and b) HLMXD and maximum July temperature. The black lines illustrate the correlation over time and the dashed lines illustrate the bounds of significant values $(r=0.444$ to -0.444$)$. 


\subsubsection{Ring-Width and Regional Temperatures}

Based on the strongest correlations displayed in the stationary analysis, one figure was chosen to best represent the relationship of TRW with regional temperature over a moving interval of 24 years using DendroClim2002 (Biondi and Waikul, 2004). At CDU1, there appears to be a shift in the relationship between tree growth and climate during the 1950-60's (Figure 4.13). Prior to 1960, CDU1TRW is negatively correlated to minimum April and August temperatures (Figure 4.13). After 1960, this shifts to a positive relationship with minimum March and July temperatures during the late $20^{\text {th }}$ century (Figure 4.13). During the later portion of the record, few notable relationships are noted (Figure 4.13). A similar trend is apparent with CDU2TRW with a shift in sensitivity during the mid-century (Figure 4.13). In the early half of the century, tree growth is negatively correlated with maximum April and September temperatures. During this period, the influence of maximum July temperature appears to be heightened (Figure 4.13).

Correlations with HL1TRW also track a change in the most influential temperature variables affecting tree growth. Early in the century, the most highly correlated variable is minimum April temperature as well as minimum June and July temperatures (Figure 4.13). The most consistent correlations with HL3TRW are with minimum temperature variables (Figure 4.13). As with the other TRW chronologies, minimum April temperatures are important in the first half of the century with negative correlations (Figure 4.13). During the second half of the century from $\sim 1960$ to 1985 , there is a positive relationship with minimum March and July temperatures (Figure 4.13). Late in the $20^{\text {th }}$ century, starting in about 1990 , there is a negative correlation with all 
May temperature variables that dominates the growth trend over the last 20 years (Figures 4.13). 

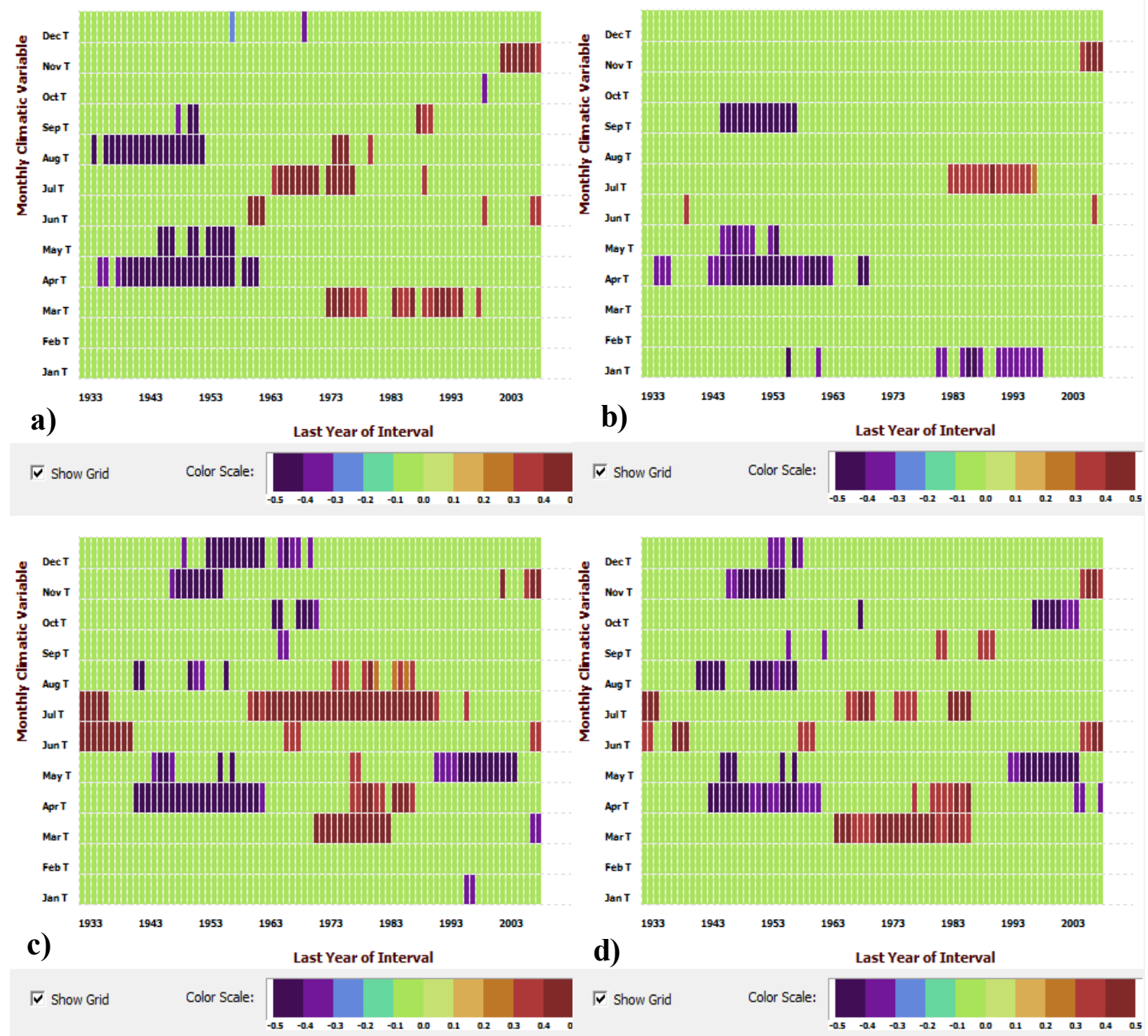

Figure 4.13 - Evolutionary moving window analysis using the composite temperature record between a) CDU1TRW and minimum monthly temperature; b) CDU2TRW and maximum monthly temperature; c) HL1TRW and minimum monthly temperature; and d) HL3TRW and minimum monthly temperature. The colour scale illustrates the range of depicted correlation coefficients, significant at the $95 \%$ confidence interval. 


\subsubsection{Maximum Density and Regional Temperatures}

The MXD chronologies are both best represented by minimum temperature based on the stationary analysis. During the first half of the century, there is a positive relationship between CDUMXD and June temperature, which changes sign during the second half of the century. August temperatures are most important during a 30-year period from about 1950-1980, during which time there are low correlation values with June temperature (Figures 4.14). The best correlation with temperature and CDUMXD is with average minimum August temperature $(r=0.290, p=0.05)$ over the length of the analysis.

For HLMXD, prior to approximately 1960, only a few intervals are correlated to monthly climate variables, which may be because of sample depth and signal strength prior to this time (Figure 4.14). Following 1960 and extending to the end of the record in 2009, July temperature is positively correlated to growth. Also important is August temperature, though the positive relationship drops off around 1990. The strongest moving correlation values are also with minimum August $(\mathrm{r}=0.411)$ and July temperature $(\mathrm{r}=0.393)$. There are no changes in the sign of the relationship with the most consistently correlated variables (Figure 4.14). 

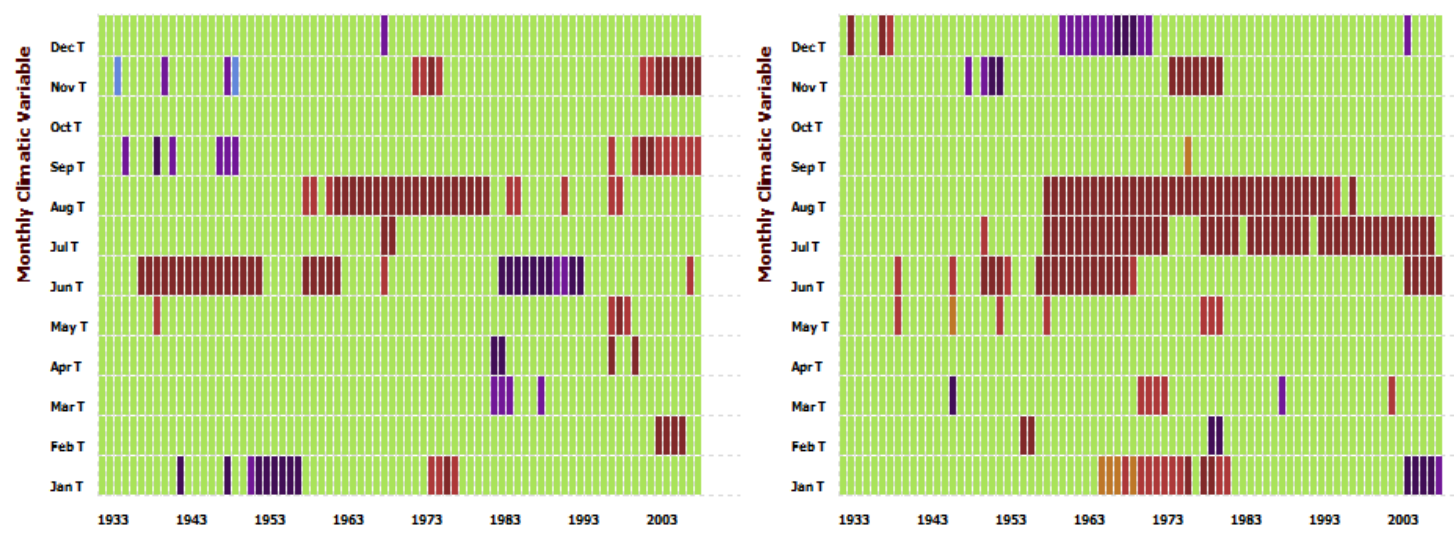

a) Last Year of Interval

b)

$\nabla$ Show Grid Color Scale:

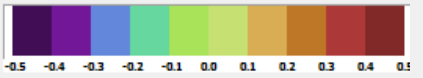

V Show Grid Color Scale:

Figure 4.14 - Evolutionary moving window analysis using the composite temperature record between a) CDUMXD and minimum monthly composite temperature and b) HLMXD and minimum monthly temperature. The colour scale illustrates the range of depicted correlation coefficients, significant at the $95 \%$ confidence interval. 


\subsubsection{Relationship with Composite Seasonal Indices}

A moving window interval analysis was run using the chronologies and the composite seasonal indices (minimum JJA, mean JJA, and maximum JA) over a 24-year evolutionary moving interval using DendroClim2002 (not shown). There are distinct changes in the sign of the TRW relationships with climate over time. At CDU, CDU1TRW exhibits a mixture of negative and positive correlations with all three indices. CDU2TRW displays mostly low and insignificant correlations. HL1TRW is correlated near the beginning of the analysis and also in the mid- to late-century period. Compared to the other chronologies, HL3TRW has little to no correlation to the indices.

The MXD chronologies have more intervals with positive relationships with the indices than the TRW chronologies. CDUMXD displays periods of positive correlation with all three records over the mid-century. Of all chronologies, HLMXD displays the strongest and most consistent positive relationship with the indices, particularly after 1950 and fairly consistently until the end of the record. The strongest CDUMXD correlation is with minimum JJA (0.338) and for HLMXD it is also with minimum JJA (0.499), though the correlations with mean JJA and max JA are also high compared to the monthly moving correlation analysis. 


\section{Chapter 5 - Discussion}

\subsection{White Spruce Radial Growth}

\subsubsection{Ring-Width Measurements}

The ring-width measurements in this research have a wide range of inter-annual variability. The average ring-width values are more conservative and are highly comparable to those measured in white spruce in other studies (e.g. Schweingruber et al., 1993; White, 2010; Muise, 2013). The average ring-width values from this research for all sites range from 0.96 to $0.97 \mathrm{~mm}$. Schweingruber (1993) measured average ring-width values of 0.403 to $1.668 \mathrm{~mm}$ along a white spruce transect from Alaska to Labrador. The average ring-width measurement from White's (2010) research is $0.845 \mathrm{~mm}$ and Muise (2013) presents a range of 0.256 to $0.446 \mathrm{~mm}$ from Yellowknife, Northwest Territories. The TRW values observed in this research are similar to those of Schweingruber et al. (1993) and White (2010) but considerably exceed those of Muise (2013). There is a tendency for narrower and wider ring-width values at HL (0.25 to $3.63 \mathrm{~mm})$ as opposed to $\mathrm{CDU}(0.31$ to $2.75 \mathrm{~mm})$, possibly an indication of greater climatic sensitivity (Fritts, 1976) at the more northerly location.

\subsubsection{Density Measurements}

The maximum density values vary within a more narrow range than the ringwidth values. The least dense measurement is $0.65 \mathrm{~g} \mathrm{~cm}^{-3}$ (HLMXD) and the most dense is $1.64 \mathrm{~g} \mathrm{~cm}^{-3}$ (HLMXD). The average MXD values are nearly identical between the density chronologies, being $0.99 \mathrm{~g} \mathrm{~cm}^{-3}$ at CDU and $1.0 \mathrm{~g} \mathrm{~cm}^{-3}$ at HL. These values are akin to the average values of Schweingruber's CANA172 and CANA173 chronologies of $0.998 \mathrm{~g} \mathrm{~cm}^{-3}$. The values observed at CDU and HL are on the higher end of the average 
CDU maximum density measurements of Schweingruber's (1993) which range from 0.584 to $0.952 \mathrm{~g} \mathrm{~cm}^{-3}$.

\subsubsection{Summary Statistics}

The TRW and MXD series express series intercorrelation (SI) and mean sensitivity (MS) statistics comparable with those of other regional studies (Table 5.1;

5.2). Mean sensitivity values lower than 0.19 are indicative of low sensitivity between annual growth from year to year, compared to values above 0.3 that are representative of highly climate sensitive trees (Fritts, 1976; Grissino-Mayer, 2001). The TRW values for this research are considered moderately sensitive to climate according to this metric, although MS may be more valuable as a relative comparison between sites of the same tree species (Table 5.1). 
Table 5.1 - A comparison of TRW chronology summary statistics (series intercorrelation and mean sensitivity) from CDU and HL to other northern white spruce chronologies.

\begin{tabular}{lccccccc}
\hline & CDU1 & CDU2 & HL1 & HL3 & Yellowknife, & Napaktok & El Grande \\
& TRW & TRW & TRW & TRW & NT $^{1}$ & Bay, NL ${ }^{2}$ & Lake, NL \\
\hline SI & 0.500 & 0.500 & 0.575 & 0.573 & 0.515 to & 0.581 & 0.621 \\
& & & & & 0.590 & & \\
MS & 0.239 & 0.266 & 0.260 & 0.263 & $\begin{array}{c}0.163 \text { to } \\
0.228\end{array}$ & 0.194 & 0.198 \\
& & & & & & \\
\hline
\end{tabular}

${ }^{1}$ Muise, 2013

${ }^{2}$ White, 2010 
Table 5.2 - A comparison of MXD chronology summary statistics (series intercorrelation and mean sensitivity) from CDU and HL to other northern white spruce chronologies.

\begin{tabular}{lcccccc}
\hline & $\begin{array}{c}\text { CDU } \\
\text { MXD }\end{array}$ & $\begin{array}{c}\text { HL } \\
\text { MXD }\end{array}$ & CANA172 $^{1}$ & CANA173 $^{1}$ & $\begin{array}{c}\text { Napaktok } \\
\text { Bay, NL }\end{array}$ & $\begin{array}{c}\text { El Grande } \\
\text { Lake, NL }\end{array}$ \\
\hline SI & 0.472 & 0.552 & 0.567 & 0.579 & 0.396 & 0.409 \\
MS & 0.078 & 0.084 & 0.085 & 0.101 & 0.211 & 0.233 \\
\hline
\end{tabular}

${ }^{1}$ International Tree Ring Database (ITRDB)

${ }^{2}$ White, 2010 


\subsection{White Spruce Climate Response}

\subsubsection{Climate and Tree-Ring Proxies}

Based on the strength of the results of the climate analysis, MXD is indeed a better temperature proxy than TRW. In this specific case however, there may be sample depth limitations (Figure 4.10) that are potentially lowering the strength of the climate signal of the MXD index. As noted in recent research (e.g. Briffa et al., 2002; Grudd, 2008; Esper et al., 2012), the climate response in both the stationary and moving window analyses illustrates the preservation of the growing season climate signal in the maximum density chronologies, especially in HLMXD (Figure 4.14b), that is not present in the TRW chronologies. All of the summer (May-August) MXD correlations are higher than the TRW correlations for the same variables, where there are often no significant TRW correlations.

Upon analysis of the composite temperature-growth relationship of the TRW chronologies over the period from 1910 to 2009, a single consistent correlation appeared among them, an inverse relationship with maximum July temperatures of the previous growing season. This could be an indication of growth inhibition late in the growing season resulting from moisture stress and affecting the development of earlywood the following spring (Kozlowski et al., 1991). However, no other consistent response to growing season temperatures are observed among the TRW chronologies, although research suggests the strong potential influence of growing season temperature on tree growth in this region (Fritts, 1976; Körner, 1998; Richardson and Friedland, 2009). This result confirms the presence of divergence within the TRW chronologies and the poor quality of the index as a temperature proxy. 
Warmer winter (Natural Resources Canada, 2014) and spring temperatures

(Figures $3.4 ; 3.6$ ) since 1957 at the study sites appear to mark a phenological shift in the initiation of earlywood growth at CDU and HL. Hoye et al. (2007) and Post et al. (2009) both document rapid changes in the phenology of Arctic plant and animal species, with the timing of spring events occurring on average two weeks earlier than in 1996 (Hoye et al., 2007). Spring events tend to be limited by snow cover conditions (Hoye et al., 2007), and with rising temperatures and more precipitation falling as rain rather than snow in the Canadian Arctic (Natural Resources Canada, 2014), these events are happening earlier. A shift toward the earlier initiation of growth in the white spruce ring-width series is illustrated in the moving window climate analysis (Figure 4.13). At CDU and HL, April temperatures were limiting to growth in the early half of the last century. However, following 1960, March temperatures are observed to have a positive effect on growth. Research in Alaska by Stone et al. (2001) also support the earlier initiation of snowmelt by 8 days since the 1960s, possibly influencing earlier growth in northern trees.

\subsubsection{Climate Extremes and Tree Growth}

As northern climate continues to change rapidly, the tree species growing in these environments will be required to adapt to survive. Monthly or annual climatic means are typically used to understand the climate-growth relationships of tree species (Zimmerman et al., 2009), however, Zimmerman et al. (2009) present evidence that climate extremes may be more valuable in understanding the growth response under changing climatic conditions, and to improve the predictive power of species distribution models in conjunction with variables representing mean temperatures. 
The results illustrate that both ring-width and maximum density chronologies are more sensitive to minimum and maximum temperatures than to mean monthly or seasonal temperature indices, an indication of the rapid changes occurring at the study locations. Reyer et al. (2013) also present arguments that support the importance of extremes in understanding future plant species distributions and further notes that plants are vulnerable to moisture stress under conditions with higher variability in temperature and precipitation regimes, as is the case in the Northwest Territories under climate change conditions.

\subsection{Site-Specific Climate Signals}

The climate analyses presented in this thesis have demonstrated the importance of growing season temperature and precipitation to white spruce growth. The strongest climate relationships with composite temperature were with the HL chronologies, at the northern extent of tree-line (Table 4.8). The CDU chronologies were more responsive to precipitation, and this relationship was heightened in the maximum density record. June precipitation is in fact the strongest climate relationship with CDUMXD $(r=0.473, p<$ 0.05), although high correlations are also observed with the seasonal indices of the composite climate record (Table 4.8). Within the MXD chronologies, CDUMXD also expresses weaker temperature signals than HLMXD. Porter et al. (2013) observed a climate response characteristic of divergence at CDU2 but not at CDU1. There is a chance that combining series from both CDU sites into the same density chronology may have masked distinct climate signals, however without their merger, the resulting MXD chronology would not have been as strongly correlated to climate. It may be the case that precipitation limits latewood development at CDU1 rather than temperature. 
Husky Lakes and Campbell Dolomite Uplands appear to have different primary climate-growth responses. This difference may arise from the unique nature of the physical environment at CDU, where shallow soils and rocky substrate affect growth trends. Szeicz and MacDonald (1996) developed a 930-year long TRW chronology from white spruce nearest to the CDU2 site of this research. The authors determined that this location was highly moisture sensitive as the chronologies exhibited inverse correlations with past-year growing season temperature and positive correlations to late winter and spring precipitation of the current growing season over an analysis period from 19291990. These results are similar to those observed in this research at CDU. This moisture sensitivity is likely as a result of the growth substrate of the trees where ground water is unavailable, making snowmelt vital to spring growth.

\subsection{Divergence in White Spruce}

Numerous studies have lauded the potential of maximum density as an index capable of tracking temperature, even during the period when divergence has been observed in ring-width indices (Schweingruber et al., 1993; Frank and Esper, 2005; Andreu-Hayles et al., 2011; Anchukaitis et al., 2013). Results of the climate analyses in Chapter 4 reveal the influence of divergence on the CDU and HL ring-width chronologies through their low climate sensitivity, as hypothesized in Chapter 1.

In this research, divergence was determined to be present in the TRW chronologies on the basis of the weak and inconsistent climate signals calculated. Upon further examination of the TRW temperature-growth relationship, divergence in the ringwidth series may mark the onset of a new equilibrium in the temperature-growth relationship of white spruce in the Northwest Territories. There are no consistent 
temperature relationships for the current growing season in the TRW chronologies, but there appear to be two distinct periods where different climate variables are important. This shift (as discussed in section 5.2.1) is centered on the 1950 to 1960 period, identified in regional studies as the onset of divergence (Briffa et al., 1998a; Lloyd and Fastie, 2002; Davi et al., 2003; Porter and Pisaric, 2011). On the basis of the strength of the temperature-growth relationships of the MXD chronologies, divergence is believed to be absent from this index. No shifts in the sign of the most important temperature variables are observed in MXD chronologies (Figure 4.12), nor do the primary influences on MXD (minimum June-August temperatures) change over time (Figure 4.14).

\subsection{Reconstruction Potential of Maximum Density}

Based on the strength of the climate-growth relationship with the MXD chronologies, the potential to develop a precipitation reconstruction for CDU and a minimum JJA temperature reconstruction for HLMXD was assessed using split-period calibration-verification. Response and transfer functions were created and tested using the classic verification statistics reduction of error (RE) and the coefficient of efficiency (CE). Neither verification test was successfully passed by any of the splits for either of the reconstructions. The fluctuations in signal strength over the instrumental period, as illustrated in Figure 4.10, may have detrimentally affected the ability of the regression

model to reconstruct climate, but that with increased sample depth the performance of the MXD proxy would greatly exceed that of TRW.

\subsection{Impact of Arctic warming on white spruce growth}

The climate-growth relationships described in this thesis contribute insight into the future growth of white spruce at CDU and at tree-line in the Northwest Territories. At 
tree-line at the Husky Lakes study site, the primary influences on tree growth are minimum growing season temperatures. If average summer temperatures warm, minimum and maximum temperatures are likely to do the same, provided the actual range of temperature variability remains stable. With warming temperatures, Schweingruber et al. (1993) has suggested increases in tree growth, while more recent research by D'Arrigo et al. (2004) at tree-line in Yukon suggest declines in tree growth on the basis of exceeding temperature thresholds.

The idea of a temperature threshold to tree growth put forth by Barber et al. (2000), Lloyd and Fastie (2002), D'Arrigo et al. (2004), and Wilmking et al. (2004) is supported by the TRW climate-growth relationships presented in this research. Following temperature increases in northern regions over the $20^{\text {th }}$ century, the ring-width indices at CDU cease to respond to temperature variables in a consistent manner (Figure 4.13a, b). This temperature threshold is believed to cause a decline in photosynthetic activity in affected trees (Kramer and Kozlowski, 1979). A further link to tree mortality resulting from climate warming has been identified by Allen et al. (2010) based on a study period from 1985 to 2009 in North America.

Warming may lengthen the growing season at $\mathrm{CDU}$ and $\mathrm{HL}$ and result in more growth until moisture stress becomes limiting (D'Arrigo et al., 2004). Past research has documented temperature-induced drought stress, namely Szeicz and MacDonald (1996), D'Arrigo et al. (2004), and Epstein et al. (2004) among others. While moisture stress is highly likely at CDU given the physical site characteristics, it is unlikely at HL given the abundance of moisture observed during field sampling. At HL, the entire growing season could be extended, while at CDU it may simply contribute to earlier growth initiation and 
termination. The timing of tree growth may be transitioning to the new reality of earlier snow melt seasons that better correspond to peaks in solar radiation (April - June; Hare and Ritchie, 1972) and to temperature-induced drought stress later in summer. 


\section{Chapter 6 - Conclusion}

\subsection{Summary}

The main goals of this research were to examine the climate-growth relationship of TRW and MXD. The research questions asked were:

1. Do TRW and MXD respond similarly to climate conditions over time?

2. Can divergence-free temperature reconstructions be developed using MXD chronologies?

Further objectives were developed to guide answering the primary research questions: 1) to develop white spruce TRW and MXD chronologies near the Northwest Territories tree-line, 2) to evaluate the sensitivity of TRW and MXD chronologies to climate variables, and 3) to assess the temporal stability of white spruce climate-growth relations. First, white spruce samples were collected from two sites at tree-line in the Northwest Territories. The sample sites were distinctly different in terms of physical characteristics. The Campbell Dolomite Uplands south of Inuvik are an exposed bedrock formation characterized by a thin soil layer and rocky substrate. Husky Lakes is located further north and is characterized by more mesic conditions and thicker soils. The living and subfossil samples collected at these sites were used to develop four ring-width chronologies and two maximum density chronologies. The ring-width chronologies were prepared at Carleton University using standard dendrochronological processing methods. Measurements of maximum density were taken at the University of Victoria's Tree Ring Laboratory (UVTRL) using x-ray densitometry. These measurements were crossdated against the ring-width chronologies to establish and/or confirm growth years. No measures were taken to separate TRW series with different climate responses as the aim 
was to compare the strengths of the two proxy indices in their traditionally used forms. More specifically, the chronologies were simply processed and detrended using standard dendrochronological methods.

Standardization of the ring-width and maximum density measurements was done using Melvin and Briffa's (2008) signal-free (SF) method. For CDU, the final ring-width chronologies contains a total of 317 series spanning 1158 to $2012 \mathrm{CE}$ (CDU1TRW) and 1025 to 2012 CE (CDU2TRW). The density chronology for CDU is 705 years long, from 1321 to $2012 \mathrm{CE}$ and contained 70 series. The HL ring-width chronologies contained a total of 219 series and spans 1321 to $2012 \mathrm{CE}$ (HL1TRW) and 1383 to $2012 \mathrm{CE}$ (HL3TRW).

In order to meet the second objective, the TRW and MXD chronologies were statistically compared to local and regional climate variables to assess their sensitivity. Climate-growth analyses of these chronologies utilized composite temperature data compiled by Porter (2013) and local station data from Inuvik and Tuktoyaktuk. Analysis of the relationship involved the calculation of Pearson product-moment correlation coefficients for minimum, mean, and maximum monthly temperature and summed monthly precipitation over a 16-month window. Stationary correlation analyses revealed a single consistent correlation among all four ring-width chronologies; an inverse relationship with maximum July temperatures of the previous growing season. The absence of strong correlations with current year growing season temperatures confirmed the hypothesis presented in Chapter 1 that divergence is indeed present in the TRW chronologies, as temperature is highly limiting in the study region. 
In the stationary analysis, minimum composite August temperatures were most influential to MXD, although correlations with June and July temperatures were also significant. Numerous other correlations with growing season temperatures were also found. Correlations at the local level were higher than those with regional climate data but illustrate the same importance of growing season temperatures to growth. Results of the stationary correlation analysis further confirmed the strength of MXD as a proxy for temperature in northern regions as the index was highly responsive to temperature variables. To partly answer question 1 , the stationary analysis indicated a difference in the response of TRW and MXD to the same temperature variables.

The third and final objective involved conducting a moving interval analysis of the climate-growth relationship with TRW and MXD in order to evaluate the strength of this relationship over time. As in the stationary analysis, TRW was poorly correlated with growing season temperature, further confirming the presence of divergence within the chronology. The relationship between MXD and temperature was once again strong, with the correlation values remaining high throughout the moving window analysis. Due to the strength of the climate relationship with the maximum density chronologies, divergence was posited to be absent within this index. Fluctuations in the strength of correlations with climate variables were attributed to periods of low EPS. These results indicated that TRW and MXD respond differently to climate variables over time and that the relationship between climate and MXD is stronger than that with TRW.

In order to further address question 2, an attempt was made to reconstruct growing season temperatures for the length of the MXD record, however, verification statistics indicated a regression model with poor skill. This is likely due to the low sample 
depth of the density chronology over the $21^{\text {st }}$ century, affecting the strength of the common climate signal. Although a reconstruction could not be developed, the results of this research support the ability of MXD to preserve and reconstruct divergence-free temperature reconstructions.

\subsection{Recommendations for Future Research}

This study found that trees growing along the northernmost extent of tree-line exhibited sensitivity to temperature variables. Additional samples from tree-line sites should be collected for densitometric analysis in order to increase the signal strength and coherence. The development of additional MXD chronologies would allow for the development of a multi-centennial divergence-free MXD chronology that could be used to reliably recreate past temperatures for this region. A comparison between TRW and MXD temperature reconstructions would further solidify the importance of MXD as a valuable tree-ring proxy record. The divergence-free temperature reconstruction could be verified against other proxies to further examine the strength of the MXD proxy. 


\section{References}

ACIA (2005). Arctic climate impact assessment. New York: Cambridge University Press, 1042.

Anchukaitis, K. J., D’Arrigo, R. D., Andreu-Hayles, L., Frank, D., Verstege, A., Curtis, A., ... \& Cook, E. R. (2013). Tree-Ring-Reconstructed Summer Temperatures from Northwestern North America during the Last Nine Centuries. Journal of Climate, 26(10), 3001-3012. doi:10.1175/JCLI-D-11-00139.1

Andreu-Hayles, L., D’Arrigo, R., Anchukaitis, K. J., Beck, P. S. A, Frank, D., \& Goetz, S. (2011). Varying boreal forest response to Arctic environmental change at the Firth River, Alaska. Environmental Research Letters, 6(4), 045503. doi:10.1088/1748-9326/6/4/045503

Baldocchi, D., Kelliher, F. M., Black, T. A., \& Jarvis, P. (2000). Climate and vegetation controls on boreal zone energy exchange. Global Change Biology, 6(S1), 69-83. doi:10.1046/j.1365-2486.2000.06014.x

Barber, V. A, Juday, G. P., \& Finney, B. P. (2000). Reduced growth of Alaskan white spruce in the twentieth century from temperature-induced drought stress. Nature, 405(6787), 668-73. doi:10.1038/35015049

Begin, C., Michaud, Y., \& Archambault, S. (2001). Tree-ring evidence of recent climate changes in the Mackenzie Basin, Northwest Territories. Bulletin of the Geological Survey of Canada, 547, 65-77.

Biondi, F., \& Waikul, K. (2004). DENDROCLIM2002: A C++ program for statistical calibration of climate signals in tree-ring chronologies. Computers \& Geosciences, 30(3), 303-311. doi:10.1016/j.cageo.2003.11.004

Black, R.A., \& Bliss, L.C. (1980). Reproductive ecology of Picea mariana (Mill.) BSP, at tree line near Inuvik, Northwest Territories, Canada. Ecological Monographs 50, $331-354$.

Bloomfield, P. (2000). Fourier analysis of time series: An introduction. New York: John Wiley \& Sons, 261. 
Bonan, G. B. (2008). Forests and climate change: forcings, feedbacks, and the climate benefits of forests. Science (New York, N.Y.), 320(5882), 1444-9. doi:10.1126/science.1155121

Bradley, R.S. (2011). High resolution paleoclimatology. In M.K. Hughes, T.W. Swetnam \& H.F. Diaz (Eds.), Developments in Paleoenvironmental Research, Vol. 11., 3-17. Dordrecht; New York: Springer.

Briffa, K. R., \& P. D. Jones, (1990). Basic chronology statistics and assessment. In E. R. Cook, and L. A. Kairiukstis (Eds.), Methods of Dendrochronology: Applications in the Environmental Sciences, 137-152. Dordrecht, Netherlands: Kluwer Academic Publishers.

Briffa, K. R., Osborn, T. J., \& Schweingruber, F. H. (2004). Large-scale temperature inferences from tree rings: a review. Global and Planetary Change, 40(1-2), 11-26. doi:10.1016/S0921-8181(03)00095-X

Briffa, K., Schweingruber, F., \& Jones, P. (1998a). Reduced sensitivity of recent treegrowth to temperature at high northern latitudes. Nature, 391(February), 678-682.

Briffa, K.R., Bartholin, T.S., Eckstein, D., Jones, P.D., Karlén, W., Schweingruber, F.H., \& Zetterberg, P. (1990). A 1400-year tree-ring record of summer temperatures in Fennoscandia. Nature, 346, 434-439.

Briffa, K.R., Schweingruber, F.H., Jones, P.D., Osborn, T.J., Harris, I., Shiyatov, S.G., Vaganov, E.A., \& Grudd, H. (1998b). Trees tell of past climates: but are they speaking less clearly today? Philosophical Transactions of the Royal Society, Biological Sciences 353, 65-73.

Brooks, J. R., Flanagan, L. B., \& Ehleringer, J. R. (1998). Responses of boreal conifers to climate fluctuations: indications from tree-ring widths and carbon isotope analyses. Canadian Journal of Forest Research, 28(4), 524-533. doi:10.1139/x98-018

Brown, J., Ferrians, Jr. O.J., Heginbottom, J.A., \& Melnikov, E.S. 1998 (rev. 2001) Circumarctic map of permafrost and ground ice conditions. Boulder, CO: National Snow and Ice Data Center. Digital media.

Brown, R.J.E., \& Péwé, T.L. (1973). Distribution of permafrost in North America and its relationship to the environment: A review, 1963-1973. In Permafrost: North 
American Contribution, Second International Conference, 71-100. Washington, DC: National Academy of Sciences.

Bryson, R.A. (1966). Air masses, streamlines, and the boreal forest. Geographical Bulletin 8, 228-269.

Bunn, A. G. (2008). A dendrochronology program library in R (dplR). Dendrochronologia, 26(2), 115-124. doi:10.1016/j.dendro.2008.01.002

Büntgen, U., Frank, D. C., Schmidhalter, M., Neuwirth, B., Seifert, M., \& Esper, J. (2005). Growth/climate response shift in a long subalpine spruce chronology. Trees, 20(1), 99-110. doi:10.1007/s00468-005-0017-3

Burn, C.R. (1997). Cryostratigraphy, paleogeography, and climate change during the early Holocene warm interval, western Arctic coast, Canada. Canadian Journal of Earth Sciences, 34, 912-925.

Burn, C.R., \& Kokelj, S.V. (2009). The environment and permafrost of the Mackenzie Delta area. Permafrost and Periglacial Processes 20, 83-105.

Callaghan, T.V., Björn, L.O., Chernov, Y.I., Chapin III, F.S., Christensen, T.R., Huntley, B., Ims, R., Johansson, M., Jolly, D., Matveyeva, N.V., Panikov, N., Oechel, W.C. \& Shaver, G.R. (2005) Arctic tundra and polar ecosystems. In C. Symon, L. Arris, \& B. Heal (Eds.) Arctic Climate Impact Assessment. Cambridge University Press, Cambridge, 243-351.

Carlson, M., Wells, J., \& Roberts, D. (2009). The carbon the world forgot: conserving the capacity of Canada's Boreal Forest region to mitigate and adapt to climate change. Seattle, WA, and Ottawa, ON: Boreal Songbird Initiative and Canadian Boreal Initiative, 33.

Chapin III, F.S., McGuire, A.D., Randerson, J., Pielke Sr., R., Baldocchi, D., Hobbie, S.E., Roulet, N., Eugster, W., Kasischke, E., Rastetter, E.B., Zimov, S.A., \& Running, S.W. (2000). Arctic and boreal ecosystems of western North America as components of the climate system. Global Change Biology, 6(1), 211-223.

Cook, E. R. (1985). A time series analysis approach to tree ring standardization. Ph.D. dissertation, University of Arizona, Tucson, USA, 171. 
Cook, E. R., \& Peters, K. (1997). Calculating unbiased tree-ring indices for the study of climatic and environmental change. The Holocene, 7(3), 361-370. doi:10.1177/095968369700700314

Cook, E. R., Esper, J., \& D’Arrigo, R. D. (2004). Extra-tropical Northern Hemisphere land temperature variability over the past 1000 years. Quaternary Science Reviews, 23(20-22), 2063-2074. doi:10.1016/j.quascirev.2004.08.013

Cook, E.R., \& Briffa, K.R., (1990). Methods of calibration, verification, and reconstruction. In Cook, E.R., \& Kairiukstis, L.A. (Eds.), Methods of Dendrochronology, 104-123. Dordrecht, Netherlands: Kluwer Academic Publishers.

Cook, E.R., \& Kairiukstis, L.A. (1990). Methods of Dendrochronology: Applications in the Environmental Sciences. Boston: Kluwer Academic Publishers, 394.

Cook, E.R., \& Peters, K. (1981). The smoothing spline: a new approach to standardizing forest interior tree-ring width series for dendroclimatic studies. Tree-Ring Bulletin $41,45-53$.

Costanza, R., d'Arge, R., de Groot, R., Farber, S., Grasso, M., Hannon, B., .. \& v van den Belt, M. (1997). The value of the world's ecosystem services and natural capital. Nature, 387(6630), 253-260. doi:10.1038/387253a0

D’Arrigo, R. D., Kaufmann, R. K., Davi, N., Jacoby, G. C., Laskowski, C., Myneni, R. B., \& Cherubini, P. (2004). Thresholds for warming-induced growth decline at elevational tree line in the Yukon Territory, Canada. Global Biogeochemical Cycles, 18(3), n/a-n/a. doi:10.1029/2004GB002249

D'Arrigo, R., Jacoby, G.C., \& Free, R.M. (1992). Tree-ring width and maximum latewood density at the North American tree line: parameters of climatic change. Canadian Journal of Forest Research, 22, 1290-1296.

D’Arrigo, R., Wilson, R., Liepert, B., \& Cherubini, P. (2008). On the "Divergence Problem" in northern forests: A review of the tree-ring evidence and possible causes. Global and Planetary Change, 60(3-4), 289-305.

doi:10.1016/j.gloplacha.2007.03.004

Daubenmire, R. (1954). Alpine timberlines in the Americas and their interpretation. Butler University Botanical Studies, 11, 119-136. 
Davi, N.K., Jacoby, G.C., \& Wiles, G.C. (2003). Boreal temperature variability inferred from maximum latewood density and tree-ring width data, Wrangell Mountain region, Alaska. Quaternary Research, 60, 252-262. doi:10.1016/S00335894(03)00115-7

Dye, D. G. (2002). Variability and trends in the annual snowcover cycle in Northern Hemisphere land areas, 1972-2000. Hydrological Processes 16, 3065-3077.

Ecosystem Classification Group. (2012). Ecological Regions of the Northwest Territories - Southern Arctic. Department of Environment and Natural Resources, Government of the Northwest Territories, Yellowknife, NT, Canada. $x+170$ pp. + insert map.

Ecosystem Classification Group. 2007 (rev. 2009). Ecological Regions of the Northwest

Territories - Taiga Plains. Department of Environment and Natural Resources, Government of the Northwest Territories, Yellowknife, NT, Canada. viii + 173 pp. + folded insert map.

Elliott-Fisk, D. (1983). The stability of the northern Canadian tree limit. Annals of the Association of American Geographers, 73(4), 560-576.

Epstein, H. E., Beringer, J., Gould, W. A., Lloyd, A. H., Thompson, C. D., Chapin, F. S., ... \& Walker, D. A. (2004). The nature of spatial transitions in the Arctic. Journal of Biogeography, 31(12), 1917-1933. doi:10.1111/j.1365-2699.2004.01140.x

Esper, J., \& Schweingruber, F. (2004). Large-scale treeline changes recorded in Siberia. Geophysical Research Letters, 31(6), L06202. doi:10.1029/2003GL019178

Esper, J., Cook, E., \& Krusic, P. (2003). Tests of the RCS method for preserving lowfrequency variability in long tree-ring chronologies. Tree Ring Research, 59, 81-98.

Fleming, M., \& Chapin, F. (2000). Geographic patterns and dynamics of Alaskan climate interpolated from a sparse station record. Global Change Biology, 6(S1), 49-58.

Frank, D., \& Esper, J. (2005). Characterization and climate response patterns of a highelevation, multi-species tree-ring network in the European Alps.

Dendrochronologia, 22(2), 107-121. doi:10.1016/j.dendro.2005.02.004

Fritts, H.C. (1969). Bristlecone pine in the White Mountains of California: Growth and ring-width characteristics. Papers of the Laboratory of Tree-Ring Research, 4. Tucson, AZ, USA: University of Arizona Press.

Fritts, H.C. (1976). Tree Rings and Climate. London, UK: Academic Press, 567. 
Fritts, H.C. (2001). Tree Rings and Climate. Caldwell, New Jersey, USA: Blackburn Press, 567.

Glerum, C. (1980). Food sinks and food reserves of trees in temperate climates. New Zealand Journal of Forest Science, 10, 176-185.

Grace, J. (2002). Impacts of Climate Change on the Tree Line. Annals of Botany, 90(4), 537-544. doi:10.1093/aob/mcf222

Grace, J., Allen, S., \& Wilson, C. (1989). Climate and meristem temperatures of plant communities near the tree-line. Oecologia 79: 198-204.

Grissino-Mayer, H.D. (2001). Evaluating cross-dating accuracy: A manual and tutorial for the crossdating program COFECHA. Tree-ring Research 57, 205-221.

Grudd, H. (2008). Torneträsk tree-ring width and density ad 500-2004: A test of climatic sensitivity and a new 1500-year reconstruction of north Fennoscandian summers. Climate Dynamics, 31(7-8), 843-857. doi:10.1007/s00382-007-0358-2

Hadley, J. L., \& Smith, W. K. (1983). Influence of wind exposure on needle desiccation and mortality for timberline conifers in Wyoming, U.S.A. Arctic and Alpine Research 15, 127-135.

Hansen, E., \& Karl, T. (2013). 2012 global temperatures. NOAA/NASA. Retrieved online April 11, 2013 from www.nasa.gov/topics/earth/features/2012-temps.html.

Hare, F. (1950). Climate and zonal divisions of the boreal forest formation in Eastern Canada. Geographical Review 40(4), 615-635.

Hare, F., \& Ritchie, J.C. (1972). The boreal bioclimates. Geographical Review 62(3): $333-365$.

Haygreen, J.G., \& Bowyer, J.L. (1996). Wood Science and Forest Products - An Introduction (3rd ed.). Ames: Iowa State University Press.

Henderson, J.P., \& Grissino-Mayer, H.D. (2009). Climate-Tree Growth Relationships of Longleaf Pine (Pinus palustris Mill.) in the Southeastern Coastal Plain, U.S.A. Dendrochronologia 27(1), 31-43.

Hoadley, R.B. (1990). Identifying wood: Accurate results with simple tools. Newtown, CT, USA: Taunton Press, 240.

Holmes, R.L. (1983). Computer assisted quality control in tree-ring dating and measurement. Tree-Ring Bulletin 43, 69-78. 
Holtmeier, F.K., \& Broll, G. (1992). The influence of tree islands on microtopography and pedoecological conditions in the forest-alpine tundra ecotone on Niwot Ridge, Colorado Front Range, USA. Arctic and Alpine Research 24, 216-228.

Houghton, J. T, Jenkins, G. J., \& Ephraums, J. J. (1990). Climate Change: the IPCC Scientific Assessment. Cambridge: Cambridge University Press, 364.

Hugelius, G., Strauss, J., Zubrzycki, S., Harden, J. W., Schuur, E. a. G., Ping, C. L., .. \& Kuhry, P. (2014). Improved estimates show large circumpolar stocks of permafrost carbon while quantifying substantial uncertainty ranges and identifying remaining data gaps. Biogeosciences Discussions, 11(3), 4771-4822. doi:10.5194/bgd-114771-2014

Hughes, M.K. (2011). Dendroclimatology in high resolution paleoclimatology. In M.K. Hughes, T.W. Swetnam \& H.F. Diaz (Eds.), Developments in Paleoenvironmental Research, Vol. 11., (17-36). Dordrecht; New York: Springer.

IPCC, 2007. Climate change 2007: the physical science basis. In Contribution of

Working Group I to the Fourth Assessment Report of the Intergovernmental Panel on Climate Change. Cambridge: Cambridge University Press, 996.

Jacoby, G. C., \& D'Arrigo, R. D. (1995). Tree ring width and density evidence of climatic and potential forest change in Alaska. Global Biogeochemical Cycles, 9(2), 227-234. doi:10.1029/95GB00321

Jacoby, G.C. Jr., \& D'Arrigo, R. (1989). Reconstructed northern hemisphere annual temperature since 1671 based on high-latitude tree-ring data from North America. Climatic Change 14, 39-59.

Johnson, D. M., Germino, M. J., \& Smith, W. K. (2004). Abiotic factors limiting photosynthesis in Abies lasiocarpa and Picea engelmannii seedlings below and above the alpine timberline. Tree Physiology 24, 377-386.

Kasischke, E.S., Bergen, K., Fennimore, R., Sotelo, F., Stephens, G., Janetos, A., \& Shugart, H.H. (1999). Satellite imagery gives a clear picture of Russia's boreal forest fires. EOS, Transactions of the American Geophysical Union, 80(141), 147.

Kasischke, E.S., Williams, D., \& Barry, D. (2002). Analysis of the patterns of large fires in the boreal forest region of Alaska. International Journal of Wildland Fire 11, $131-144$. 
Kaufman, D. S., Schneider, D. P., McKay, N. P., Ammann, C. M., Bradley, R. S., Briffa, K. R., ... \& Vinther, B. M. (2009). Recent warming reverses long-term arctic cooling. Science (New York, N.Y.), 325(5945), 1236-9.

doi:10.1126/science. 1173983

King, G. M. 2009. Factors influencing the growth of white spruce (Picea glauca) in the Mackenzie Delta, NT. (Unpublished M.Sc. thesis). Carleton University, Ottawa, Canada, 160.

Kirchhefer, A. J. (2001). Reconstruction of summer temperatures from tree-rings of Scots pine (Pinus sylvestris L.) in coastal northern Norway. The Holocene, 11(1), 41-52. doi:10.1191/095968301670181592

Körner, C. (1998). A re-assessment of high elevation treeline positions and their explanation. Oecologia, 115, 445-459.

Kozlowski, T.T., Hughes, J.F., \& Leyton, L. (1966). Patterns of water movement in dormant gymnosperm seedlings. Biorheology 3, 77-85.

Kozlowski, T.T., Kramer, P.J., \& Pallardy, S.G. (1991). The physiological ecology of woody plants. New York, USA: Academic Press.

Kramer, P. J., \& Kozlowski, T. T. (1960). Physiology of Trees. New York, NY: McGrawHill Book Company.

Kuusela, K. (1992). The boreal forests: An overview. In S.A. Dembner, R. Tucker, \& M. Criscuolo (Eds.), Unasylva, 43, 3-13.

Lantz, T. C., Kokelj, S. V., Gergel, S. E., \& Henry, G. H. R. (2009). Relative impacts of disturbance and temperature: persistent changes in microenvironment and vegetation in retrogressive thaw slumps. Global Change Biology, 15(7), 1664-1675. doi:10.1111/j.1365-2486.2009.01917.x

Larsen, J.A. (1980). The boreal ecosystem. New York: Academic Press.

Lebourgeois, F. (2000). Climatic signals in earlywood, latewood and total ring width of Corsican pine from western France. Annals of Forest Science, 57(2), 155-164. doi:10.1051/forest:2000166

Lloyd, A. H., \& Bunn, A. G. (2007). Responses of the circumpolar boreal forest to 20th century climate variability. Environmental Research Letters, 2(4), 045013. doi:10.1088/1748-9326/2/4/045013 
Lloyd, A., \& Fastie, C. (2002). Spatial and temporal variability in the growth and climate response of treeline trees in Alaska. Climatic Change, 481-509.

Loescher, W.H., McCant, T., \& Keller, J.D. (1990). Carbohydrate reserves, translocation, and storage in woody plant roots. HortScience, 25, 274-281.

MacDonald, G., \& Gajewski, K. (1992). The northern tree-line of Canada. In D.G. Janelle (Ed.), Geographical snapshots of North America. New York: Guilford Press, pp. 34-37.

MacDonald, G.M., Velichko, A.A., Kremenetski, C.V., Borisova, O.K., Goleva, A.A., Andreev, A.A., ... \&Gattaulin, V.N. (2000). Holocene tree-line history and climate change across northern Eurasia. Quaternary Research 53, 302-311.

Mann, D.E. (2002). Little Ice Age. In M. C. MacCracken \& J. S. Perry (Eds.), Encyclopedia of Global Environmental Change, Volume 1: The Earth system: physical and chemical dimensions of global environmental change. Chichester: John Wiley \& Sons, pp. 504-509.

Mather, J.R., \& Yoshoika, G.A. (1968). The role of climate in the distribution of vegetation. Annals of the Association of American Geographers 58(1), 29-41.

Matthews, E., Payne, R., Rohweder, M., \& Murray, S. (2000). Pilot analysis of global ecosystems: Forest ecosystems. World Resources Institute, 86.

McGuire, A., \& Anderson, L. (2009). Sensitivity of the carbon cycle in the Arctic to climate change. Ecological Monographs, 79(4), 523-555.

McKenzie, D., Hessl, A. E., \& Peterson, D. L. (2001). Recent growth of conifer species of western North America: assessing spatial patterns of radial growth trends. Canadian Journal of Forest Research, 31(3), 526-538. doi:10.1139/cjfr-31-3-526

McLeod, K.T. (2001). The ecology of Picea glauca (Moench) Voss at its range limits in Northwest Canada. (Unpublished PhD thesis). University of British Columbia, Vancouver, Canada, 212 pp.

Meko, D. M., \& Baisan, C. H. (2001). Pilot study of latewood-width of conifers as an indicator of variability of summer rainfall in the North American monsoon region. International Journal of Climatology, 21(6), 697-708. doi:10.1002/joc.646

Meko, D. M., Woodhouse, C. A., \& Touchan, R. (2014). Klamath / San Joaquin / Sacramento Hydroclimatic Reconstructions from Tree Rings. 
Melvin, T. (2004). Historical growth rates and changing climatic sensitivity of boreal conifers. Ph.D. thesis, Climatic Research Unit, East Anglia, UK, 271.

Melvin, T. M., \& Briffa, K. R. (2008). A “signal-free” approach to dendroclimatic standardisation. Dendrochronologia, 26(2), 71-86.

doi:10.1016/j.dendro.2007.12.001

Miller, G. H., Brigham-Grette, J., Alley, R. B., Anderson, L., Bauch, H. a., Douglas, M. S. V., .. \& W Wolff, E. W. (2010). Temperature and precipitation history of the Arctic. Quaternary Science Reviews, 29(15-16), 1679-1715.

doi:10.1016/j.quascirev.2010.03.001

Morey, P.R. (1973). How trees grow. Studies in Biology 39, 59.

Muise, P.E. (2013). The dendroclimatic signal in white spruce (Picea glauca) ringwidths, central Northwest Territories. (Unpublished MSc. thesis). Carleton University, Ottawa ON, 122.

Natural Resources Canada (2014). Overview of climate change in Canada. Retrieved online from http://www.nrcan.gc.ca/environment/resources/publications/impactsadaptation/reports/assessments/2008/ch2/10321

Oke, T.R. (1978). Boundary Layer Climates (2 ${ }^{\text {nd }}$ Ed.). London: Methuen, 435.

Overland, J. E., Wang, M., Walsh, J. E., \& Stroeve, J. C. (2013). Future Arctic climate changes: Adaptation and mitigation time scales. AGU Publications: Earth's Future, 1-7. doi:10.1002/2013EF000162

Overpeck, J. (1997). Arctic Environmental Change of the Last Four Centuries. Science, 278(5341), 1251-1256. doi:10.1126/science.278.5341.1251

Pallardy, S.G. (2008). Physiology of woody plants. London: Academic Press, 454.

Payette, S., \& Filion, L. (1985). White spruce expansion at the tree line and recent climatic change. Canadian Journal of Forest Research 15: 241-251.

Pisaric, M. F. J., Carey, S. K., Kokelj, S. V., \& Youngblut, D. (2007). Anomalous 20th century tree growth, Mackenzie Delta, Northwest Territories, Canada. Geophysical Research Letters, 34(5). doi:10.1029/2006GL029139

Porter, T. J. (2012). White spruce tree-rings from Arctic tree-line in Old Crow Flats and the Mackenzie Delta, Northwestern Canada: Indicators of past climate change. PhD. dissertation, Carleton University, Ottawa, Canada, 235. 
Porter, T. J., \& Pisaric, M. F. J. (2011). Temperature-growth divergence in white spruce forests of Old Crow Flats, Yukon Territory, and adjacent regions of northwestern North America. Global Change Biology, 17(11), 3418-3430. doi:10.1111/j.13652486.2011.02507.x

Porter, T. J., Pisaric, M. F. J., Field, R. D., Kokelj, S. V., Edwards, T. W. D., deMontigny, P., .. \& LeGrande, A. N. (2013a). Spring-summer temperatures since AD 1780 reconstructed from stable oxygen isotope ratios in white spruce tree-rings from the Mackenzie Delta, northwestern Canada. Climate Dynamics, 42(3-4), 771785. doi:10.1007/s00382-013-1674-3

Porter, T., Pisaric, M., Kokelj, S., \& deMontigny, P. (2013b). A ring-width-based reconstruction of June-July minimum temperatures since AD1245 from white spruce stands in the Mackenzie Delta region, northwestern Canada. Quaternary Research 80, 167-179.

Reasoner, M.A., \& Tinner, W. (2008). Holocene tree-line fluctuations. In V. Gornitz (Ed.), Encyclopedia of Paleoclimatology and Ancient Environments. Dordrecht: Springer, 442-446.

Rehfeldt, G., Wykoff, W., \& Ying, C. (2001). Physiologic plasticity, evolution, and impacts of a changing climate on Pinus contorta. Climatic Change, 50, 355-376.

Richardson, A. D., \& Friedland, A. J. (2009). A Review of the Theories to Explain Arctic and Alpine Treelines Around the World. Journal of Sustainable Forestry, 28(1-2), 218-242. doi:10.1080/10549810802626456

Ritchie, J. (1977). The modern and late Quaternary vegetation of the Campbell-Dolomite Uplands, near Inuvik, NWT, Canada. Ecological Monographs, 47(4), 401-423.

Rossi, S., Deslauriers, A., Griçar, J., Seo, J.-W., Rathgeber, C. B., Anfodillo, T., ... \& Jalkanen, R. (2008). Critical temperatures for xylogenesis in conifers of cold climates. Global Ecology and Biogeography, 17(6), 696-707. doi:10.1111/j.14668238.2008.00417.x

Roy, J. (2001). Terrestrial Global Productivity. San Diego, CA: Academic Press.

Runesson, U.T. (2011). Overview. Faculty of Natural Resources Management, Lakehead University. Retrieved online from 
http://www.borealforest.org/index.php?category=world_boreal_forest\&page= overvi ew

Schweingruber, F., Fritts, H., Bräker, O., Drew, L., \& Schär, E. (1978). The x-ray technique as applied to Dendroclimatology. Tree-Ring Bulletin 38, 61-91.

Schweingruber, F.H., Briffa, K.R., \& Nogler, P. (1993). A tree-ring densitometric transect from Alaska to Labrador. International Journal of Biometeorology 37, 151-169.

Sellers, P., Hall, F., Kelly, R., \& Black, A. (1997). BOREAS in 1997: Experiment overview, scientific results, and future directions. Journal of Geophysical Research, 102(97), 731-769.

Serreze, M. C., \& Francis, J. A. (2006). The Arctic Amplification Debate. Climatic Change, 76(3-4), 241-264. doi:10.1007/s10584-005-9017-y

Serreze, M.C., Barrett, A.P., Stroeve, J.C., Kindig, D.N., \& Holland, M.M. (2009). The emergence of surface-based Arctic amplification. The Cryosphere 3, 11-19.

Serreze, M.C., Walsh, J.E., Chapin, F.S., Osterkamp, T., Dyurgerov, M., Romanovsky, V., Oechel, W.C., Morison, J., Zhang, T., \& Barry, R.G. (2000). Observational evidence of recent change in the northern high-latitude environment. Climatic Change 46, 159-207.

Smith, W. K., Germino, M. J., Hancock, T. E., \& Johnson, D. M. (2003). Another perspective on altitudinal limits of alpine timberlines. Tree Physiology 23, 11011112.

Speer, J.H. (2010). Fundamentals of Tree Ring Research. Tucson, Arizona: The University of Arizona Press, 333.

Stanhill, G., \& Cohen, S. (2001). Global dimming: a review of the evidence for widespread and significant reduction in global radiation with discussion of its probably causes and possible agricultural consequences. Agricultural and Forest Meteorology 107, 255-278.

Stevens, G. C., \& Fox, J.F. (1991). The causes of tree-line. Annual Review of Ecological Systems 22, 171-191.

Stine, A. R., \& Huybers, P. (2014). Arctic tree rings as recorders of variations in light availability. Nature Communications, 5(May), 1-8. doi:10.1038/ncomms4836 
Stokes, M.A., \& Smiley, T.L. (1968). An Introduction to Tree-ring Dating. Tucson, Arizona: The University of Arizona Press.

Stone, R.S., Dutton, E.G., Harris, J.M., \& Longenecker, D. (2001). The advancing date of spring snowmelt in the Alaskan Arctic. Proceedings of the Eleventh Atmospheric Radiation Measurement (ARM) Science Team Meeting, March 1923, 2001, Atlanta, Georgia.

Szeicz, J. M., \& MacDonald, G. M. (1996). A 930-year ring-width chronology from moisture-sensitive white spruce (Picea glauca Moench) in northwestern Canada. The Holocene, 6(3), 345-351. doi:10.1177/095968369600600309

Thurner, M., Beer, C., Santoro, M., Carvalhais, N., Wutzler, T., Schepaschenko, D., ... \& Schmullius, C. (2014). Carbon stock and density of northern boreal and temperate forests. Global Ecology and Biogeography, 23(3), 297-310. doi:10.1111/geb.12125

Tingley, M. P. \& Huybers, P. (2013). Recent temperature extremes at high northern latitudes unprecedented in the past 600 years. Nature 496, 201-205.

Tranquillini, W. (1979). The Physiological Ecology of the Alpine Timberline. New York: Springer-Verlag.

Troll, C. (1973). The upper timberlines in different climatic zones. Arctic and Alpine Research, 5(3), A3-A18.

Vaganov, E.A., Anchukaitis, K.J., \& Evans, M.A. (2011). How well understood are the processes that create dendroclimatic models? A mechanistic model of the climate control on conifer tree-ring growth dynamics. In M.K. Hughes, T.W. Swetnam \& H.F. Diaz (Eds.), Developments in Paleoenvironmental Research, Vol. 11., (37-76). Dordrecht; New York: Springer.

Vaganov, E., M. Hughes, \& Shashkin, A. (2006). Growth Dynamics of Tree Rings: An Image of Past and Future Environments. New York: Springer, 354.Volney, W.J.A., \& Fleming, R.A. (2000). Climate change and impacts of boreal forest insects. Agriculture, Ecosystems \& Environment, 82(1-3), 283-294. doi:10.1016/S01678809(00)00232-2

Wardle, P. (1965). A comparison of alpine timber lines in New Zealand and North America. New Zealand Journal of Botany 3, 113-135. 
Way, D. A., \& Oren, R. (2010). Differential responses to changes in growth temperature between trees from different functional groups and biomes: a review and synthesis of data. Tree Physiology 30, 669-688.

Weller, G., Chapin, F., \& Everett, K. (1995). The Arctic Flux Study: a regional view of trace gas release. Journal of Biogeography, 22(2), 365-374.

White, C. (2010). Comparison of maximum density analysis and ring width measurements: Applications in dendroclimatology. (Upublished BSc. Thesis). Mount Allison University, Sackville, NB, 85 pp.

Wigley, T.M., Briffa, K.R, \& Jones, P.D. (1984). On the average value of correlated time series, with applications in dendroclimatology and hydrometeorology. Journal of Climate and Applied Meteorology 23, 201-213.

Wild, M., Ohmura, A., \& Makowski, K. (2007). Impact of global dimming and brightening on global warming. Geophysical Research Letters, 34(4), L04702. doi:10.1029/2006GL028031

Wilmking, M., D’Arrigo, R., Jacoby, G. C., \& Juday, G. P. (2005). Increased temperature sensitivity and divergent growth trends in circumpolar boreal forests. Geophysical Research Letters 32 L15715. doi:10.1029/2005GL023331

Wilmking, M., Juday, G. P., Barber, V. A., \& Zald, H. S. J. (2004). Recent climate warming forces contrasting growth responses of white spruce at tree-line in Alaska through temperature thresholds. Global Change Biology 10, 1724-1736.

Wilson, R. J. S., \& Luckman, B. H. (2003). Dendroclimatic reconstruction of maximum summer temperatures from upper tree-line sites in Interior British Columbia, Canada. The Holocene 13(6), 851-861.

Wilson, R., D’Arrigo, R., Buckley, B., Büntgen, U., Esper, J., Frank, D., Luckman, B., Payette, S., Vose, R., \& Youngblut, D. (2007). A matter of divergence: tracking recent warming at hemispheric scales using tree ring data. Journal of Geophysical Research 112, D17103, doi: 10.1029/2006JD008318.

Wilson, R.J.S., \& Luckman, B.H. (2002). Tree-ring reconstruction of maximum and minimum temperatures and the diurnal temperature range in British Columbia, Canada. Dendrochronologia 20(3), 1-12. 
Woods Hole Research Center (WHRC) 2014. The boreal forest ecosystem. Retrieved online from http://www.whrc.org/ecosystem/highlatitude/

Yamaguchi, D.K. (1991). A simple method for cross-dating increment cores from living trees. Canadian Journal of Forest Research 21, 414-416.

Young, H.E. (1952) Practical limitations of the dial gauge dendrometer. Ecology 33, $568-570$.

Zimov, S. A., Yoropaev, Y.V., Semiletov, I.P., Davidov, S.P., Prosiannikov, S.F., Chapin III, F.S., Trumbore, S., \& Tyler, S. (1997). North Siberian Lakes: A Methane Source Fueled by Pleistocene Carbon. Science, 277(5327), 800-802. doi:10.1126/science.277.5327.800

Zimov, S., Schuur, E., \& Chapin III, F. C. (2006). Permafrost and the global carbon budget. Science 312, 1612-1613. 